\title{
Meisosomes, folded membrane platforms, link the epidermis to the cuticle in $C$. elegans
}

\author{
Dina Aggad ${ }^{1}$, Shizue Omi ${ }^{1}$, Clara L. Essmann ${ }^{3}$, Nicolas Brouilly ${ }^{2}$, Fabrice Richard ${ }^{2}$, Chantal \\ Cazevieille ${ }^{4}$, Kristin A. Politi ${ }^{5}$, David H. Hall ${ }^{5}$, Jonathan J. Ewbank ${ }^{1}$, Remy Pujol ${ }^{4}$ and Nathalie \\ Pujol $^{1 *}$ \\ ${ }^{1}$ Aix Marseille Univ, INSERM, CNRS, CIML, Turing Centre for Living Systems, Marseille, France \\ 2 IBDM, Institut de Biologie du Développement de Marseille, Département de microscopie électronique de la \\ plateforme PICSL, Aix Marseille Univ, Marseille, France \\ ${ }^{3}$ UCL, University College London, Department of Computer Science, Engineering Building, Malet Place, London, \\ WC1E 7JG UK

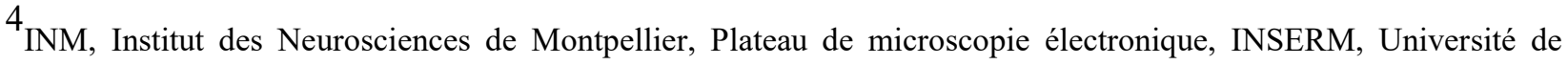 \\ Montpellier, Montpellier, France \\ 5 Department of Neuroscience, Albert Einstein College of Medicine, Bronx, NY 10461, USA. \\ * Author for correspondence
}

\begin{abstract}
Apical extracellular matrices (aECMs) form a physical barrier to the environment. In C. elegans, the epidermal aECM is the cuticle, composed mainly of different types of collagen, associated in circumferential ridges separated by furrows. Damage to the cuticle causes stress responses in the underlying epidermis by a process that is poorly understood. Here, we focus on structures connecting the cuticle to the epidermis, that we term "meisosomes". We show that meisosomes are composed of stacked parallel folds of the epidermal plasma membrane, filled with cuticle. Before moulting, meisosomes align with the underlying cytoskeleton in between furrows. In mutants lacking furrows, that exhibit a constitutive damage response in the epidermis, meisosomes are smaller and fail to align. A loss of connection between the epidermis and the cuticle is also observed in these mutants, as well as a modification of the biomechanical properties of the skin. Meisosomes are therefore an essential component of the skin, serving as attachment platforms between the cuticle and epidermis. They could also be involved in relaying tensile information from the cuticle to the underlying epidermis as part of an integrated stress response to injury and infection.
\end{abstract}




\section{Introduction}

Apical extracellular matrices (aECMs) are associated with all epithelia and are essential for animal life. The cuticle of C. elegans is a collagen-rich aECM that covers the entire surface of the worm. It is a complex multilayer structure that acts as an exoskeleton, to which body wall muscles are connected via structures called hemidesmosomes (Davies and Curtis, 2011; Johnstone, 2000; Page and Johnstone, 2007). Specific subsets of the more than 170 collagens are enriched in the different layers of the cuticle. Some are involved in the formation of distinct structures, including the circumferential parallel pattern of furrows that cover the entire animal (Cox and Hirsh, 1985; Cox et al., 1980; McMahon et al., 2003; Page and Johnstone, 2007; Thein et al., 2003), and the longitudinal lateral alae, important for ensuring the traction of $C$. elegans to its substrate during locomotion (Johnstone, 2000).

The cuticle also constitutes a physical barrier, protecting the underlying epidermal syncytium from biotic and abiotic stresses. When the cuticle is damaged, mechanically or through infection, the epidermis reacts, activating an immune response, reflected by the increased expression of antimicrobial peptide (AMP) genes, including those of the $n l p-29$ cluster (Belougne et al., 2020; Pujol et al., 2008a; Taffoni et al., 2020). An elevated level of AMP gene expression is also observed in a subset of mutants that affect the cuticle, specifically those that lack furrows (Dodd et al., 2018; Pujol et al., 2008b). These furrowless mutants ( $d p y-2,3,7,8,9$, and 10) exhibit other characteristic physiological alterations, including an activation of detoxification genes, dependent on the Nrf transcription factor SKN-1, and the induction of genes required for osmolyte accumulation, in a process that is only partially dependent on $s k n-1$ (Dodd et al., 2018).

If the pathway leading to AMP induction in the epidermis is well described (reviewed in (Kim and Ewbank, 2018; Martineau et al., 2021)), exactly how the epidermis senses cuticular damage remains obscure. Part of the induction seen in $d p y-10$ mutants is the consequence of an increase in the levels of hydroxyphenyllactic acid (HPLA). This metabolite, derived from tyrosine by transamination and reduction, activates the G-protein coupled receptor (GPCR) DCAR-1 (Zugasti et al., 2014), switching on a signalling cascade that leads to AMP gene expression (Polanowska et al., 2018; Zugasti et al., 2016). What provokes elevated HPLA levels in dpy-10 mutants is, however, currently unknown. Further, the HPLA/DCAR-1 signalling pathway only accounts for 
part of the elevated $n l p-29$ expression seen in furrow collagen mutants (Zugasti et al., 2014). We have therefore proposed that a hypothetical, cuticle-associated, damage sensor exists that would control, in an as yet undefined manner, AMP gene expression. This damage sensor would also function to coordinate antimicrobial responses with the distinct detoxification and hyperosmotic responses that are simultaneously activated in furrow collagen mutants (Dodd et al., 2018; Rohlfing et al., 2010; Wheeler and Thomas, 2006).

In yeast, eisosomes, single invaginations of the plasma membrane underneath the ECM, the cell wall, are responsible for detecting changes in nutrient availability, but also cell wall integrity and membrane tension. They relay information primarily via BAR domain proteins to induce the appropriate responses to environmental changes (Appadurai et al., 2020; Lanze et al., 2020; Moseley, 2018). While nematodes lack eisosomes, the plasma membrane of the epidermis is characterised by localised regions of folds that can be observed by electron microscopy (Wood, 1988). Given their superficial similarity, we refer to these structures as meisosomes, for multifoldeisosomes. In this study, we undertook a detailed ultrastructural analysis of meisosomes in adults, as well as characterising them during development, and in furrowless mutants. This mutant analysis revealed an essential role for meisosomes in maintaining the structural integrity of the cuticle and the epidermis, and has opened the way to future, more detailed, characterisation of their function.

\section{Results}

\section{Meisosomes: folded structures at the interface of the cuticle and epidermis}

The stacked organelles that we refer to as meisosomes were mentioned during early electron microscopy characterisation of $C$. elegans (Wood, 1988). A survey of the long transverse transmission electron microscopy (TEM) series "N2U” from the MRC archive (White et al., 1986), which is of a 4-5 day old adult, found hundreds of meisosomes across the ca. 400 available transverse prints in the midbody. As a first step in the detailed investigation of meisosome structure and function, we undertook a focused TEM study to determine their 2D organization and their 3D structure. Meisosomes are repeated folded structures at the interface of the cuticle and epidermis that can be found in similar locales at all larval stages, predominantly in the epidermal syncytium hyp7 at the lateral, dorsal and ventral ridges, and in the tail tip epidermal cells. They are not present 
in the seam cells, the rectal epithelia, nor in the pharynx (Figure $1 \&$ Figure 1-figure supplement 1). Meisosomes typically comprised 4 to 10 closely apposed parallel folds of the plasma membrane, although we observed individual organelles with up to 30 folds (Figure 1A). Most folds formed an indentation 200-400 nm deep (Figure 1A-E). The folds were regularly spaced, with a mean internal width of $35 \mathrm{~nm}$, and a mean cuticle invagination width, in between each membrane fold, of $20 \mathrm{~nm}$ (Figure 1E). The cytoplasmic faces of the folds were free of ribosomes but contained dense material organized in a ladder-like fashion (Figures 1E). Meisosomes were frequently found in close proximity to mitochondria $(85 \%, n=355)$ (Figures $1 \mathrm{~A}-\mathrm{C})$. On their apical side, some folds were found close to the furrow (Figure 1C). Although very variable in a single worm, the mean size of meisosomes did not change with the plane (transverse or longitudinal) of the sections (Table S1), consistent with a random orientation relative to the animal's antero-posterior axis. This random orientation was clearly visible in electron micrographs of freeze fractured samples (Figure 1-figure supplement 2A-B). It contrasted with the alignment of meisomes at the epidermal plasma membrane with annuli in molting larvae, (Figure 1-figure supplement 2C-D), similar to the alignment described below using in vivo markers.

To understand the 3D structure of these organelles, we undertook a tomographic analysis on serial $350 \mathrm{~nm}$-thick sections (Figure 2). This approach confirmed the existence of groups of parallel folds, made from indentations of the plasma membrane with cuticular material between each fold. All the observed folds were found in continuity with the plasma membrane. The tomographic analysis also revealed variability in the geometry of the folds. Although most groups of folds were perpendicular to the apical surface, some were tilted. The folds had a relatively uniform depth, but were deeper at the centre of each stack. At their basal tip, the folds were closed. Despite their close apposition with mitochondria, no membrane continuity was observed between meisosomes and mitochondria. (Figure 2D, Sup movie 1). Some smaller meisosomes, typically with only 2-4 shallow folds were seen in the thin epidermal tissue that lies between body-wall muscles and the cuticle and that is largely devoid of cytoplasmic content (Figure 2-figure supplement 1).

\section{Density of meisosomes in wild-type worms}

In order to evaluate not just the topology, but also the distribution of these organelles, we developed a fixation protocol for serial block-face scanning electron microscopy (SBF-SEM) of C. elegans 
samples. Starting with protocols previously described (Deerinck et al., 2010; Hall et al., 2012a; Hall et al., 2012b), we adapted the solvents and temperatures for each contrasting agent, including lead and uranyl acetate, to maximize sample contrast (see Materials and Methods). We acquired series of electron micrographs of the lateral epidermis as a transversal view and along sections of $12 \mu \mathrm{m}$. We produced pixel-based segmentations within the Waikato Environment for Knowledge Analysis (WEKA in Fiji) and then used its machine learning algorithms to perform automated organelle recognition. This revealed that the meisosomes were irregularly spaced at the apical surface of the main lateral epidermis, with various sizes and orientations and confirmed their frequent apposition to mitochondria (Figure 3A-D).

\section{VHA-5 is a marker of meisosomes}

VHA-5, one of four $\alpha$-subunits of the transmembrane V0 complex of the vacuolar ATPase (VATPase) (Pujol et al., 2001), and RAL-1, ortholog of human RALA (RAS like proto-oncogene A) (Frische et al., 2007), are the only known markers of meisosomes. Both proteins are also associated with multivesicular bodies (MVB) that play a role in exosome secretion (Hyenne et al., 2015; Liegeois et al., 2006). The expression pattern of VHA-5 is the better characterised of the two proteins', by both conventional fluorescence and immuno-electron microscopy. Consistent with previous observations (Liegeois et al., 2006), using a GFP-tagged version of VHA-5, we observed punctate fluorescence at the apical surface of the lateral epidermis, from the head to the tail, in the ventral and dorsal ridges, but not in the dorsal or ventral epidermis above the body wall muscles, nor underneath the seam cell (Figure 3E-G). When we examined worms co-expressing VHA5::GFP and HGRS-1::mScarlet, a known marker of MVBs and the endosome degradation pathway (Liegeois et al., 2006; Norris et al., 2017; Roudier et al., 2005; Serrano-Saiz et al., 2020), we observed no colocalization (Figure $3 \mathrm{H}$ ). This indicates that MVB are not detectable with our standard fluorescence microscopy techniques. We also did not observe any co-localisation between VHA-5::GFP and SNX-1::mScarlet, a marker for the recycling endosomes, nor with LGG1::mScarlet, an autophagolysosome marker (Serrano-Saiz et al., 2020) (Figure 3-figure supplement 1). The structures labelled with VHA-5::GFP in the adult epidermis were similar in size and spatial distribution to the meisosomes reconstituted from the SBF data (Figure 3D). Together with previous observations in the excretory duct (Kolotuev et al., 2009), these results indicate that the VHA-5::GFP signal that we observe at the apical membrane in the epidermis corresponds 
specifically to meisosomes and that VHA-5::GFP can be used in vivo as an bona fide meisosome marker for this study.

\section{Abnormal meisosomes in adult furrow mutant worms}

As meisosomes connect the cuticle to the epidermis, we investigated the consequences of modifying the cuticle on meisosomes. Different classes of cuticular collagen mutants exist that affect either furrows or annuli (Figure 4) (Cox and Hirsh, 1985; Cox et al., 1980; McMahon et al., 2003; Page and Johnstone, 2007; Thein et al., 2003). Furrowless mutants, in contrast to mutants of annuli collagens, exhibit an increased expression of the AMP reporter $n l p-29$ ::GFP (Pujol et al., 2008b). This is one reason that furrow collagens have been proposed to be part of a damage sensor that relays information about cuticle integrity to the epidermis (Dodd et al., 2018). Interestingly, this reporter is also induced before the L4/adult moult when the cuticle is reshaping (Figure 4figure supplement 1A). We confirmed that abrogation by RNAi of the expression of two furrow collagen genes, $d p y-3$ and $d p y-7$, leads to the increased expression of $n l p-29 p:: G F P$, in contrast to the RNAi of four annuli collagen genes, $d p y-1, d p y-4, d p y-5$ and $d p y-13$ (Figure 4-figure supplement 1B-C). We then examined the consequences of knocking down the expression of these different collagen genes on the pattern of meisosomes, using VHA-5::GFP. At the apical surface of the lateral epidermis in adult worms (Figure 4A), compared to control worms, while $d p y-1, d p y$ 4, $d p y-5$ and $d p y-13$ inactivation had no obvious effect, both $d p y-3(R N A i)$ and $d p y-7$ inactivation provoked a marked and specific alteration in the pattern of VHA-5::GFP. The meisosomes' normal reticulated pattern was fragmented, as reflected by a decrease in their average size and Feret's diameter, and $\mathrm{a}>25 \%$ increase in their density (Figures 4B-C, Figure 4-figure supplement 2A-B). A similar fragmentation was observed in $d p y$-3 mutant worms (Figure 4-figure supplement 2C-D). Upon RNAi inactivation of furrow collagen gene expression, there was still no overlap between the signal from VHA-5::GFP or any of the endocytic pathway markers (Figure 3-figure supplement 1). Further, neither $d p y-3$ nor $d p y-7$ inactivation had any effect on the pattern of EEA-1::GFP (Figure 4-figure supplement 3), a marker of early endosomes (Shi et al., 2009). Thus, loss of furrow collagen gene expression leads to a substantial fragmentation of meisosomes, without affecting the endocytic pathway. This suggests that furrow collagens play an important and specific role in maintaining meisosome integrity. 


\section{Furrow collagens determine the organisation of the cytoskeleton and meisosomes in L4 larvae}

Before moulting, there is profound reorganisation of the cytoskeleton in the lateral epidermis. Microtubules and actin fibres align in a series of circumferential bands that are not present in adults (Castiglioni et al., 2020; Costa et al., 1997; Taffoni et al., 2020). We confirmed the previous observation that VHA-5::GFP aligns parallel to the actin fibres, in animals entering the L4/adult moult (Liegeois et al., 2007), a stage we refer to here as "late L4". We refined this observation by precisely staging the worms through the L4 stage by looking at the vulva, as described (Cohen et al., 2020). This parallel circumferential alignment of VHA-5::GFP could be observed at the beginning of the L4 stage, in L4.1, was then lost in L4.2. It reappeared progressively starting in the L4.3 stage, culminating between the L4.7 and L4.9 stages, just before the moult. Interestingly, the same sequence of dynamic changes in alignment was observed for actin and microtubules. After the moult, there was a concomitant loss of alignment of VHA-5, actin and microtubules, so that in wild-type adult animals, as described above, there was no clear overall pattern to the organisation of meisosomes, actin or microtubule (Figures 5 and Figure 5-figure supplement 1A).

Since the size of meisosomes in adult worms requires furrow collagens, we then examined the consequence of knocking down $d p y-7$ on the regular and organised VHA-5::GFP pattern in late L4s worms. While RNAi of the annuli collagen gene $d p y-1$ had no obvious effect, RNAi of $d p y-7$ provoked a loss of meisosome alignment (Figures 5 and Figure 5-figure supplement 1B). A similar phenotype was observed in $d p y$-3 mutants (Figure 5-figure supplement 1C). Strikingly, this loss of expression of furrow collagens was also associated with a disruption of the normal organized pattern of both actin fibres and microtubules from the L4.3 stage (Figures 5, Figure 5-figure supplement 2-3). It was previously proposed that the formation of actin fibres and microtubules in apposed circumferential bands plays an instructive role in positioning the furrows (Costa et al., 1997). Our results suggest, on the contrary, that furrow collagens in the cuticle govern the alignment of the underlying cytoskeleton as development progresses into the final moult. Thus, furrow collagens appear to be required to align both meisosomes and the actin-microtubule cytoskeleton. 


\section{Actin is required for the alignment of meisosomes in L4 larvae}

To test whether the effect of furrow collagen disruption on meisosomes was direct, or whether actin might be required for their correct patterning at the late L4 stage, we examined the consequence of knocking down actin gene expression on VHA-5::GFP in wild-type late L4 worms. As prolonged act-2 inactivation that targets all actin isoforms (see Methods) provoked a general sickness, we only started RNAi treatment $24 \mathrm{~h}$ before our observations. We confirmed the efficacy of this short treatment in a strain expressing LifeAct::GFP; as expected, actin fibres were not detected after act2 RNAi treatment (Figures 6A). Loss of circumferential actin fibres was associated with the loss of alignment of meisosomes at the late L4 stage. Notably, act-2 (RNAi) did not however, affect the circumferential patterning of microtubules (Figures 6B-E and Figure 6-figure supplement 1). Our results suggest that furrow collagens pattern meisosome alignment during the late L4 stage through their effect on the actin fibres. Although the alignment of the meisosomes was lost upon act-2 RNAi, their size was not affected, either in late L4s or in adults, in contrast to what was observed in the furrow collagen mutant $d p y-3$ (Figures 6B-C and Figure 6-figure supplement 1A-B). These results suggest that actin fibres, but not furrow collagens, are dispensable for the expansion of meisosomes to their mature size in the adult.

\section{Meisosomes are not required for furrow collagen secretion}

VHA-5 has been shown to have an essential role in alae formation and secretion of Hedgehog related peptides through exocytosis via multivesicular body (Liegeois et al., 2006). To assess whether VHA-5 could be involved in the secretion of furrow collagens, we knocked down by RNAi the expression of $v h a-5$, or vha-19, which encodes a second component of the V0 sector of the VATPase. We observed no effect on the normal banded pattern of DPY-7::GFP, nor on the formation of furrows at the L4 or the adult stages. In addition, we show that actin inactivation doesn't affect the secretion of DPY-7::GFP nor the formation of furrow (Figure 7A). Moreover, and consistent with the EM observations, there was a clear alignment of VHA-5 in between the furrows at the late L4 stage, as revealed with the DPY-7::GFP marker when associated with either the VHA-5::GFP or with VHA-5::RFP marker (Figures 7B-C), It is also interesting to note that during the L4.7 stage, DPY-7::GFP can be observed in small vesicles on the apical side of the epidermis, that we believe represent the ongoing secretion of furrow collagen at that stage, and these vesicles do not co- 
localise with VHA-5::RFP (Figure 7C). Thus, VHA-5, and by extension, meisosomes, appears not to be important for the formation of furrows.

\section{Furrow mutants, with small meisosomes, display a detached cuticle}

We next examined the ultrastructure of the cuticle and the epidermis in furrow $(d p y-2, d p y-3, d p y$ 7) mutants. Consistent with our observations by fluorescence microscopy, compared to the wildtype, in $d p y-2, d p y-3$ and $d p y-7$ mutants, by EM, the meisosomes were smaller, contained fewer folds and had an irregular shape (Figures 8A-E, Table S1). In the three furrow collagen mutants, alteration of the meisosomes was often associated with a disruption of the contact between the epidermal plasma membrane and the cuticle (Figures 8C-D). This opened a space between the cuticle and the underlying epidermal cell that was filled with a diverse range of cytoplasmic content, including membrane-bound vesicles with the appearance of endosomes, lysosomes, mitochondria, as well as electron-dense particles the size of ribosomes (Figures 8E-F).

To exclude the remote possibility that this detachment was an artefact linked to the fixation protocol used for electron microscopy, we carried out live imaging on two strains in which the epidermal plasma membrane was labelled with a prenylated, or a pleckstrin domain-tagged form of GFP (GFP::CAAX and GFP::PH-PLC1 $\delta$, respectively). When we knocked down expression of any one of the three furrow collagen genes in these strains, we observed a striking change in fluorescence. Instead of being restricted to heterogeneous macrodomains in the plasma membrane (Taffoni et al., 2020), GFP was seen in numerous brightly-stained vesicular structures that accumulated outside the epidermis (Figure 8G-H and Figure 8-figure supplement 1). Together, these novel phenotypes suggest that the meisosomes may play an important role in attaching the cuticle to the underlying epidermal cell and that loss of this intimate connection causes a profound alteration of epidermal integrity.

\section{Furrow mutants have abnormal biomechanical properties}

We predicted that the changes in cuticle attachment seen in the furrow mutants would impact the biomechanical properties of worms. It was previously shown that furrows are stiffer than the rest of the cuticle in wild-type worms (Essmann et al., 2016). We therefore used atomic force microscopy to measure the resistance to force in wild-type and mutant worms, as previously 
described (Essmann et al., 2016; Essmann et al., 2020). While topographic AFM imaging (Figures 9A) provided further corroboration of the fact that in the absence of furrow collagens the cuticle has a disorganised aspect with irregular folds, lacking the usual repeated linear pattern of annuli and furrows, force spectroscopy AFM revealed differences in stiffness. In contrast to the nonfurrow $d p y-13$ mutant that had a rigidity similar to wild-type, the different $d p y$ furrow mutants (dpy-2, dpy-3, dpy-7 and $d p y-8)$ exhibited markedly less steep force-indentation curves (Figure 9B), and hence lower stiffness or Young's Moduli (Figure 9C). This suggests that furrow collagens are required for stiffness, potentially as they are essential for the presence of normal meisosomes.

\section{Discussion}

In this study, we undertook the characterisation of structures that link the nematode epidermis to the cuticle. Across species, interfaces exist between flexible and dynamic cell membranes and more rigid extracellular matrices. Because of requirements for growth, signal transduction, and repair, the microstructures of the ECM need to be tightly linked to the plasma membrane and cytoskeleton of the underlying cell (Chebli et al., 2021). In yeast, eisosomes are single membrane invaginations located under the cell wall that bridge this boundary and fulfil this function. They can disassemble in minutes to buffer changes in membrane tension, protecting cells from osmotic shock (Lemiere et al., 2021). Eisosomes are specific to yeast; there are no orthologues for core components, such as LSP-1, in animals. Conversely, the meisosomes that we describe here in C. elegans, with their multiple membrane invaginations that individually are similar in appearance to eisosomes, are, to the best of our knowledge, distinct from interfacial structures in non-nematode species.

While the presence of meisosomes had been noted in earlier studies (Hyenne et al., 2015; Liegeois et al., 2006), we have been able to go beyond their previous characterisation, in part because of improvements in electron microscopy techniques. Specifically, we adapted the fixation protocol after high pressure freezing to have a better membrane contrast in serial block scanning electron microscopy. This allowed automated in silico segmentation of meisosomes, revealing a distribution that matched that of VHA-5::GFP observed by fluorescence microscopy. VHA-5, together with RAL-1, are currently the only known meisosome components. In contrast to the well-defined roles of these two proteins in alea secretion and exosomes biogenesis (Hyenne et al., 2015; Liegeois et al., 2006), their function in meisosomes remains to be characterised. Notably, inactivation neither 
of ral-1 (Hyenne et al., 2015) nor of vha-19, which encodes a subunit of the V0 sector of the VATPase, did not eliminate VHA-5::GFP fluorescence in the epidermis, and knocking down the expression of vha-5 or vha-19 did not affect the secretion of DPY-7::GFP, nor furrow formation. This suggests that the V-ATPase on meisosomes is not involved in cuticle synthesis nor in meisosome formation. Further study will be required to determine the catalogue of proteins that are needed for meisosome formation and maintenance.

Nevertheless, by taking an ultrastructural approach, we were able to build up a detailed picture of the organisation of meisosomes. One of their defining features is the constant $25 \mathrm{~nm}$ spacing of their constituent plasma membrane folds. This raises the question of how the membrane folds with such precision. One possibility is that the striking orthogonal bands of electron-dense material that fill the cytoplasm-facing folds, spaced less than $10 \mathrm{~nm}$ apart, maintain the uniform width of each meisosome fold, and influence their mechanical properties. These structures will require more precise characterisation. We equally have yet to establish whether the frequent proximity of meisosomes to mitochondria, with a close apposition of membranes, has a functional significance.

Contrary to the cuticle of many adult insects, the nematode cuticle is flexible enough to allow bending during locomotion. It is also thought to stretch to accommodate growth between moults. The major changes of size, however, occur at moults, when the old cuticle is shed, leaving in its place the new cuticle that had been moulded underneath it. The circumferential furrows of the new cuticle thus appear exactly in register with the position of old furrows. Before moulting, the cytoskeleton aligns in the apical epidermis, underneath and parallel to each furrow. Although this had been proposed to be important for positioning the furrows of the new cuticle (Costa et al., 1997; McMahon et al., 2003; Page and Johnstone, 2007), we found, unexpectedly, that actin is dispensable for the alignment of furrows, consistent with more recent reports (Katz et al., 2018). On the other hand, we found that the furrows are required for the alignment of actin fibres before the last moult. We propose therefore that only the old furrows are required to pattern the new furrows. Consistent with such a model, the transient pre-cuticle that is formed between the old and the new cuticles before each moult is absent from the region of the furrows (Cohen and Sundaram, 2020; Forman-Rubinsky et al., 2017). We have shown that furrow and actin fibre alignment determines the regular parallel and circumferential positioning of meisosomes. It is not yet clear, however, whether this alignment of meisosomes is functionally important. It could simply result 
from steric constraints during moulting, in the limited space between nascent furrows of the new cuticle and the closely apposed circumferential actin fibres. Notably, the absence of their normal alignment before moulting, caused by knocking down actin expression, does not alter meisosome size in adults, nor the normal intimate connection between the epidermis and cuticle.

On the other hand, as adults, furrowless collagen mutants have fragmented meisosomes and a detached cuticle. While currently we cannot determine with certainty whether fragmentation is a cause or a consequence of the detachment, we favour the former and hypothesise that the multiple folds of plasma membrane increase its contact surface with the cuticle thus ensuring a more robust connection of the aECM to the lateral epidermis. While the lateral epidermis is rich in meisosomes, it is devoid of hemidesmosomes. Conversely, in the dorsal and ventral quadrants, there are no meisosomes, but abundant hemidesmosomes. These structures secure the muscles to the cuticle through epidermis and are indispensable for worm development and viability. Above the muscles, the epidermis is extremely thin, with the apical and basal plasma membranes juxtaposed, linked via intermediate filaments that bridge apical and basal hemidesmosome protein complexes (Zhang and Labouesse, 2010). MUA-3 is an hemidesmosome transmembrane protein in direct contact with the cuticle. In hypomorphic mиа-3 mutants, large gaps form between the apical epidermal surface and the cuticle in the dorso-ventral quadrants, reflecting a loss of attachment of apical hemidesmosomes to the cuticle. Unlike the cytoplasm-filled gaps we observed in furrowless mutants, in mua-3(rh195) worms, these spaces appear devoid of contents, and the apical epidermal membrane is intact (Bercher et al., 2001). So, in contrast to the loss of hemidesmosomes, fragmentation of meisosomes in furrowless mutant affects the integrity of the apical epidermal membrane in the lateral epidermis, potentially explaining the permeability phenotype of furrowless mutants (Sandhu et al., 2021). Despite these differences, both meisosomes in the lateral epidermis and hemidesmosomes in the dorso-ventral quadrants do appear to have an analogous function, ensuring the attachment of the apical plasma membrane to the cuticle.

In animals, ECMs provide mechanical support for tissue assembly and organ shape. During embryogenesis in C. elegans, the aECM is essential during elongation as it not only maintains embryonic integrity, but also relays the mechanical stress produced by the actomyosin cytoskeleton and the muscles (Vuong-Brender et al., 2017a; Vuong-Brender et al., 2017b). In the adult, the mechanical properties of the aECM have only recently started to be explored. Atomic force 
microscopy revealed that the annular furrows have a higher stiffness than the rest of the cuticle (Essmann et al., 2016). Here, we show that furrow loss decreases stiffness. Furrow Dpy mutants are known to have a higher internal concentration of glycerol (Wheeler and Thomas, 2006), which will decrease their internal hydrostatic pressure. We propose that this decreased hydrostatic pressure is a consequence of the decrease in the stiffness of the cuticle. It would maintain the necessary balance of inward and outward pressures required for body integrity. Since we used a 10 micrometer diameter AFM probe to indent the worm, and the indentation depth was greater than the thickness of the cuticle (ca. $800 \mathrm{~nm}$ compared to $500 \mathrm{~nm}$ for the cuticle), our measurements did not directly assess the cuticle stiffness, so further investigations will be needed to confirm our hypothesis. It is interesting to note, however, that a decrease in stiffness and an increase in the activity of innate immune signaling pathways in the epidermis are signatures of ageing in $C$. elegans (E et al., 2018; Essmann et al., 2020). How physiological and pathological modifications of the biomechanical properties of the aECM are surveilled by the epidermis remains an open question for future studies.

\section{Materials and Methods}

\section{Nematode strains}

All C. elegans strains were maintained on nematode growth medium (NGM) and fed with $E$. coli OP50, as described (Stiernagle, 2006), the wild-type N2, IG274 frIs7[col-12p::DsRed, nlp29p::GFP] IV (Pujol et al., 2008a), IG1697 dpy-2(e8) II; frIs7[nlp-29p::GFP, col-12p::DsRed] $I V$, IG1685 dpy-3(e27) X; frIs7[nlp-29p::GFP, col-12p::DsRed] IV, IG1689 dpy-7(e88) X; frIs7[nlp-29p::GFP, col-12p::DsRed] IV (Dodd et al., 2018), IG1699 dpy-8(e130) X; frIs7[nlp29p::GFP, col-12p::DsRed] IV, IG344 dpy-13(e184) frIs7[nlp-29p::GFP, col-12p::DsRed] IV, RT424 pwIs126[eea-1p::GFP::EEA-1 (Shi et al., 2009), RT3657 pwSi46[hyp7p::mScarlet::HGRS-1+G418-R], RT3640 pwSi65[hyp7p::mScarlet::SNX-1+G481R], RT3635 pwSi62[hyp7p::mScarlet::LGG-1+G418-R] (Serrano-Saiz et al., 2020), ML2113 mcIs67[dpy-7p::LifeAct::GFP; unc-119(+)] V; stIs10088[hlh-1::his-24::mCherry, unc-119(+)] (Lardennois et al., 2019) to visualise actin in larval stages, IG1813 frSi9[pNP151(col62p::Lifeact::mKate_3'c-nmy), unc-119(+) ttTi5605]/+ II; tbb-2(tj26[GFP::TBB-2]) III (Taffoni et al., 2020) to visualise actin in the adult, IG1935 frSi9[pNP151(col-62p::Lifeact::mKate_3'c- 
nmy), unc-119(+) ttTi5605] II; Is[wrt-2p::GFP::PH-PLC18, wrt-2p::GFP::H2B, lin48p::mCherry], XW18042 qxSi722[dpy-7p::DPY-7::sfGFP; ttTi5605] II (Miao et al., 2020) and MBA365 Ex[dpy-7p::GFP::CAAX, myo-2p::GFP] kindly provided by M. Barkoulas (UCL).

Transgenic strain containing GFP tagged version of VHA-5 were generated by microinjection in N2 worms of the vha-5pVHA-5::GFP construct pML670 (Liegeois et al., 2006) kindly provided by M. Labouesse (LBD/IBPS) at $3 \mathrm{ng} / \mu 1$ together with $u n c-122 \mathrm{p}:: \mathrm{GFP}$ at $100 \mathrm{ng} / \mu 1$ to generate IG1930. The transgene frSi26 is a single copy insertion on chromosome II (ttTi5605 location) of pNP165 (dpy-7p::VHA-5::GFP) by CRISPR using a self-excising cassette (SEC) (Dickinson et al., 2015). pNP165 was obtained by insertion of the $d p y-7$ promoter, which leads to an epidermal specific expression, in front of VHA-5::GFP into the pNP154 vector. pNP154 was made from a vector containing the SEC cassette for single insertion on Chromosome II at the position of ttTi5605 (pAP087, kindly provided by Ari Pani) (Watts et al., 2020). Constructs were made using Gibson Assembly (NEB Inc., MA) and confirmed by sequencing. pNP165 was injected in N2 at $20 \mathrm{ng} / \mu \mathrm{l}$ together with pDD122 (eft-3p::Cas9) at $50 \mathrm{ng} / \mu 1, \mathrm{pCFJ} 90$ (myo-2p::mCherry) at $2 \mathrm{ng} / \mu 1$, and \#46168 (eef-1A.1p::CAS9-SV40_NLS::3'tbb-2) at $30 \mathrm{ng} / \mathrm{ml}$. Non-fluorescent roller worms were selected then heat shocked to remove the SEC by FloxP as described in (Dickinson et al., 2015). All the multiple reporter strains generated in this study were obtained by conventional crosses (see Table S3 for a list of all strains).

\section{Transmission electron microscopy}

Day 1 adult worms were frozen in $\mathrm{NaCl} 50 \mathrm{mM}$ medium containing $5 \%$ of BSA and E.coli bacterias using Leica EM Pact 2 high pressure freezer. After freezing, samples were incubated at $90{ }^{\circ} \mathrm{C}$ in acetone containing $2 \% \mathrm{OsO} 4$ for 96 hours. The temperature was gradually increased to $60{ }^{\circ} \mathrm{C}$ and maintained for 8 hours. The temperature was then raised to $-30{ }^{\circ} \mathrm{C}$ and maintained for 8 hours, before to be raised again to RT. Samples were finally washed in acetone and embedded in Durcupan resin. Resin was polymerised at $60^{\circ} \mathrm{C}$ for 48 hours. $70 \mathrm{~nm}$ ultrathin and $350 \mathrm{~nm}$ semithin sections were performed using a Leica UC7 ultramicrotome and post-stained with $2 \%$ uranyl acetate and Reynolds' lead citrate. Images were taken with a Tecnai G2 microscope (FEI) at 200 $\mathrm{kV}$. For tomography acquisitions, tilted images $\left(+60^{\circ} /-60^{\circ}\right.$ according to a Saxton scheme) were 
acquired using Xplorer 3D (FEI) with a Veleta camera (Olympus, Japan). Tilted series alignment and tomography reconstruction was performed using IMOD (Mastronarde, 1997).

\section{Freeze fracture}

Wild-type adults were fixed in buffered $2.5 \%$ glutaraldehyde, then cryoprotected in $30 \%$ glycerol overnight prior to freezing. Fixed animals were positioned between two gold discs, and plunge frozen in liquid nitrogen-chilled isopentane. Frozen worms were placed into a double replica holder for a Balzer's 301 freeze etch device. Samples were cleaved within the freeze etch device by free breaks, then shadowed with $\mathrm{Pt} / \mathrm{C}$ to form a metal replica. Replicas were washed in bleach to remove all tissue prior to mounting on slot grids for examination by TEM.

\section{Scanning Electron microscopy by Serial Block Face}

After freezing in the aforementioned conditions, samples were incubated at $-90{ }^{\circ} \mathrm{C}$ in acetone containing $2 \% \mathrm{OsO} 4$ for 106 hours. The temperature was gradually increased to $0{ }^{\circ} \mathrm{C}$ and samples were directly washed in acetone at RT. Samples were then incubated in acetone containing $0.1 \%$ $\mathrm{TCH}$ for $60 \mathrm{~min}$, washed in acetone, and incubated in acetone containing $2 \%$ OsO4 for 1 hour at RT. After rehydratation in ethanol decreasing graded series, samples were incubated $\mathrm{ON}$ in $1 \%$ aqueous uranyl acetate at $4{ }^{\circ} \mathrm{C}$ and in $30 \mathrm{nM}$ lead aspartate for $30 \mathrm{~min}$ at $60{ }^{\circ} \mathrm{C}$. Samples were finally dehydrated in graded series of ethanol baths and pure acetone and embedded in Durcupan resin. Resin was polymerised at $60{ }^{\circ} \mathrm{C}$ for 48 hours.

\section{Segmentations and 3D Image analysis}

For electron tomography datasets, a binned version of the reconstructed tomogram was segmented using the Weka 3D segmentation plugin in Fiji/ImageJ to visualize the mitochondria and the meisosomes. The cuticle was visualized by the Amira-embedded Volume Rendering plugin from a manually segmented mask. A cropped area of interest of the full resolution electron tomogram was segmented in iLastik to visualize a representative portion of the organelle. For Serial Blockface datasets, the segmentation of the meisosome and mitochondria was generated using the Weka 3D segmentation plugin in Fiji/ImageJ. Animations and snapshots were generated in Amira. 


\section{RNA interference}

RNAi bacterial clones were obtained from the Ahringer or Vidal libraries and verified by sequencing (Kamath et al., 2003; Rual et al., 2004). RNAi bacteria were seeded on NGM plates supplemented with $100 \mu \mathrm{g} / \mathrm{ml}$ ampicillin and $1 \mathrm{mM}$ Isopropyl- $\beta$-D-thiogalactopyranoside (IPTG). Worms were transferred onto RNAi plates as L1 larvae and cultured at $20{ }^{\circ} \mathrm{C}$ or $25^{\circ} \mathrm{C}$ until L4 or young adult stage. To knockdown actin by bacterial-mediated RNAi, we used the act-2 gene. Due to their high similarity in sequence, this lead to simultaneously knockdown all four actin genes (act-1 -2 -3 and -4) (Thakur et al., 2014; Willis et al., 2006). To minimize the lethality associated with actin, vha-5 and vha-19 RNAi during larval development, we put the worms on the RNAi conditions $24 \mathrm{~h}$ before observation, and confirm their effect on the appropriate fluorescent reporter strain. Despite a short exposure to act-2 RNAi, $d p y-3$ worms do not complete the L4 moult, with obvious signs of cuticle fragility leading to extrusion of biological material.

\section{Fluorescent Image acquisition}

Live young adult worms were placed on a $2 \%$ agarose pad containing $0.25 \mathrm{mM}$ levamisole in $\mathrm{NaCl}$ to immobilize the worms. Images were acquired using a confocal laser scanning microscopy: Zeiss LSM780 and its acquisition software Zen with a Plan-Apochromat 40 X/1.4 Oil DIC M27 objective with a zoom 2 to 4, a Plan-Apochromat 63 X/1.40 Oil DIC M27 with a zoom 1. Spectral imaging combined with linear unmixing was used in figure 7.

\section{Airyscan super-resolution microscopy}

Airyscan imaging were performed using a commercial Zeiss confocal microscope LSM 880 equipped with an Airyscan module (Carl Zeiss AG, Jena, Germany) and images were taken with a 63x/1.40NA M27 Plan Apochromat oil objective. In this mode, emission light was projected onto an array of 32 sensitive GaAsP detectors, arranged in a compound eye fashion. The Airyscan processing was done with Zen Black 2.3 software by performing filtering, deconvolution and pixel reassignment to improve SNR. The Airyscan filtering (Wiener filter associated with deconvolution) was set to the default filter setting of 6.1 in $2 \mathrm{D}$.

\section{Fluorescent Image analysis}


To extract the morphological properties of organelles we devised an automatic Fiji segmentation procedure (GitHub https://github.com/centuri-engineering/BD BlobsSeg). We first restricted the analysis to manually drawn ROIs and isolated organelles (foreground image) from the background by using the "remove outliers" function of Fiji (radius $=30$ pixels and threshold $=30$ ). We next applied a Gaussian blur (sigma $=1$ pixel) on the foreground image and automatically defined a threshold value to binarize the newly blurred image. This threshold was determined automatically by multiplying the background value (retrieved by averaging the fluorescent levels of the background image) by a constant coefficient. This allowed us to normalize the segmentation, since the expression levels of fluorescent proteins may vary from one animal to another. Finally, after filtering out smaller objects (less than $\sim 0.15 \mu \mathrm{m}^{2}$ ), we measured the averaged organelles area, Feret's diameter (longest axis) and density in the different conditions. Unpaired t test was used to compare the samples which passed the normality test (Shapiro-Wilk normality test) and with homogeneity variances (Fisher test) and unpaired nonparametric Mann-Whitney test for the others.

\section{Atomic Force Microscopy (AFM)}

Worms were prepared as described before (Essmann et al., 2016). Briefly, staged 1-day-old young adult worms were paralysed in $15 \mathrm{mg} / \mathrm{ml} \mathrm{2,} \mathrm{3-butanedione} \mathrm{monoxime} \mathrm{(Sigma)} \mathrm{for} 2 \mathrm{~h}$ at room temperature and transferred to a $\sim 2 \mathrm{~mm}$ thick $4 \%$ agarose bed in a petri dish $(30 \mathrm{~mm})$. Heads and tails were fixed with tissue glue (Dermabond, Ethicon) and the dish filled with a $2.5 \mathrm{ml}$ M9 buffer. AFM data of worms were obtained using a NanoWizard3 (JPK) under aqueous conditions. Type qp-CONT-10 (0.1 N/m; nanosensors) cantilevers were used for imaging in contact-mode at setpoint $0.3 \mathrm{~V}$ and $0.5 \mathrm{~Hz}$ scanning speed, and NSC12 tipless cantilevers (7.5 N/m; MikroMash) with a 10 $\mu \mathrm{m}$ borosilicate bead attached (produced by sQUBE www.sQUBE.de) were used in force spectroscopy mode to obtain force-indentation measures at $450 \mathrm{nN}$ force setpoint and $0.5 \mu \mathrm{m} / \mathrm{s}$ indentation speed. Cantilever sensitivity and stiffness $(\mathrm{k})$ were calibrated using the JPK system calibration tool before each experiment. AFM raw data were analysed using the JPK analysis software. All force curves were processed to zero the baseline, to determine the tip-sample contact point and to subtract cantilever bending. The Young's Modulus was calculated within the software by fitting the Hertz/Sneddon model respecting the indenter shape (10 $\mu \mathrm{m}$ bead) to each curve. All topographical images are flattened using the plane fitting option of the JPK software at 1-2 degree to correct for sample tilt and natural curvature of the worm. 


\section{Acknowledgements}

We thank Benoit Delapiot for writing the Fiji Macro, M. Labouesse, M. Barkoulas and Ari Pani for sharing strains and reagents, Chris Crocker at Wormatlas for diagrams, and Roxane Fabre for the Airyscan images. Worm sorting was performed by Jerome Belougne using the facilities of the French National Functional Genomics platform, supported by the GIS IBiSA and Labex INFORM. We thank the imaging core facility (ImagImm) of the Centre d'Immunologie de Marseille-Luminy (CIML) and the PiCSL-FBI core facility (IBDM, AMU-Marseille) supported by the French National Research Agency program (France-BioImaging; ANR-10-INBS-04-01). Electron tomography in figure 2S1 were performed at the New York Structural Biology Center, with help from KD Derr and William Rice. We thank John White and Jonathan Hodgkin for sharing the MRC/LMB archive of nematode micrographs. Some C. elegans strains were provided by the CGC, which is funded by NIH Office of Research Infrastructure Programs (P40 OD010440).

\section{Fundings}

Work is funded by the French National Research Agency ANR-16-CE15-0001-01 and ANR-10INBS-04-01 (France Bio Imaging), by the "Investissements d'Avenir" French Government program (ANR-16-CONV-0001) and from Excellence Initiative of Aix-Marseille University A*MIDEX and institutional grants from CNRS, Aix Marseille University, National institute of Health and Medical Research (Inserm) to the CIML; and by a NIH OD 010943 to DHH. 


\section{References}

Appadurai, D., Gay, L., Moharir, A., Lang, M.J., Duncan, M.C., Schmidt, O., Teis, D., Vu, T.N., Silva, M., Jorgensen, E.M., and Babst, M. (2020). Plasma membrane tension regulates eisosome structure and function. Mol Biol Cell 31, 287-303. 10.1091/mbc.E19-04-0218.

Belougne, J., Ozerov, I., Caillard, C., Bedu, F., and Ewbank, J.J. (2020). Fabrication of sharp silicon arrays to wound Caenorhabditis elegans. Sci Rep 10, 3581. 10.1038/s41598-02060333-7.

Bercher, M., Wahl, J., Vogel, B.E., Lu, C., Hedgecock, E.M., Hall, D.H., and Plenefisch, J.D. (2001). mua-3, a gene required for mechanical tissue integrity in Caenorhabditis elegans, encodes a novel transmembrane protein of epithelial attachment complexes. J Cell Biol 154, 415-426. 10.1083/jcb.200103035.

Castiglioni, V.G., Pires, H.R., Rosas Bertolini, R., Riga, A., Kerver, J., and Boxem, M. (2020). Epidermal PAR-6 and PKC-3 are essential for larval development of $C$. elegans and organize non-centrosomal microtubules. Elife 9. 10.7554/eLife.62067.

Chebli, Y., Bidhendi, A.J., Kapoor, K., and Geitmann, A. (2021). Cytoskeletal regulation of primary plant cell wall assembly. Curr Biol 31, R681-R695. 10.1016/j.cub.2021.03.092.

Cohen, J.D., Sparacio, A.P., Belfi, A.C., Forman-Rubinsky, R., Hall, D.H., Maul-Newby, H., Frand, A.R., and Sundaram, M.V. (2020). A multi-layered and dynamic apical extracellular matrix shapes the vulva lumen in Caenorhabditis elegans. Elife 9. 10.7554/eLife.57874.

Cohen, J.D., and Sundaram, M.V. (2020). C. elegans Apical Extracellular Matrices Shape Epithelia. J Dev Biol 8. 10.3390/jdb8040023.

Costa, M., Draper, B.W., and Priess, J.R. (1997). The role of actin filaments in patterning the Caenorhabditis elegans cuticle. Dev Biol 184, 373-384. 10.1006/dbio.1997.8530.

Cox, G.N., and Hirsh, D. (1985). Stage-specific patterns of collagen gene expression during development of Caenorhabditis elegans. Mol Cell Biol 5, 363-372. 10.1128/mcb.5.2.363.

Cox, G.N., Laufer, J.S., Kusch, M., and Edgar, R.S. (1980). Genetic and Phenotypic Characterization of Roller Mutants of Caenorhabditis elegans. Genetics 95, 317-339. 10.1093/genetics/95.2.317.

Davies, K.G., and Curtis, R.H. (2011). Cuticle surface coat of plant-parasitic nematodes. Annu Rev Phytopathol 49, 135-156. 10.1146/annurev-phyto-121310-111406.

Deerinck, T.J., Bushong, E., Thor, A., and Ellisman, M. (2010). NCMIR methods for 3D EM: A new protocol for preparation of biological specimens for serial block face scanning electron microscopy. Nat Center Microsc Imag Res, 6-8.

Dickinson, D.J., Pani, A.M., Heppert, J.K., Higgins, C.D., and Goldstein, B. (2015). Streamlined Genome Engineering with a Self-Excising Drug Selection Cassette. Genetics 200, 10351049. 10.1534/genetics.115.178335.

Dodd, W., Tang, L., Lone, J.C., Wimberly, K., Wu, C.W., Consalvo, C., Wright, J.E., Pujol, N., and Choe, K.P. (2018). A Damage Sensor Associated with the Cuticle Coordinates Three Core Environmental Stress Responses in C. elegans. Genetics 208, 1467-1482. 10.1534/genetics.118.300827.

E, L., Zhou, T., Koh, S., Chuang, M., Sharma, R., Pujol, N., Chisholm, A.D., Eroglu, C., Matsunami, H., and Yan, D. (2018). An Antimicrobial Peptide and Its Neuronal Receptor Regulate Dendrite Degeneration in Aging and Infection. Neuron 97, 125-138. 10.1016/j.neuron.2017.12.001.

Essmann, C.L., Elmi, M., Shaw, M., Anand, G.M., Pawar, V.M., and Srinivasan, M.A. (2016). Invivo high resolution AFM topographic imaging of Caenorhabditis elegans reveals previously unreported surface structures of cuticle mutants. Nanomedicine. 10.1016/j.nano.2016.09.006. 
Essmann, C.L., Martinez-Martinez, D., Pryor, R., Leung, K.Y., Krishnan, K.B., Lui, P.P., Greene, N.D.E., Brown, A.E.X., Pawar, V.M., Srinivasan, M.A., and Cabreiro, F. (2020). Mechanical properties measured by atomic force microscopy define health biomarkers in ageing $C$. elegans. Nat Commun 11, 1043. 10.1038/s41467-020-14785-0.

Forman-Rubinsky, R., Cohen, J.D., and Sundaram, M.V. (2017). Lipocalins Are Required for Apical Extracellular Matrix Organization and Remodeling in Caenorhabditis elegans. Genetics 207, 625-642. 10.1534/genetics.117.300207.

Frische, E.W., Pellis-van Berkel, W., van Haaften, G., Cuppen, E., Plasterk, R.H., Tijsterman, M., Bos, J.L., and Zwartkruis, F.J. (2007). RAP-1 and the RAL-1/exocyst pathway coordinate hypodermal cell organization in Caenorhabditis elegans. Embo J 26, 5083-5092. 10.1038/sj.emboj.7601922.

Hall, D.H., Hartweig, E., and Nguyen, K.C. (2012a). OTO Fixation for SEM and Blockface Imaging. 10.3908/wormatlas.9.8.

Hall, D.H., Hartwieg, E., and Nguyen, K.C. (2012b). Modern electron microscopy methods for C. elegans. Methods Cell Biol 107, 93-149. 10.1016/B978-0-12-394620-1.00004-7.

Hyenne, V., Apaydin, A., Rodriguez, D., Spiegelhalter, C., Hoff-Yoessle, S., Diem, M., Tak, S., Lefebvre, O., Schwab, Y., Goetz, J.G., and Labouesse, M. (2015). RAL-1 controls multivesicular body biogenesis and exosome secretion. J Cell Biol 211, 27-37. 10.1083/jcb.201504136.

Johnstone, I.L. (2000). Cuticle collagen genes. Expression in Caenorhabditis elegans. Trends Genet 16, 21-27. 10.1016/s0168-9525(99)01857-0.

Kamath, R.S., Fraser, A.G., Dong, Y., Poulin, G., Durbin, R., Gotta, M., Kanapin, A., Le Bot, N., Moreno, S., Sohrmann, M., et al. (2003). Systematic functional analysis of the Caenorhabditis elegans genome using RNAi. Nature 421, 231-237. 10.1038/nature01278.

Katz, S.S., Maybrun, C., Maul-Newby, H.M., and Frand, A.R. (2018). Non-canonical apical constriction shapes emergent matrices in C. elegans. bioRxiv, 189951. 10.1101/189951.

Kim, D.H., and Ewbank, J.J. (2018). Signaling in the innate immune response (The C. elegans Research Community ed.). 10.1895/wormbook.1.83.2.

Kolotuev, I., Schwab, Y., and Labouesse, M. (2009). A precise and rapid mapping protocol for correlative light and electron microscopy of small invertebrate organisms. Biol Cell 102, 121132. 10.1042/BC20090096.

Lanze, C.E., Gandra, R.M., Foderaro, J.E., Swenson, K.A., Douglas, L.M., and Konopka, J.B. (2020). Plasma Membrane MCC/Eisosome Domains Promote Stress Resistance in Fungi. Microbiol Mol Biol Rev 84. 10.1128/MMBR.00063-19.

Lardennois, A., Pasti, G., Ferraro, T., Llense, F., Mahou, P., Pontabry, J., Rodriguez, D., Kim, S., Ono, S., Beaurepaire, E., et al. (2019). An actin-based viscoplastic lock ensures progressive body-axis elongation. Nature 573, 266-270. 10.1038/s41586-019-1509-4.

Lemiere, J., Ren, Y., and Berro, J. (2021). Rapid adaptation of endocytosis, exocytosis and eisosomes after an acute increase in membrane tension in yeast cells. Elife 10. 10.7554/eLife.62084.

Liegeois, S., Benedetto, A., Garnier, J.M., Schwab, Y., and Labouesse, M. (2006). The V0ATPase mediates apical secretion of exosomes containing Hedgehog-related proteins in $C$. elegans. J Cell Biol 173, 949-961. 10.1083/jcb.200511072.

Liegeois, S., Benedetto, A., Michaux, G., Belliard, G., and Labouesse, M. (2007). Genes required for osmoregulation and apical secretion in C. elegans. Genetics 175, 709-724. 10.1534/genetics.106.066035.

Martineau, C.N., Kirienko, N.V., and Pujol, N. (2021). Innate immunity in C. elegans. Current topics in developmental biology 144, 309-351. 10.1016/bs.ctdb.2020.1. 
McMahon, L., Muriel, J.M., Roberts, B., Quinn, M., and Johnstone, I.L. (2003). Two sets of interacting collagens form functionally distinct substructures within a Caenorhabditis elegans extracellular matrix. Mol Biol Cell 14, 1366-1378. 10.1091/mbc.E02-08-0479.

Miao, R., Li, M., Zhang, Q., Yang, C., and Wang, X. (2020). An ECM-to-Nucleus Signaling Pathway Activates Lysosomes for C. elegans Larval Development. Dev Cell 52, 21-37 e25. 10.1016/j.devcel.2019.10.020.

Moseley, J.B. (2018). Eisosomes. Curr Biol 28, R376-R378. 10.1016/j.cub.2017.11.073.

Norris, A., Tammineni, P., Wang, S., Gerdes, J., Murr, A., Kwan, K.Y., Cai, Q., and Grant, B.D. (2017). SNX-1 and RME-8 oppose the assembly of HGRS-1/ESCRT-0 degradative microdomains on endosomes. Proc Natl Acad Sci U S A 114, E307-E316. 10.1073/pnas. 1612730114 .

Page, A.P., and Johnstone, I.L. (2007). The cuticle. WormBook, 1-15. 10.1895/wormbook.1.138.1.

Polanowska, J., Chen, J.X., Soule, J., Omi, S., Belougne, J., Taffoni, C., Pujol, N., Selbach, M., Zugasti, O., and Ewbank, J.J. (2018). Evolutionary plasticity in the innate immune function of Akirin. PLoS Genet 14, e1007494. 10.1371/journal.pgen.1007494.

Pujol, N., Bonnerot, C., Ewbank, J.J., Kohara, Y., and Thierry-Mieg, D. (2001). The Caenorhabditis elegans unc-32 gene encodes alternative forms of a vacuolar ATPase a subunit. J Biol Chem 276, 11913-11921. 10.1074/jbc.M009451200.

Pujol, N., Cypowyj, S., Ziegler, K., Millet, A., Astrain, A., Goncharov, A., Jin, Y., Chisholm, A.D., and Ewbank, J.J. (2008a). Distinct innate immune responses to infection and wounding in the C. elegans epidermis. Curr Biol 18, 481-489. 10.1016/j.cub.2008.02.079.

Pujol, N., Zugasti, O., Wong, D., Couillault, C., Kurz, C.L., Schulenburg, H., and Ewbank, J.J. (2008b). Anti-fungal innate immunity in $C$. elegans is enhanced by evolutionary diversification of antimicrobial peptides. PLoS Pathog 4, e1000105. 10.1371/journal.ppat.1000105.

Rohlfing, A.K., Miteva, Y., Hannenhalli, S., and Lamitina, T. (2010). Genetic and physiological activation of osmosensitive gene expression mimics transcriptional signatures of pathogen infection in C. elegans. PLoS One 5, e9010. 10.1371/journal.pone.0009010.

Roudier, N., Lefebvre, C., and Legouis, R. (2005). CeVPS-27 is an endosomal protein required for the molting and the endocytic trafficking of the low-density lipoprotein receptor-related protein 1 in Caenorhabditis elegans. Traffic 6, 695-705. 10.1111/j.1600-0854.2005.00309.x.

Rual, J.F., Ceron, J., Koreth, J., Hao, T., Nicot, A.S., Hirozane-Kishikawa, T., Vandenhaute, J., Orkin, S.H., Hill, D.E., van den Heuvel, S., and Vidal, M. (2004). Toward improving Caenorhabditis elegans phenome mapping with an ORFeome-based RNAi library. Genome Res 14, 2162-2168. 10.1101/gr.2505604.

Sandhu, A., Badal, D., Sheokand, R., Tyagi, S., and Singh, V. (2021). Specific collagens maintain the cuticle permeability barrier in Caenorhabditis elegans. Genetics 217. 10.1093/genetics/iyaa047.

Serrano-Saiz, E., Vogt, M.C., Levy, S., Wang, Y., Kaczmarczyk, K.K., Mei, X., Bai, G., Singson, A., Grant, B.D., and Hobert, O. (2020). SLC17A6/7/8 Vesicular Glutamate Transporter Homologs in Nematodes. Genetics 214, 163-178. 10.1534/genetics.119.302855.

Shi, A., Sun, L., Banerjee, R., Tobin, M., Zhang, Y., and Grant, B.D. (2009). Regulation of endosomal clathrin and retromer-mediated endosome to Golgi retrograde transport by the J-domain protein RME-8. Embo J 28, 3290-3302. 10.1038/emboj.2009.272.

Stiernagle, T., ed. (2006). Maintenance of C. elegans (The C. elegans Research Community ed).

Taffoni, C., Omi, S., Huber, C., Mailfert, S., Fallet, M., Rupprecht, J.F., Ewbank, J.J., and Pujol, N. (2020). Microtubule plus-end dynamics link wound repair to the innate immune response. Elife 9, e45047, e45047. 10.7554/eLife.45047. 
Thakur, N., Pujol, N., Tichit, L., and Ewbank, J.J. (2014). Clone mapper: an online suite of tools for RNAi experiments in Caenorhabditis elegans. G3 4, 2137-2145. 10.1534/g3.114.013052.

Thein, M.C., McCormack, G., Winter, A.D., Johnstone, I.L., Shoemaker, C.B., and Page, A.P. (2003). Caenorhabditis elegans exoskeleton collagen COL-19: an adult-specific marker for collagen modification and assembly, and the analysis of organismal morphology. Dev Dyn 226, 523-539. 10.1002/dvdy.10259.

Vuong-Brender, T.T., Ben Amar, M., Pontabry, J., and Labouesse, M. (2017a). The interplay of stiffness and force anisotropies drives embryo elongation. Elife 6. 10.7554/eLife.23866.

Vuong-Brender, T.T.K., Suman, S.K., and Labouesse, M. (2017b). The apical ECM preserves embryonic integrity and distributes mechanical stress during morphogenesis. Development 144, 4336-4349. 10.1242/dev.150383.

Watts, J.S., Harrison, H.F., Omi, S., Guenthers, Q., Dalelio, J., Pujol, N., and Watts, J.L. (2020). New Strains for Tissue-Specific RNAi Studies in Caenorhabditis elegans. G3 (Bethesda) 10, 4167-4176. 10.1534/g3.120.401749.

Wheeler, J.M., and Thomas, J.H. (2006). Identification of a novel gene family involved in osmotic stress response in Caenorhabditis elegans. Genetics 174, 1327-1336.

White, J.G., Southgate, E., Thomson, J.N., and Brenner, S. (1986). The structure of the nervous system of the nematode $C$. elegans. Philosophical Transactions of the Royal Society of London 314B, 1-340.

Willis, J.H., Munro, E., Lyczak, R., and Bowerman, B. (2006). Conditional dominant mutations in the Caenorhabditis elegans gene act-2 identify cytoplasmic and muscle roles for a redundant actin isoform. Mol Biol Cell 17, 1051-1064. 10.1091/mbc.e05-09-0886.

Wood, W.B., ed. (1988). The nematode Caenorhabditis elegans (Cold Spring Harbor Laboratory Press).

Zhang, H., and Labouesse, M. (2010). The making of hemidesmosome structures in vivo. Dev Dyn 239, 1465-1476. 10.1002/dvdy.22255.

Zugasti, O., Bose, N., Squiban, B., Belougne, J., Kurz, C.L., Schroeder, F.C., Pujol, N., and Ewbank, J.J. (2014). Activation of a G protein-coupled receptor by its endogenous ligand triggers the innate immune response of $C$. elegans. Nat Immunol 15, 833-838. 10.1038/ni.2957.

Zugasti, O., Thakur, N., Belougne, J., Squiban, B., Kurz, C.L., Soule, J., Omi, S., Tichit, L., Pujol, N., and Ewbank, J.J. (2016). A quantitative genome-wide RNAi screen in C. elegans for antifungal innate immunity genes. BMC Biol 14, 35. 10.1186/s12915-016-0256-3. 


\section{FIGURE 1}

bioRxiv preprint doi: https://doi.org/10.1101/2021.11.26.470028; this version posted November 26, 2021. The copyright holder for this preprint (which was not certified by peer review) is the author/funder, who has granted bioRxiv a license to display the preprint in perpetuity. It is made available under aCC-BY-NC-ND 4.0 International license.
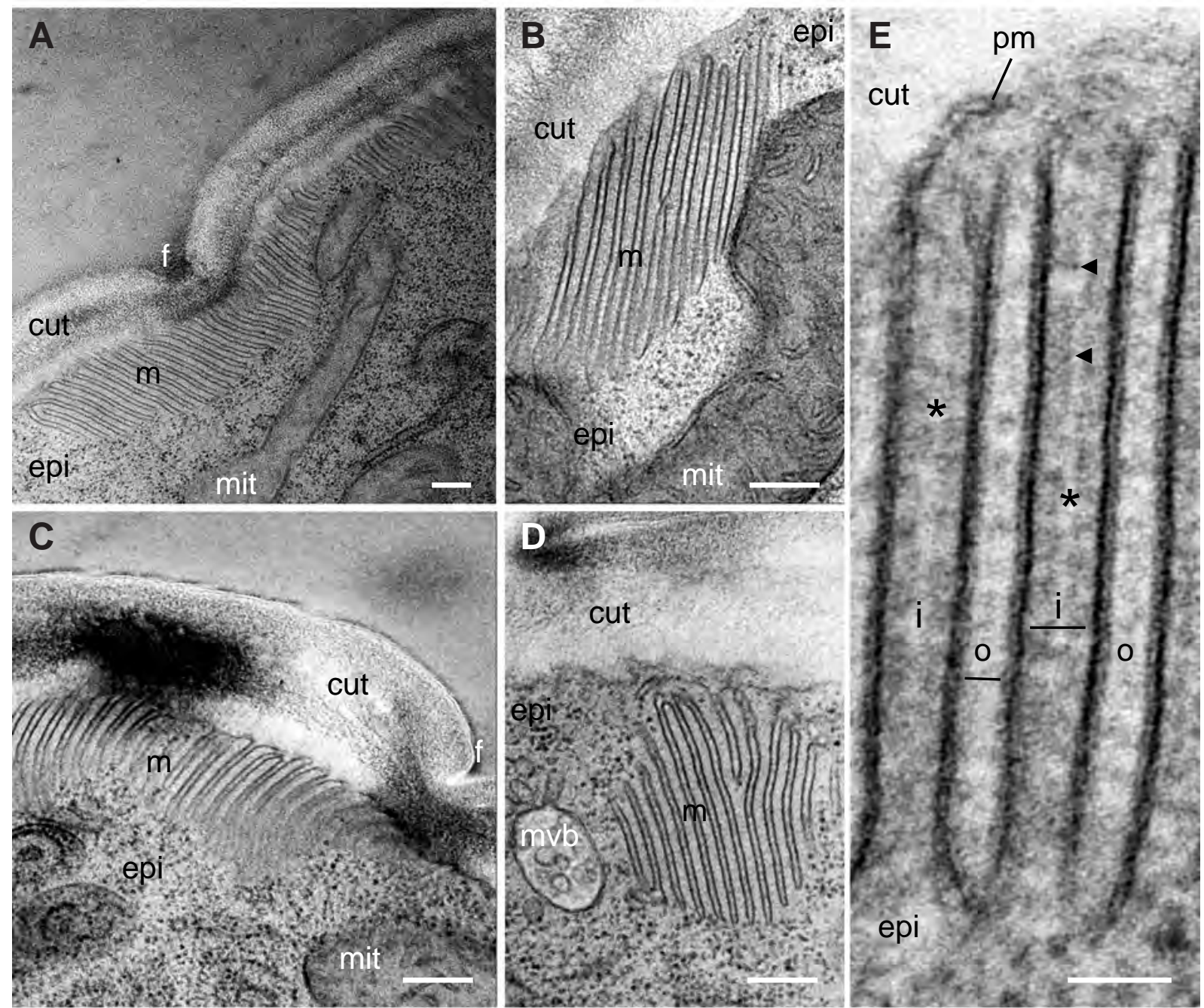

Figure 1: Meisosomes ultrastructure (by TEM) in wild-type worms. TEM images of longitudinal sections of young adult wild-type worms reveal epidermal structures, meisosomes $(\mathrm{m})$, contacting the cuticle (cut), composed of parallel plasma membrane folds. Meisosomes typically comprise less than 10 folds, but can have more than 30 , as shown in this example. The complete meisosome is some $4 \mu \mathrm{m}$ wide, and extends on both sides of a furrow (f) (A). Some folds are apposed to mitochondria (mit) (B), can vary in size and orientation (A-D) and can appear not to be in direct contact with the cuticle in some EM sections (D); scale bar, $200 \mathrm{~nm}$. (E) High magnification view of plasma membrane (pm) folds. The "internal" folds (i) are $35 \mathrm{~nm}$ wide, contain a ribosome-free cytoplasm but ladder-like banding (indicated by the black arrowheads), and are less electron dense in their middle $\left({ }^{*}\right)$. The "outer" folds (o) on the cuticle side are $20 \mathrm{~nm}$ wide. Epidermis (epi), multivesicular body (mvb); scale bar, $50 \mathrm{~nm}$. 


\section{FIGURE 1-Supplement 1}

bioRxiv preprint doi: https://doi.org/10.1101/2021.11.26.470028; this version posted November 26, 2021. The copyright holder for this preprint (which was not certified by peer review) is the author/funder, who has granted bioRxiv a license to display the preprint in perpetuity. It is made

A

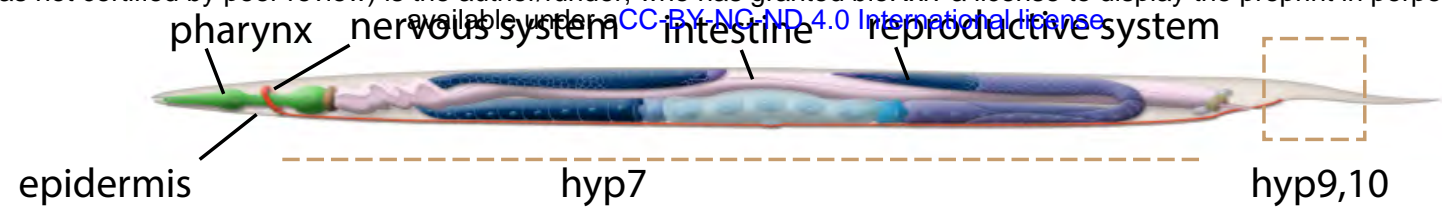

B

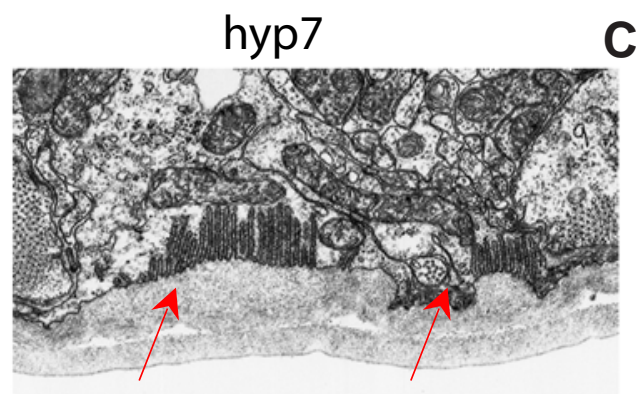

C

hyp $9 / 10$

D hyp9/10
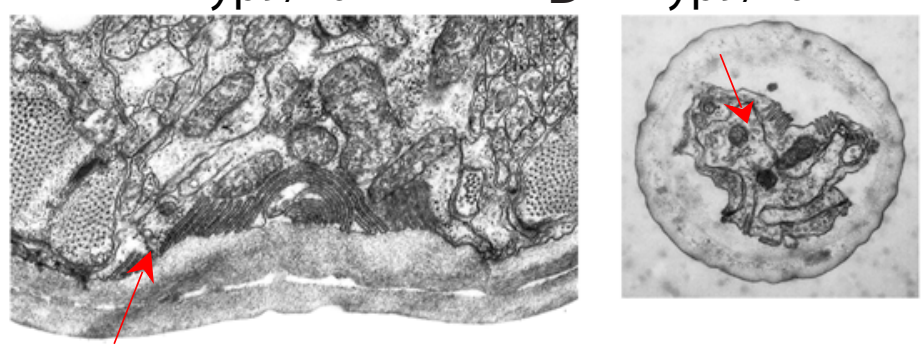

E

L1

$\mathbf{F}$

L2

G

L3

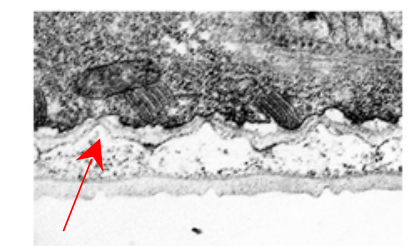

H
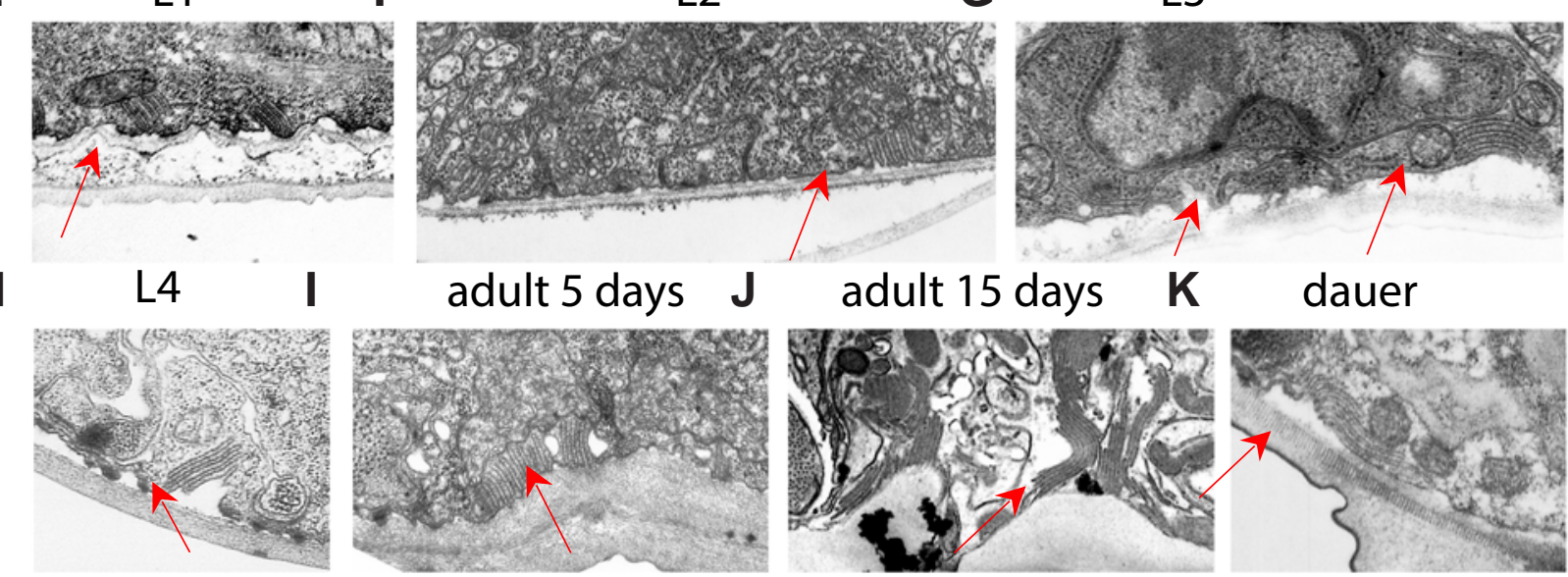

adult 5 days $\mathrm{J}$

adult 15 days $\mathbf{K}$

dauer
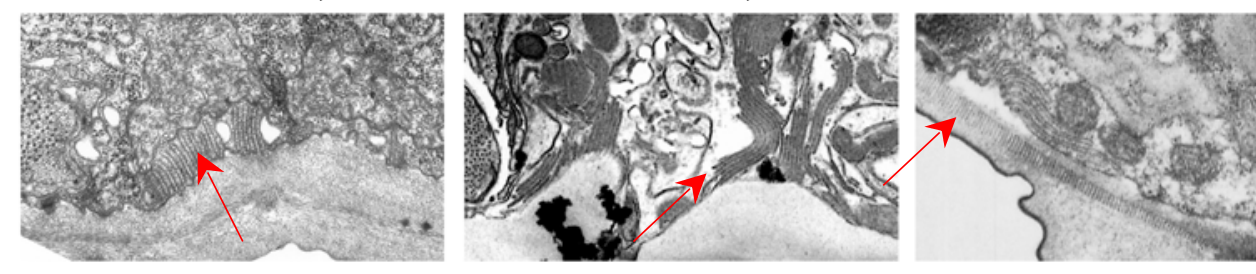

Figure 1-figure supplement 1: Meisosomes are present in epidermis at all development stages. (A) Schematic view of the tissues of an adult C. elegans worm. MRC archival transversal TEM images showing that meisosomes (red arrow) are present in different body regions in the epidermis (hyp7, B) and in the tail (hyp9/10, C-D), as well as in different larval stages L1 $(E), L 2(F), L 3(G), L 4(H)$, adult 5 days $(I)$, adult 15 days $(\mathrm{J})$, dauer stage $(K)$. 


\section{FIGURE 1-Supplement 2}

bioRxiv preprint doi: https://doi.org/10.1101/2021.11.26.470028; this version posted November 26, 2021. The copyright holder for this preprint (which was not certified by peer review) is the author/funder, who has granted bioRxiv a license to display the preprint in perpetuity. It is made

A

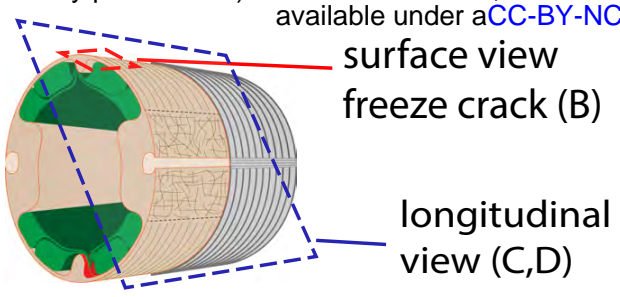

B

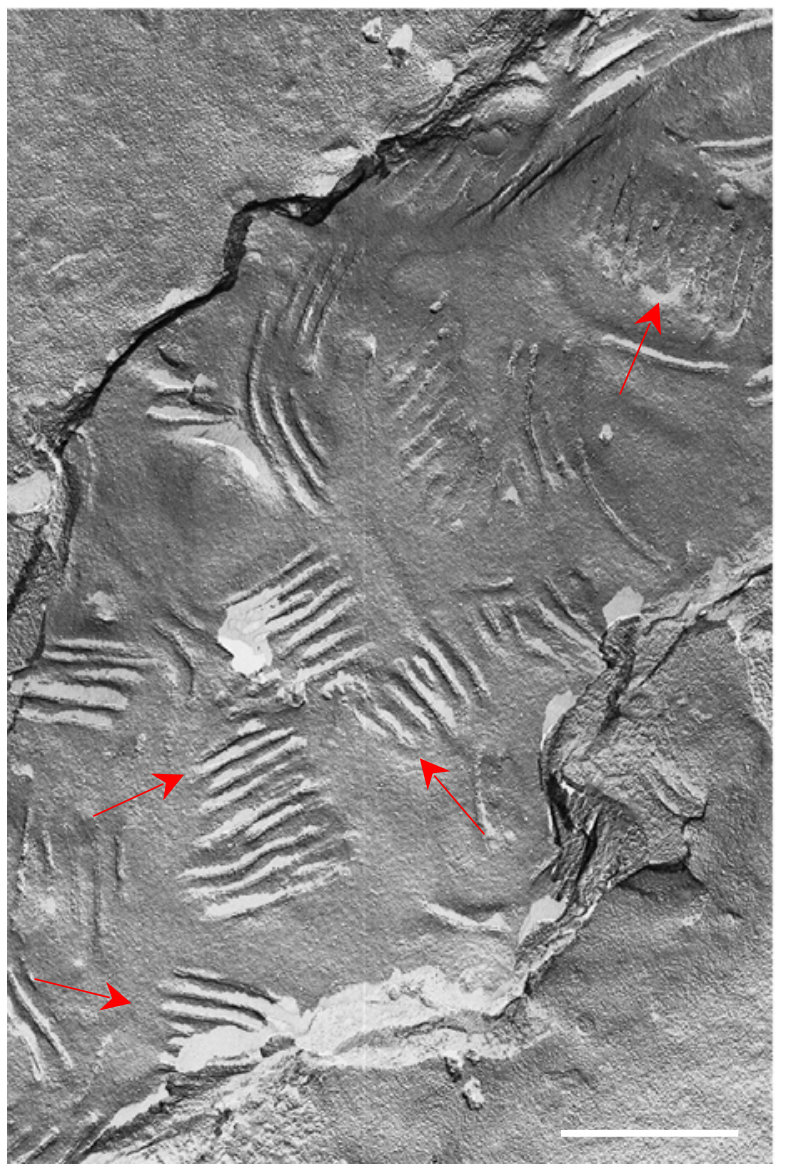

C L4 pre-moulting

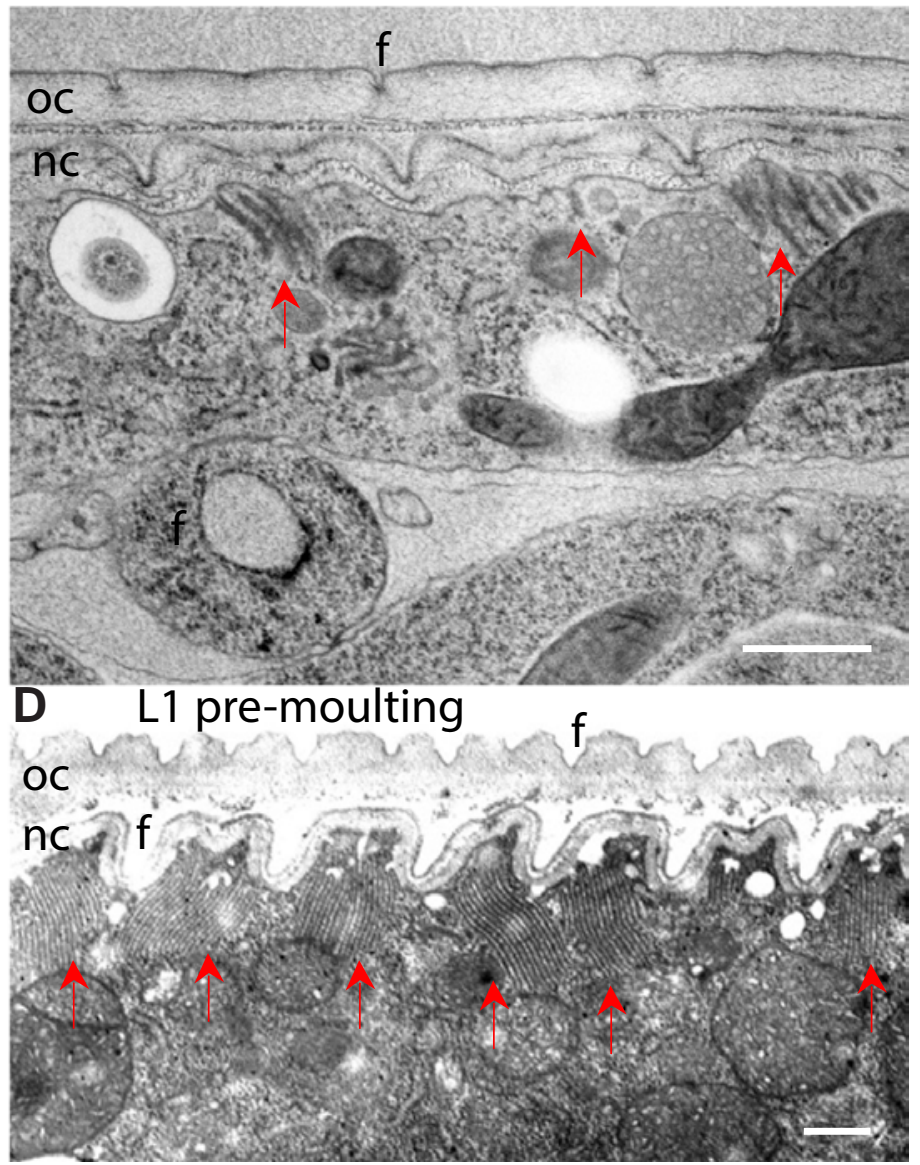

Figure 1-figure supplement 2: Meisosomes align with the furrow at the time of moulting. (A) Schematic view of the outer tissues of an adult C. elegans worm near the mid-body. The plane of longitudinal EM sections and the en face view obtained by freeze fracture are shown in blue and red dotted lines, respectively. (B). Freeze fracture view of adult epidermal plasma membrane (anterior to the top right) shows larger meisosome infoldings in the region of the dorsal epidermis. The random orientation vs the body axis for several meisosomes, highlighted by red arrows, can be seen. (C-D) Lengthwise TEM view of the epidermis at pre moult stages reveals an alignment of meisosome in between the furrows. (C) Late L4 stage, Scale bar, $500 \mathrm{~nm}$. (D) Meisosomes are tightly packed in register with each furrow of the developing L2 cuticle, while the L1 cuticle lies to the outside of the body, with more narrow furrows compared to the developing L2 cuticle. MRC archival image. Scale bar, $1 \mu \mathrm{m}$. oc, old cuticle, nc, new cuticle, f, furrow. 


\section{FIGURE 2}

bioRxiv preprint doi: https://doi.org/10.1101/2021.11.26.470028; this version posted November 26, 2021. The copyright holder for this preprint (which was not certified by peer review) is the author/funder, who has granted bioRxiv a license to display the preprint in perpetuity. It is made
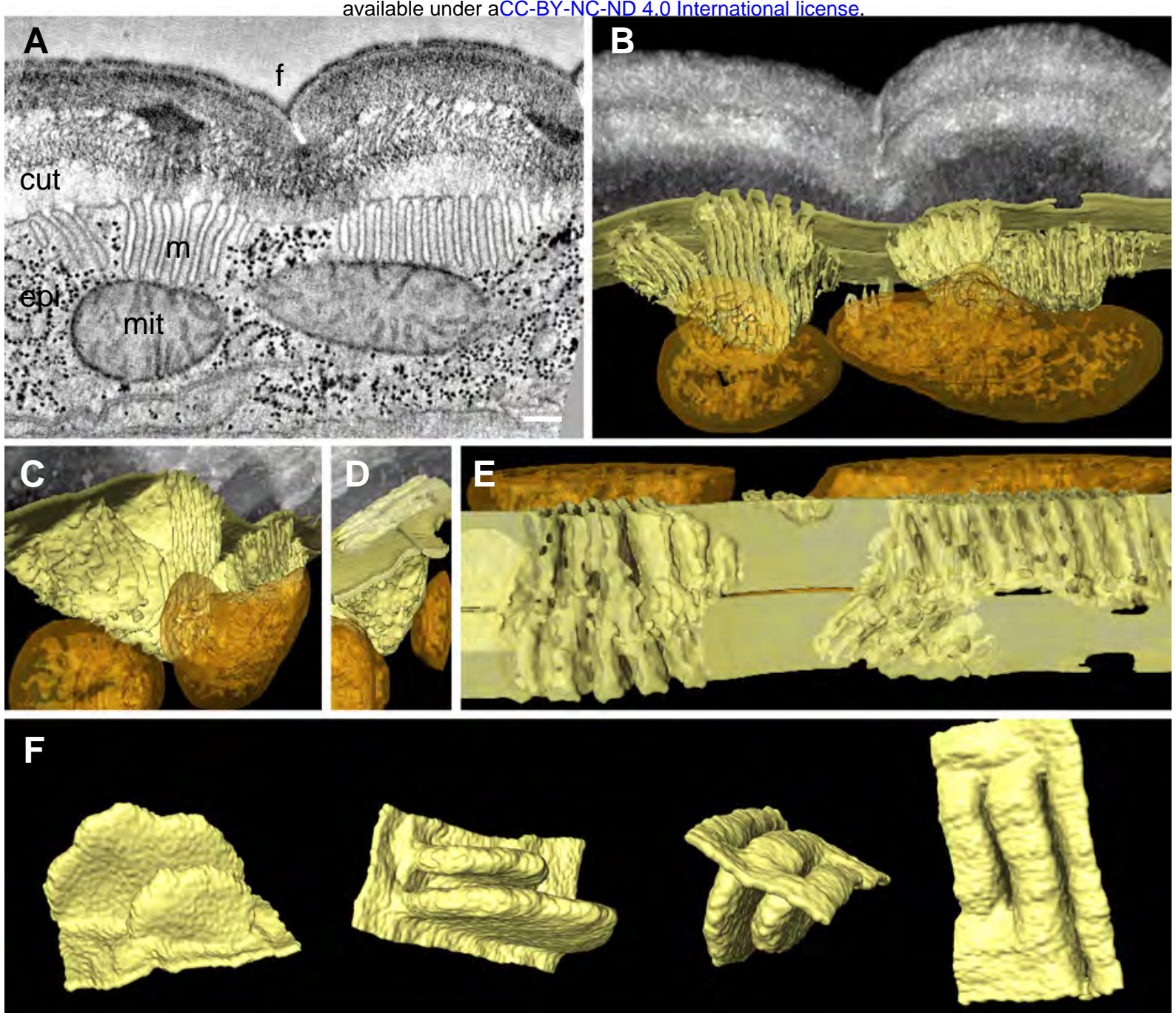

Figure 2: Meisosome topology.

Adjacent meisosomes in two serial thick $(300 \mathrm{~nm})$ sections were analysed with goniotomography. (A) Selected TEM image from the serial reconstruction. (B-E) Segmentation of membranes and mitochondria reveal their 3D topology. Meisosomes (in yellow) are in close apposition to, but not in continuity with, mitochondria (orange) and are formed by epidermal plasma membrane folds, as observed in an en face view after removing the cuticle in silico (E). (F) Two folds were extracted and manually filled for a schematic view. Cuticle (cut), epidermis (epi), furrow (f), mitochondria (mit), meisosomes (m); scale bar, $200 \mathrm{~nm}$. 


\section{FIGURE 2-Supplement 1}

bioRxiv preprint doi: https://doi.org/10.1101/2021.11.26.470028; this version posted November 26, 2021. The copyright holder for this preprint (which was not certified by peer review) is the author/funder, who has granted bioRxiv a license to display the preprint in perpetuity. It is made available under aCC-BY-NC-ND 4.0 International license.
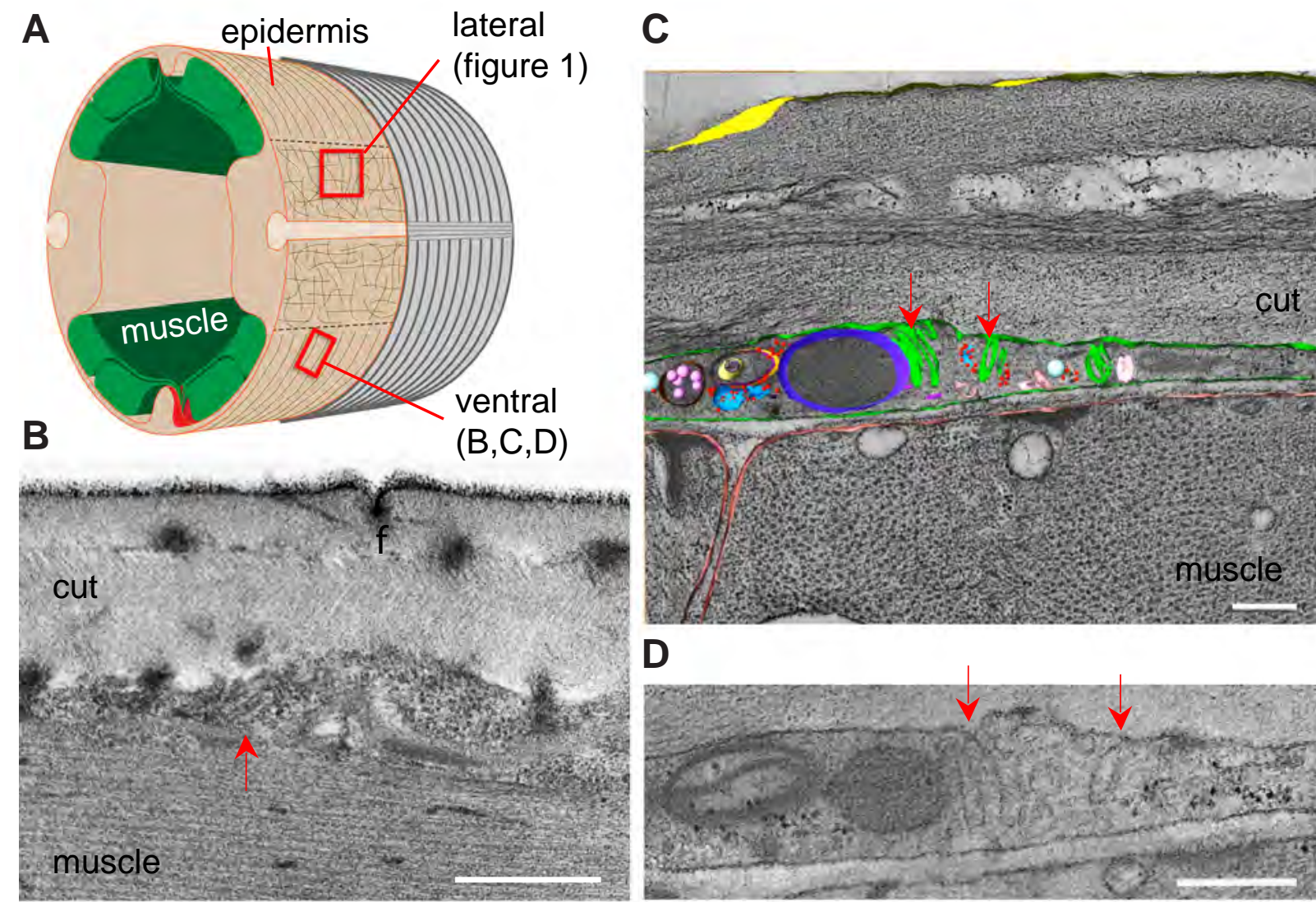

Figure 2-figure supplement 1: Smaller meisosomes can be found over the muscle quadrants. (A) Schematic view of the outer tissues of an adult C. elegans worm near the mid-body. The different regions of the epidermis analysed are represented in red rectangles: either the lateral side in Figure 1, or the ventral (or dorsal) side overlaying the muscle quadrants. (B). TEM image of longitudinal section of young adult wild-type worm reveals small meisosomes between the cuticle and the muscle quadrants. Scale bar, $500 \mathrm{~nm}$. (C) A tomogram of a transversal section reveals several smaller meisosomes (green) lying between the bodywall muscle and the cuticle. They typically have not more than 4 folds. Many other small organelles lie in this region, including multivesicular bodies (pink), ribosomes (red), and a possible small mitochondrion (dark blue). (D) One selected TEM image of the same tomogram, red arrows point to small meisosomes. Scale bars in C,D, $200 \mathrm{~nm}$. 


\section{FIGURE 3}

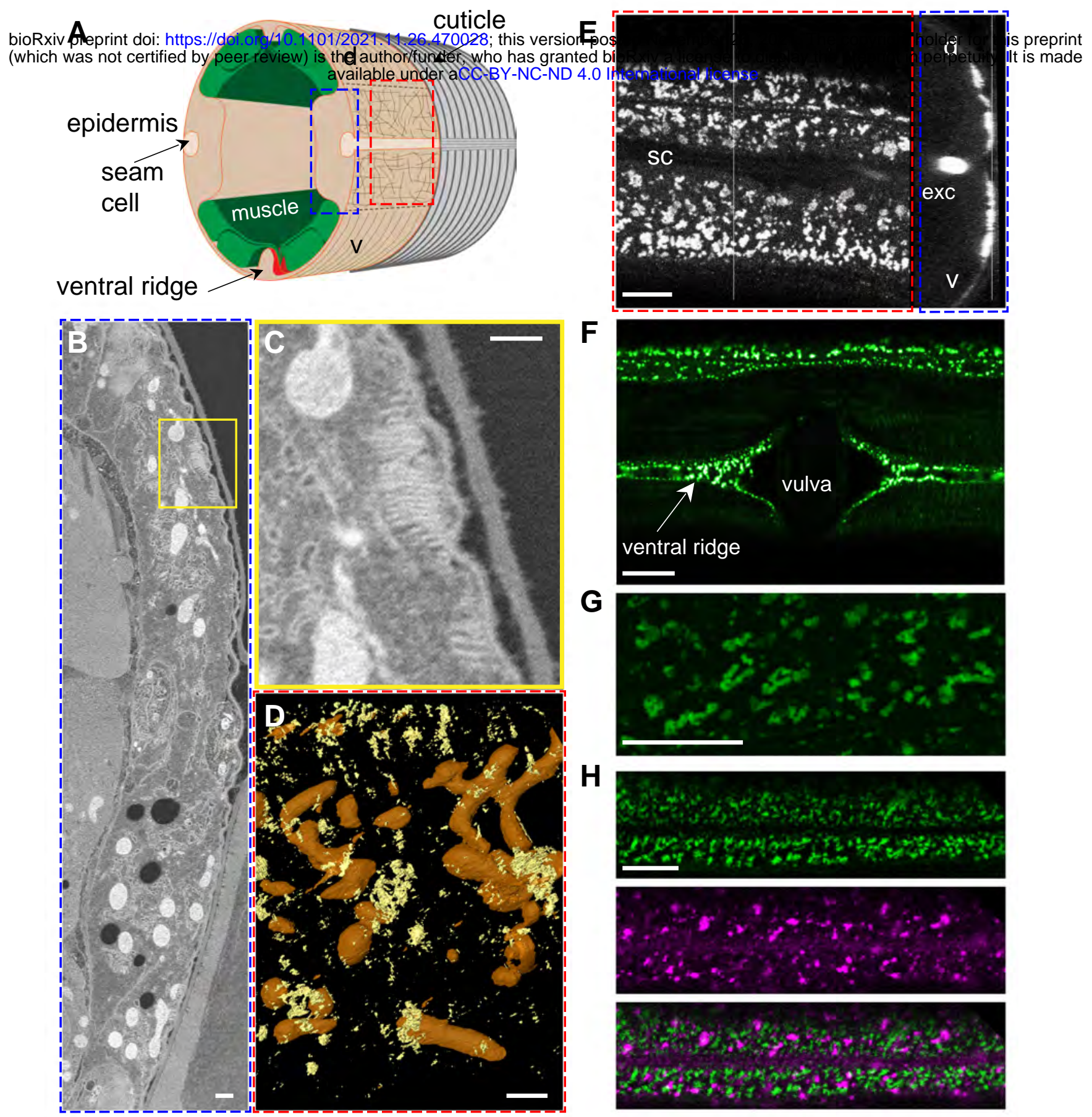

Figure 3: Meisosome density.

(A) Schematic view of the outer tissues of an adult C. elegans worm near the mid-body. The plane of transverse EM sections and the orthogonal en face view for both EM and fluorescence microscopy are indicated with the blue and red dashed rectangles, respectively. (B-C) Representative image from an SBF acquisition, the boxed area in (B) is shown at a higher magnification in (C). Scale bar, $500 \mathrm{~nm}$. (D) SBF segmentation and 3D reconstruction revealed the en face spatial distribution of meisosomes (yellow) compared to mitochondria (orange). Scale bar, $1 \mu \mathrm{m}$. (E-G) VHA-5 is a marker of meisosomes. (E) In a young adult worm, VHA-5::GFP fluorescence is observed in the lateral epidermis, as well as in the excretory canal (exc), but largely excluded from the ventral ( $v$ ) and dorsal (d) regions above the muscle quadrants, known to contain hemidesmosomes, as well as the region above the seam cell (sc), as observed in en face (left panels), and orthogonal (right) projections of reconstructed confocal stacks. (F) VHA-5::GFP is also expressed in the ventral ridge, as observed in a ventral view. (G) High resolution imaging on Airyscan mode revealed VHA-5::GFP to be associated with long and convoluted membranous structures. Scale bar, $10 \mu \mathrm{m}$. $(\mathrm{H})$ Confocal images of young adult worms expressing VHA-5::GFP (green, upper panel) together with HGRS-1::mScarlet (magenta, middle) in the epidermis; lower panel: overlay. 


\section{FIGURE 3-Supplement 1}

bioRxiv preprint doi: https://doi.org/10.1101/2021.11.26.470028; this version posted November 26, 2021. The copyright holder for this preprint (which was not certified by peer review) is the author/funder, who has granted bioRxiv a license to display the preprint in perpetuity. It is made available under aCC-BY-NC-ND 4.0 International license.

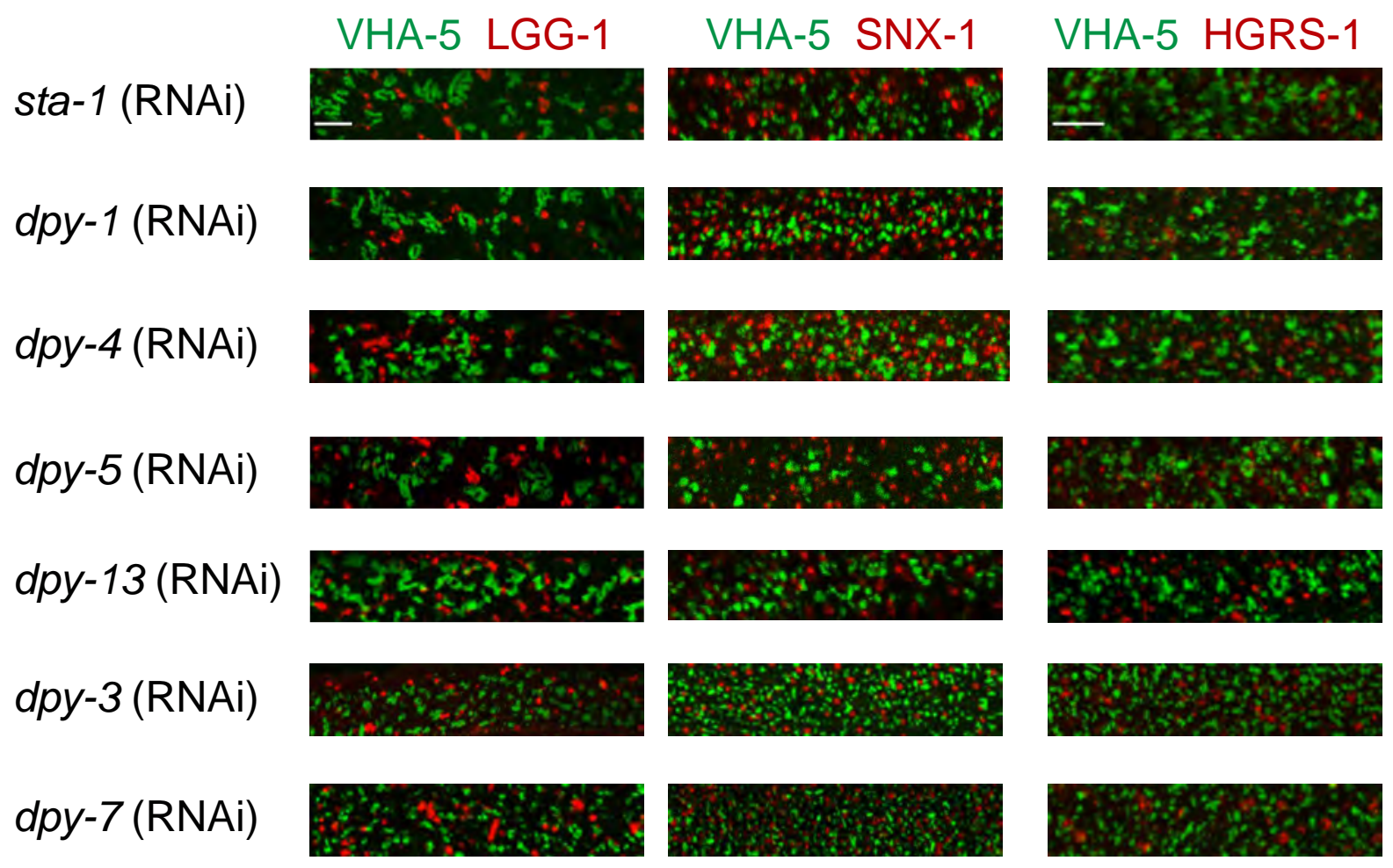

Figure 3-figure supplement 1: Meisosomes do not co-localise with endosomes, early endosomes, nor autophagosomes.

Confocal images of selected regions on the lateral epidermis of young adult epidermis expressing LGG-1::mScarlet (left panel), SNX-1::mScarlet (middle panel) or HGRS-1::mScarlet (right panel) with VHA-5::GFP and treated with the indicated RNAi clones. Control: sta-1; annuli Dpy: $d p y-1, d p y-4, d p y-5$ or $d p y-13$ and furrow Dpy: $d p y-3$ or $d p y-7, \mathrm{n}>7$. Scale bar, $5 \mu \mathrm{m}$. 


\section{FIGURE 4}

bioRxiv preprint doi: https://doi.org/10.1101/2021.11.26.470028; this version posted November 26, 2021. The copyright holder for this preprint (which was not certified by peer review) is the author/funder, who has granted bioRxiv a license to display the preprint in perpetuity. It is made

A

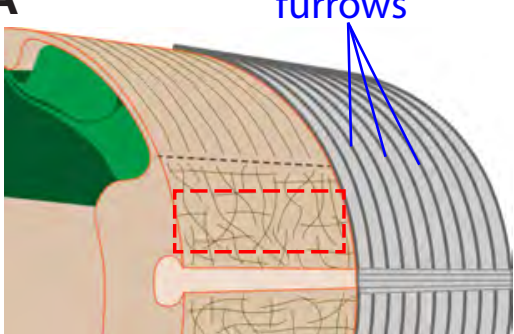

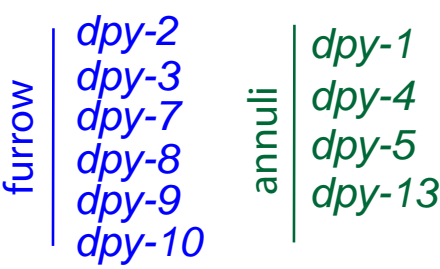

VHA-5::GFP

sta-1

$d p y-1$

dpy-4

dpy-5

dpy-3

dpy-7
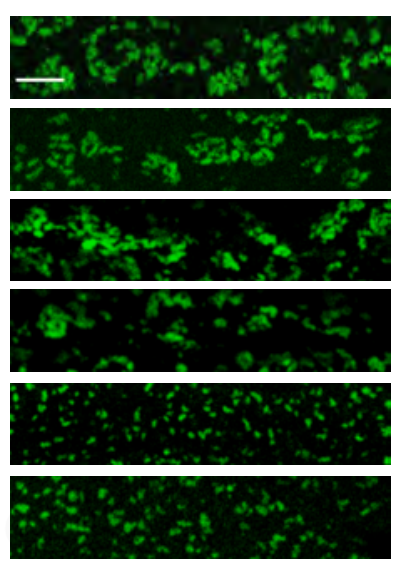

segmentation

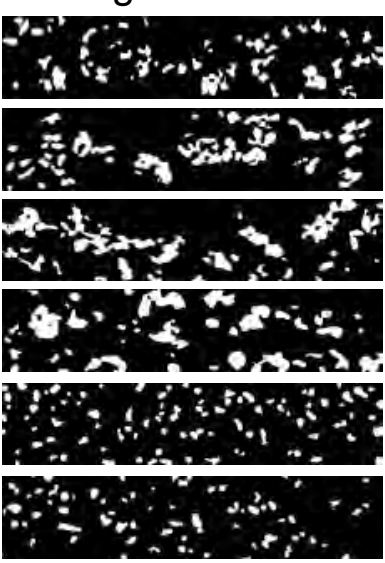

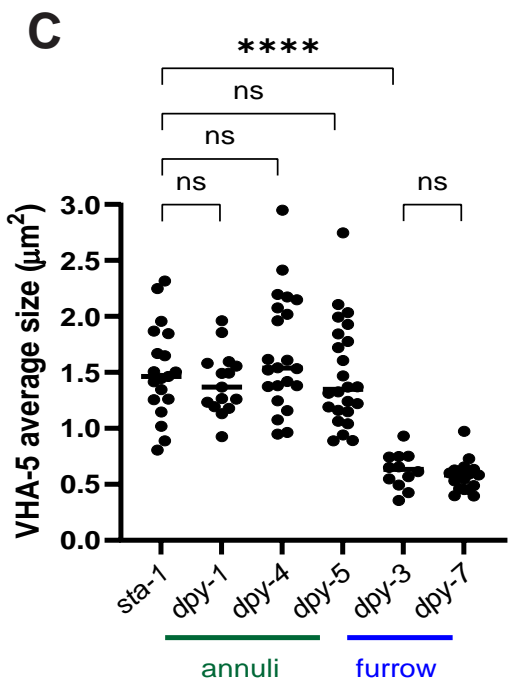
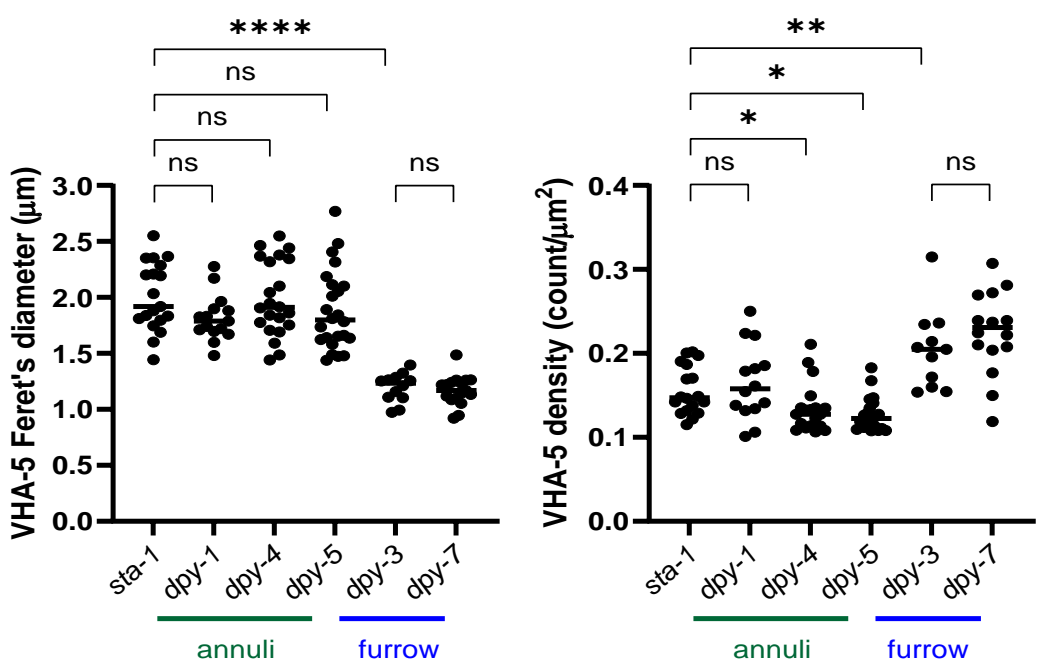

Figure 4: Furrow collagen inactivation provokes meisosome fragmentation.

(A) Schematic view of the outer tissues of an adult C. elegans worm near the mid-body, highlighting the furrows that separate the annuli, and indicating the region analysed with the red dashed rectangle. (B-C) L1 larvae expressing VHA-5::GFP were treated with the indicated RNAi clones and analysed at the young adult stage: control sta-1; annuli Dpy $d p y-1, d p y-4$ and $d p y-5$; furrow Dpy: $d p y-3$ or $d p y-7$. (B) Confocal images (left) and segmentation views (right) of selected regions on the lateral epidermis, at a constant position relative to the vulva, scale bar, $5 \mu \mathrm{m}$. (C) Quantification of VHA-5 signal average size, Feret's diameter and density. Statistics are described in Table S2, ${ }^{* * *} p<0.0001,{ }^{* *} p<0.003$ and ${ }^{*} p<0.03$. 
FIGURE 4-Supplement 1

bioRxiv preprint doi: https://dpi.org/10.11.01/202111.26.470028; this version posted November. 26, 2021. The copyright holder for this preprint

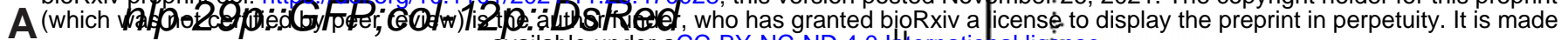
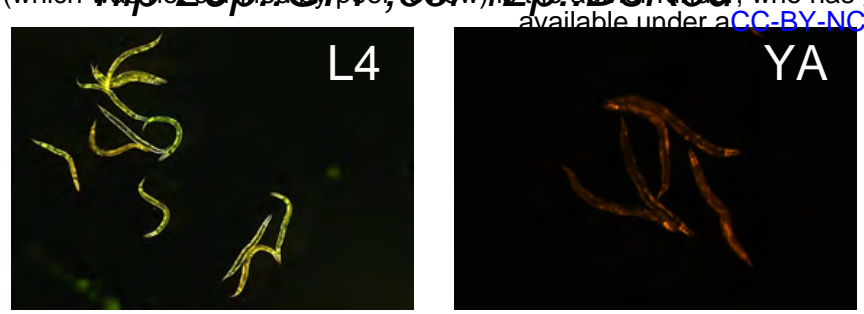

B
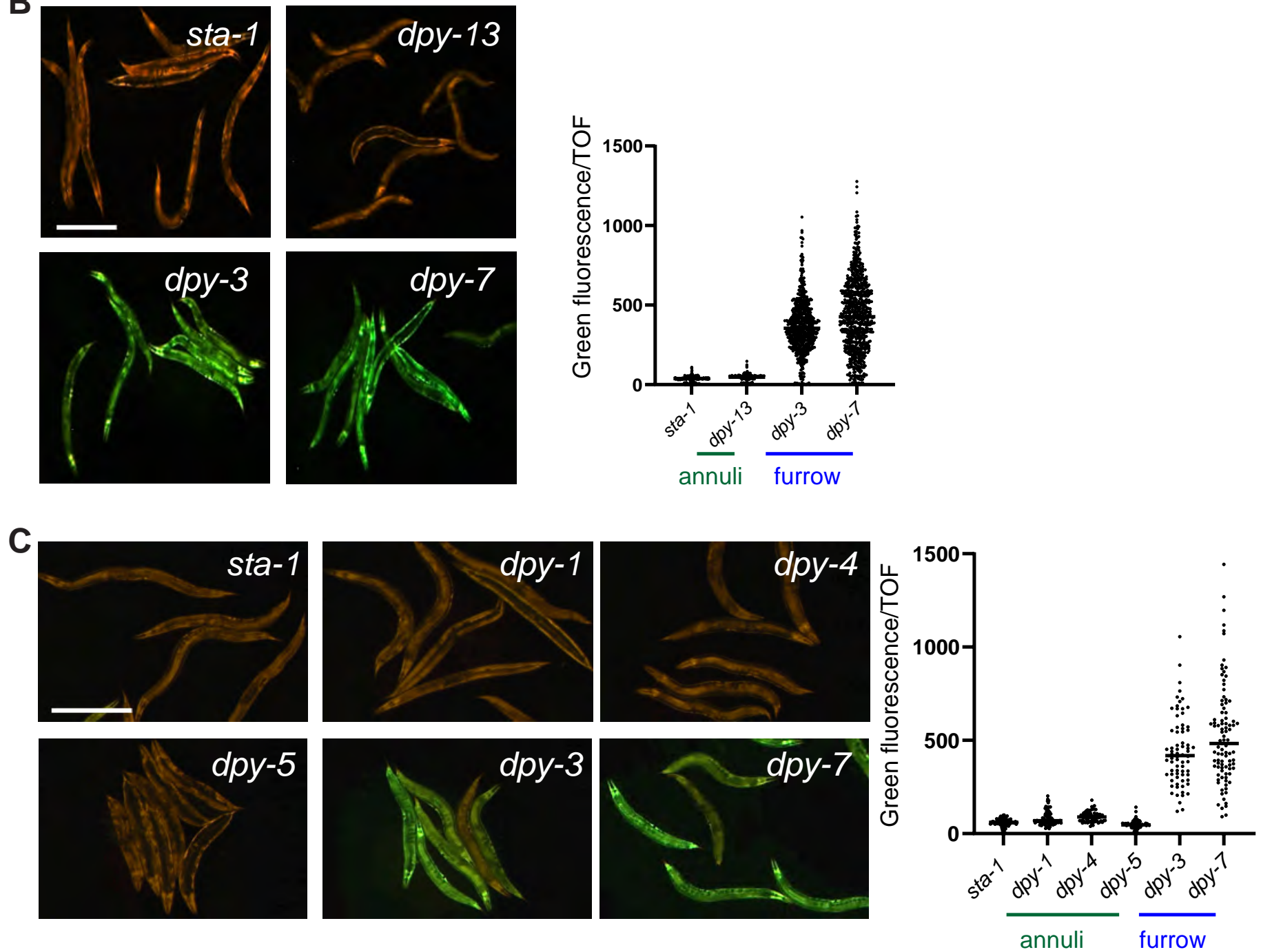

Figure 4-figure supplement 1: Worms increase AMP gene expression at the late L4 stage and in furrow collagen mutants.

IG274 worms carrying the frls7 reporter transgene constitutively express the col-12p::DsRed reporter and express nlp-29p::GFP only under certain conditions, red and green fluorescence were visualized simultaneously in all images. (A) Compared to young adults, in late L4 animals entering the moult, the expression of the nlp-29p::GFP reporter is markedly increased. Scale bar, $200 \mu \mathrm{m}$ (left). Quantification of relative green fluorescence, L4 stage $(n=260)$, young adult stage $(n=149)$ (right). (BC) RNA inactivation of selected collagen genes leads to the induction of nlp-29p::GFP in young adult worms. Compared to wild-type or annuli Dpy mutants, in furrow Dpy mutants, the expression of the nlp-29p::GFP reporter is markedly increased. Quantification of relative green fluorescence in worms carrying frls7. (B) Control: sta-1 $(\mathrm{n}=539)$, annuli Dpy: $d p y-13(\mathrm{n}=492)$ and furrow Dpy: $d p y-3(\mathrm{n}=$ 680) or $d p y-7(\mathrm{n}=688)$. (C) Control: sta-1 ( $\mathrm{n}=195)$, annuli Dpy: $d p y-1(\mathrm{n}=101), d p y-4(\mathrm{n}=68), d p y-5$ $(\mathrm{n}=81)$ or furrow Dpy: $d p y-3(\mathrm{n}=72)$ or $d p y-7(\mathrm{n}=95)$. 

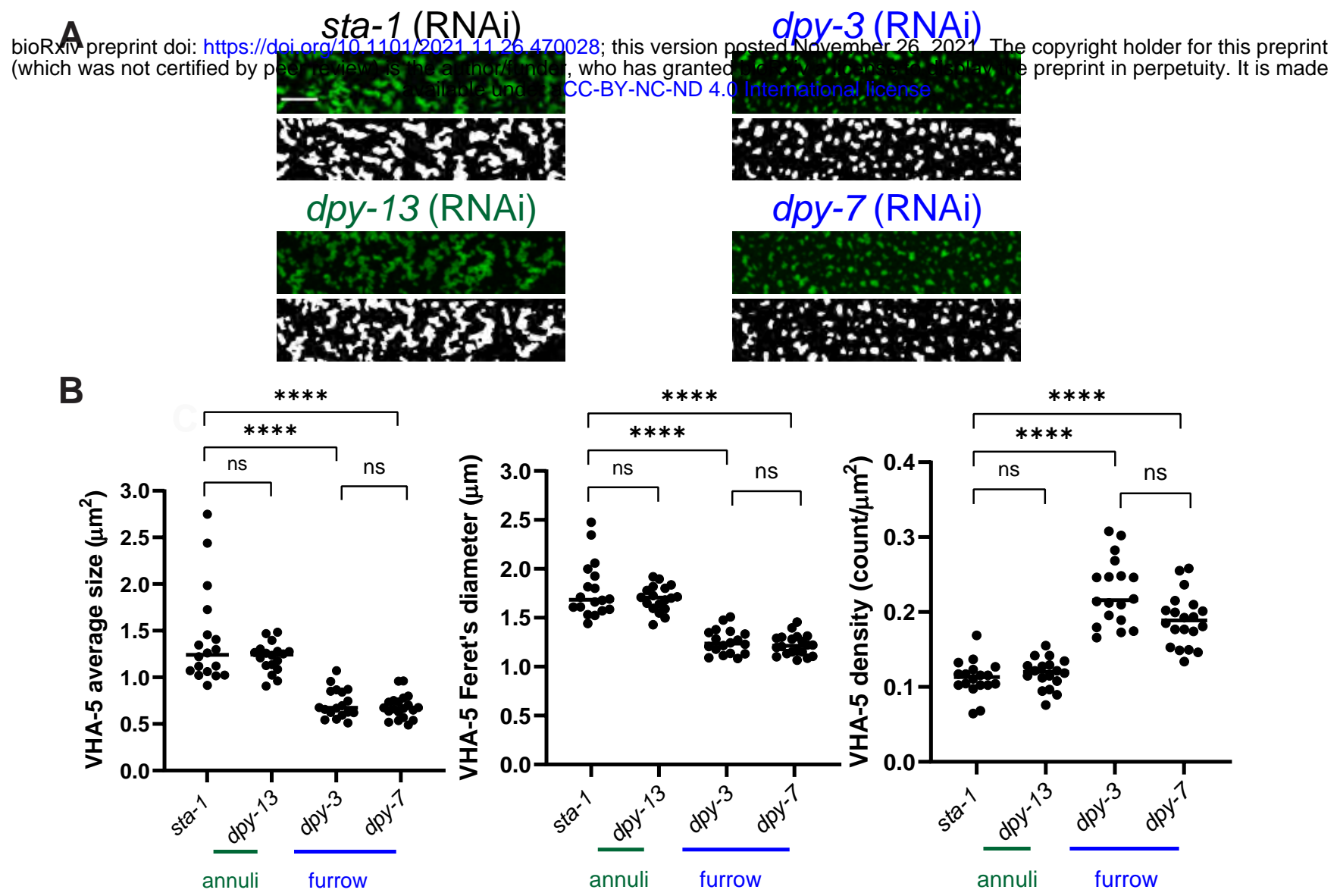

C

wt
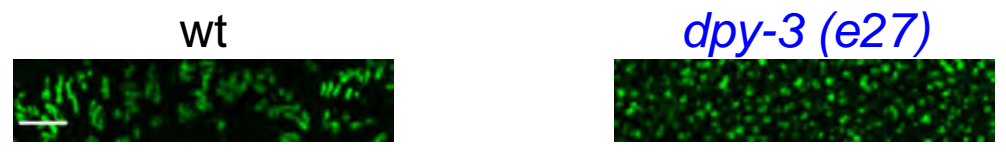

D
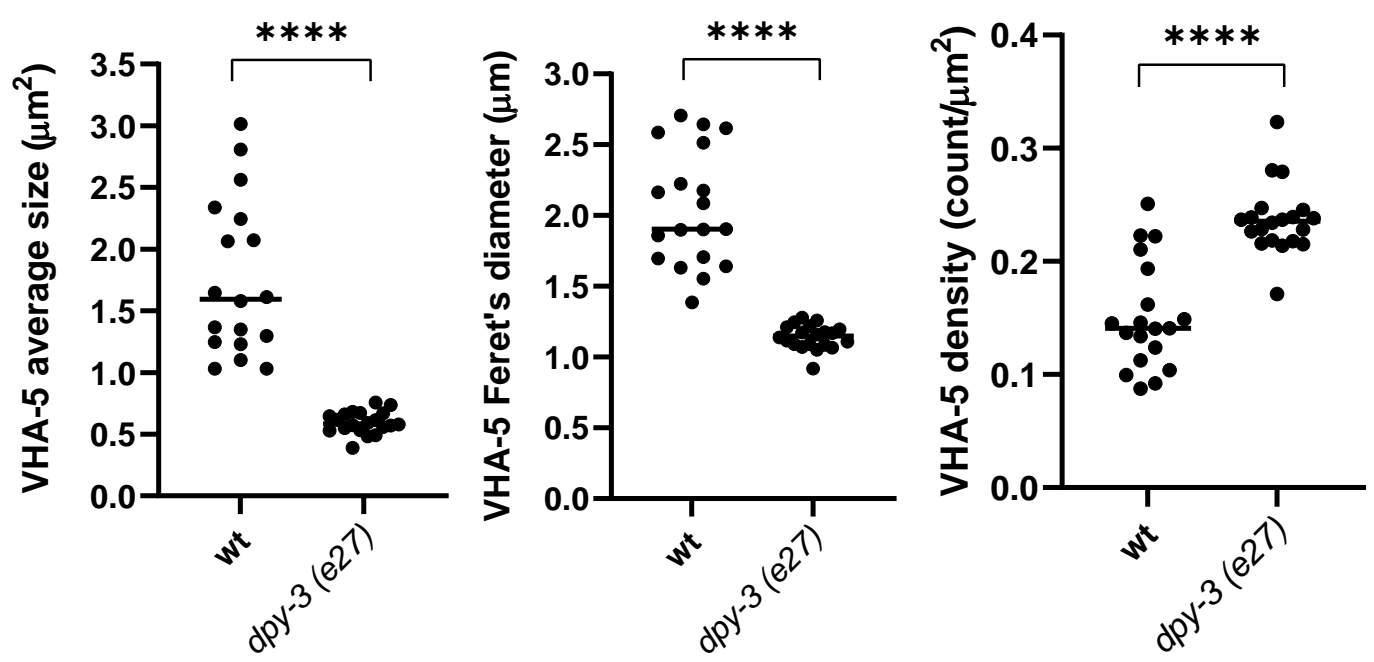

Figure 4-figure supplement 2: Furrow collagen inactivation provokes a disruption of meisosomes. (A-B) Young adults expressing VHA-5::GFP treated with the indicated RNAi clones. Control: sta-1 $(\mathrm{n}=18)$, annuli Dpy: $d p y-13 \quad(\mathrm{n}=18)$ and furrow Dpy: dpy-3 $(\mathrm{n}=18)$ or $d p y-7 \quad(\mathrm{n}=$ 20). (A) Representative confocal images (upper panels) and segmentation views (lower panels) of selected regions on the lateral epidermis, at a constant position relative to the vulva, of young adult worms expressing VHA-5::GFP; scale bar, $5 \mu \mathrm{m}$. (B) Quantification of VHA-5 signal average size, Feret's diameter and density. (C-D) Wild-type and dpy-3 mutant young adults expressing VHA-5::GFP. (C) Confocal images (upper panels) and segmentation views (lower panels) of selected regions on the lateral epidermis, scale bar, $5 \mu \mathrm{m}$. (D) Quantification of VHA-5 signal average size, Feret's diameter and density. Statistics are described in Table S2 ${ }^{* * * *} p<0.0001$. 


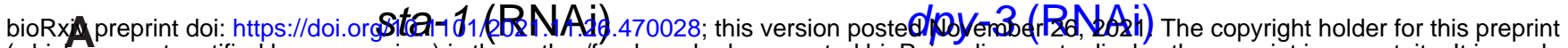

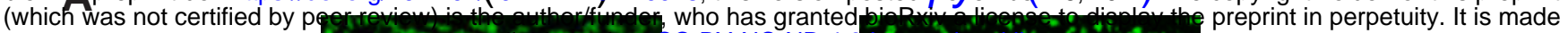
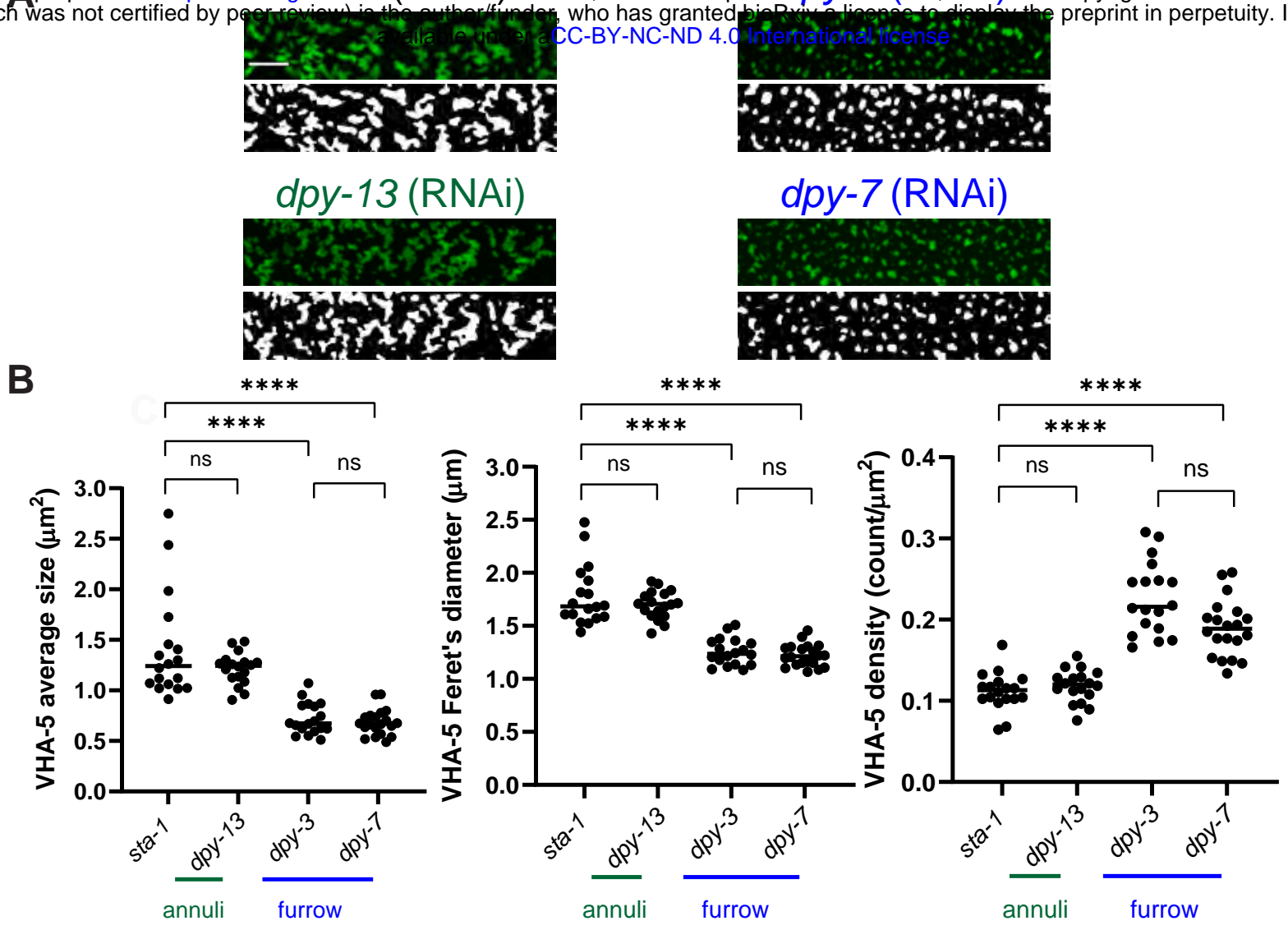

C
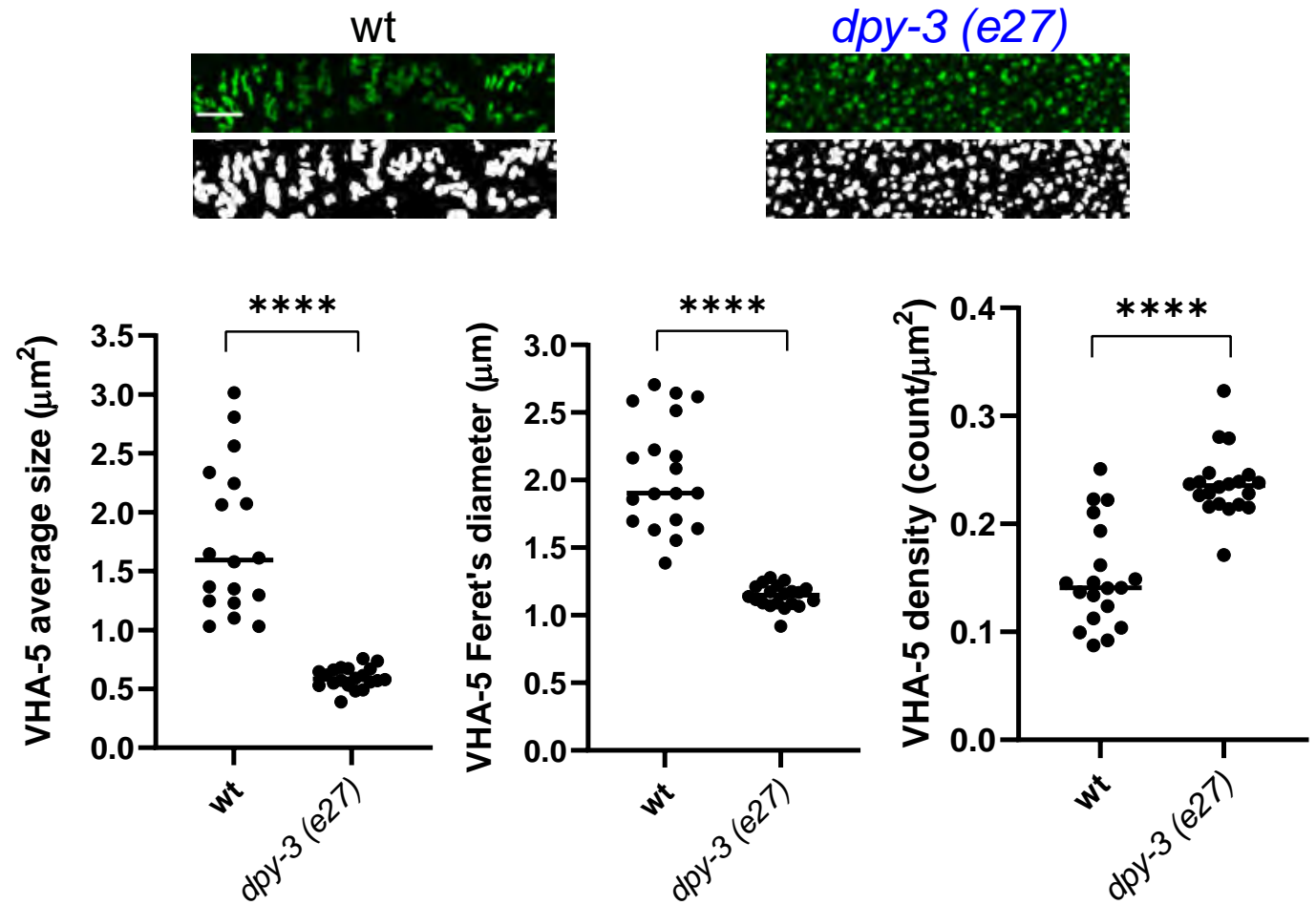

Figure 4-figure supplement 2: Furrow collagen inactivation provokes a disruption of meisosomes. (A-B) Young adults expressing VHA-5::GFP treated with the indicated RNAi clones. Control: sta-1 $(\mathrm{n}=18)$, annuli Dpy: $d p y-13(\mathrm{n}=18)$ and furrow Dpy: $d p y-3(\mathrm{n}=18)$ or $d p y-7(\mathrm{n}=$ 20). (A) Representative confocal images (upper panels) and segmentation views (lower panels) of selected regions on the lateral epidermis, at a constant position relative to the vulva, of young adult worms expressing VHA-5::GFP; scale bar, $5 \mu \mathrm{m}$. (B) Quantification of VHA-5 signal average size, Feret's diameter and density. (C-D) Wild-type and dpy-3 mutant young adults expressing VHA-5::GFP. (C) Confocal images (upper panels) and segmentation views (lower panels) of selected regions on the lateral epidermis, scale bar, $5 \mu \mathrm{m}$. (D) Quantification of VHA-5 signal average size, Feret's diameter and density. Statistics are described in Table S2 ${ }^{* * *} \mathrm{p}<0.0001$. 
bioRxiv preprint doi: https://doi.org/10.1101/2021.11.26.470028; this version posted November 26, 2021. The copyright holder for this preprint

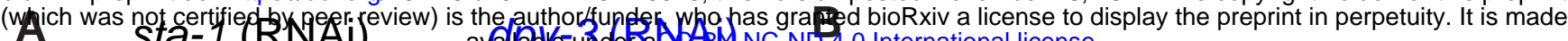

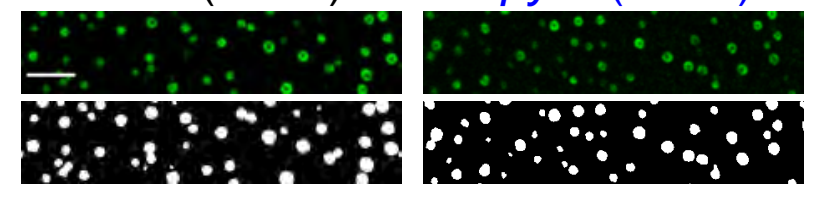

dpy-13 (RNAi)
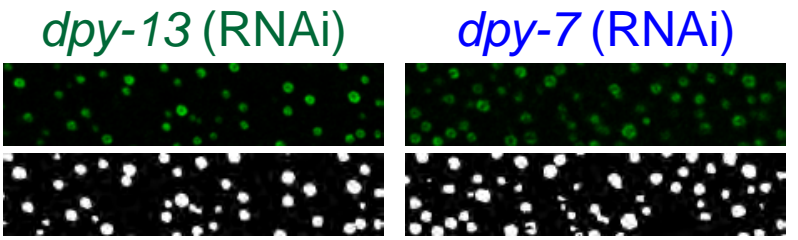

C
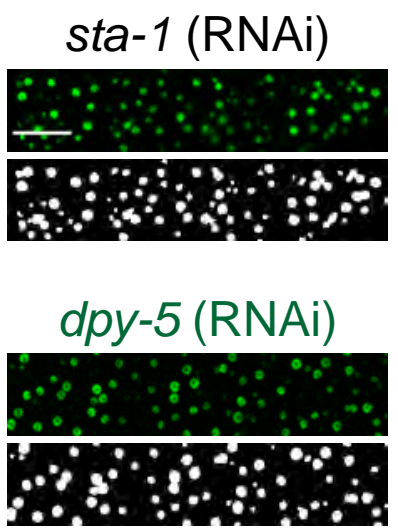
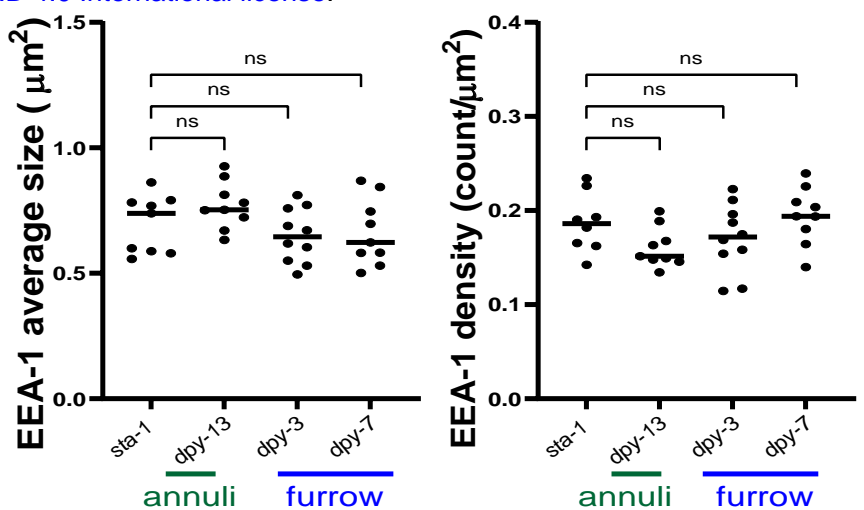

D
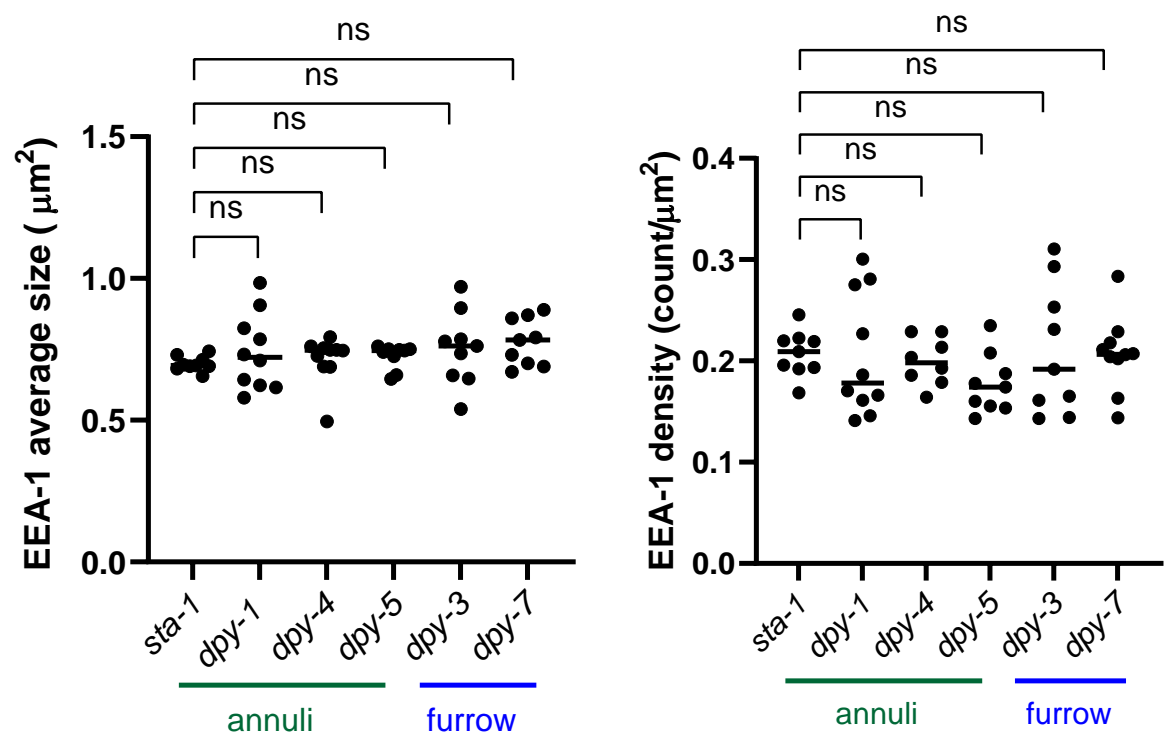

Figure 4-figure supplement 3: Furrow and annuli collagen have no effect on the epidermal marker EEA-1.

(A-C) Representative confocal images and segmentation views of selected regions on the lateral epidermis of young adults expressing EEA-1::GFP and treated with the indicated RNAi clones. Scale bar, $5 \mu \mathrm{m}$. (B-D) Quantification of EEA-1 signal average size and density in wild-type young adult epidermis expressing a EEA-1::GFP and treated with the indicated RNAi clones. (B) Control: sta-1 ( $\mathrm{n}=9$ ), annuli Dpy: $d p y-13(\mathrm{n}=10)$ and furrow Dpy: $d p y-3(\mathrm{n}=10)$ or $d p y-7(\mathrm{n}=9)$. (D) Control: sta-1 $(\mathrm{n}=9)$, annuli Dpy: $d p y-1(\mathrm{n}=10), d p y-4(\mathrm{n}=10)$ or $d p y-5(\mathrm{n}=9)$ and furrow Dpy: $d p y-3(\mathrm{n}=9)$ or $d p y-7(n=9)$. 
FIGURE 5

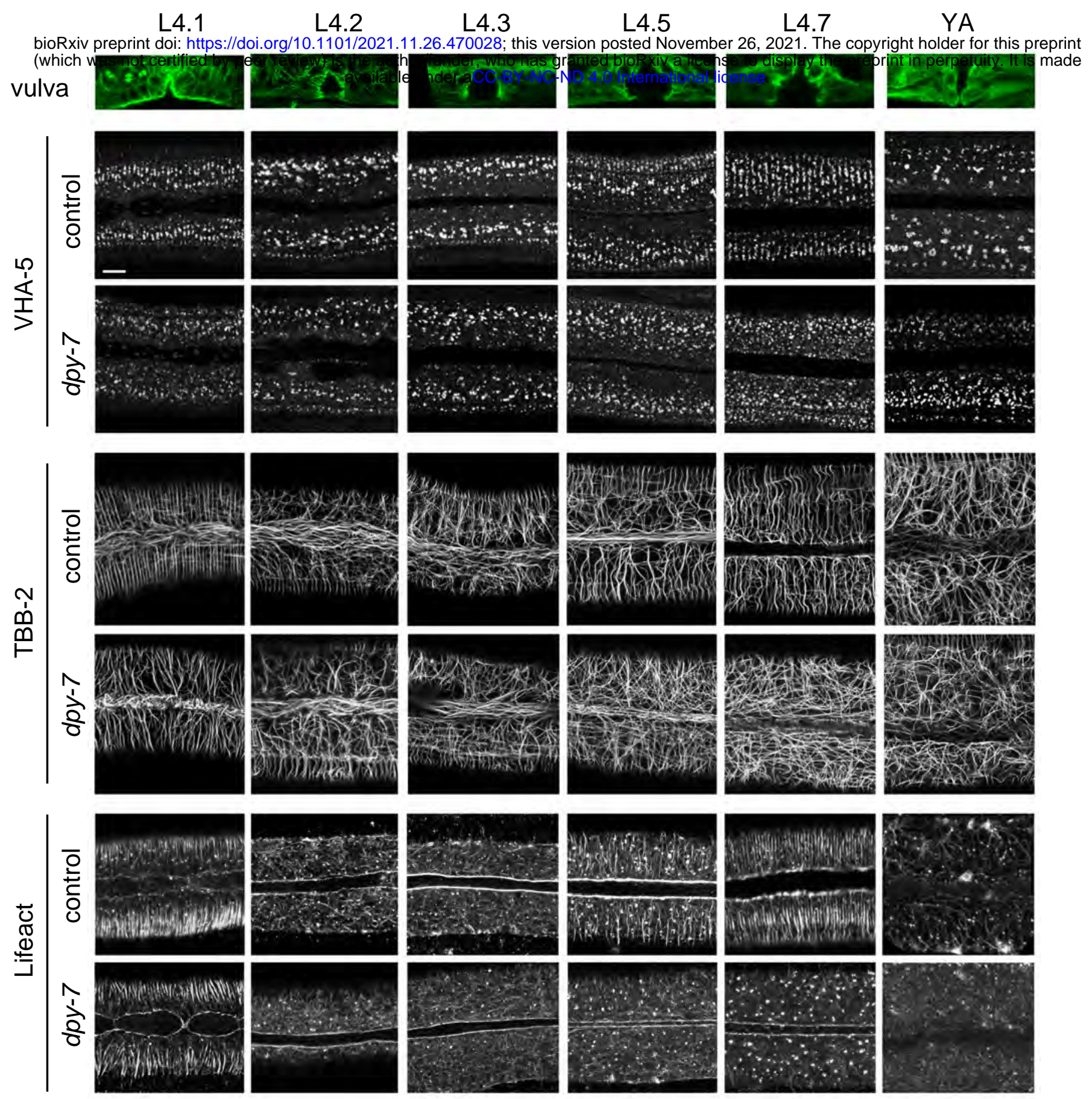

Figure 5: Furrow collagen inactivation provokes a loss of meisosome and cytoskeleton alignment during the $L 4$ stage.

Confocal images of worms expressing VHA-5::GFP (upper panel), TBB-2::GFP (middle panel), LIFEACT::GFP (lower panel) from early L4 to young adult (YA) stage, treated with the control (sta-1) or furrow Dpy (dpy-7) RNAi clones, $n>4$. Scale bar, $5 \mu \mathrm{m}$. To define the precise $L 4$ stage, the vulva was observed and worms classified according to (Cohen et al., 2020). A representative example of the vulva at each stage is shown on the top row in worms expressing the marker TBB-2::GFP. 
FIGURE 5-Supplement 1

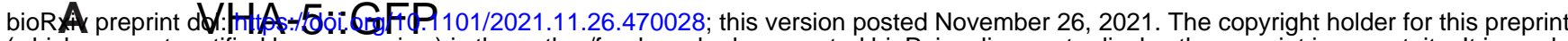
(which was not certified by peer review) is the author/funder, who has granted bioRxiv a license to display the preprint in perpetuity. It is made

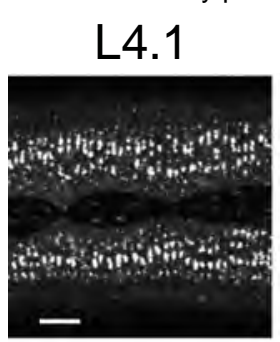

L4.2

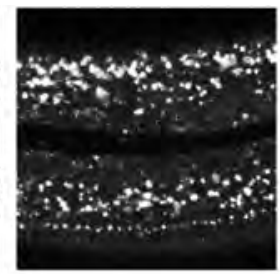

L4.6

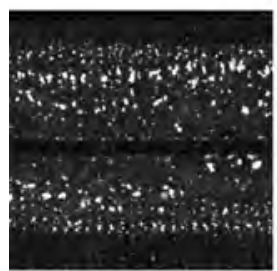

L4.7

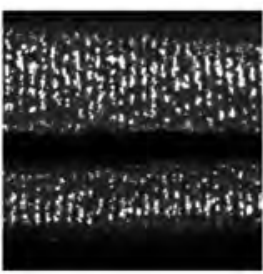

L4.3

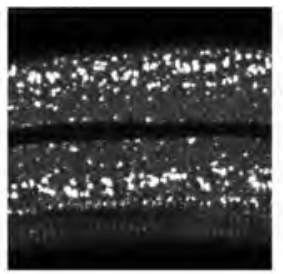

L4.8

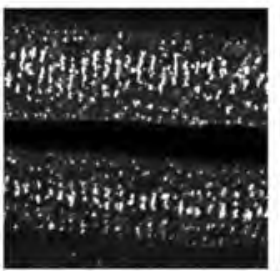

L4.5

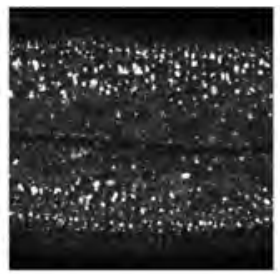

L4.9

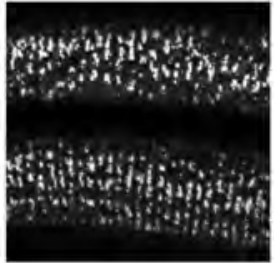

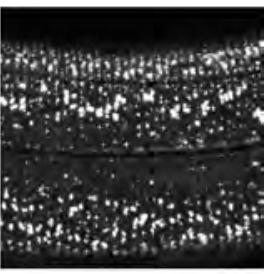

YA

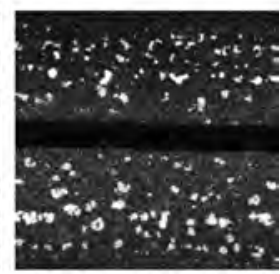

B

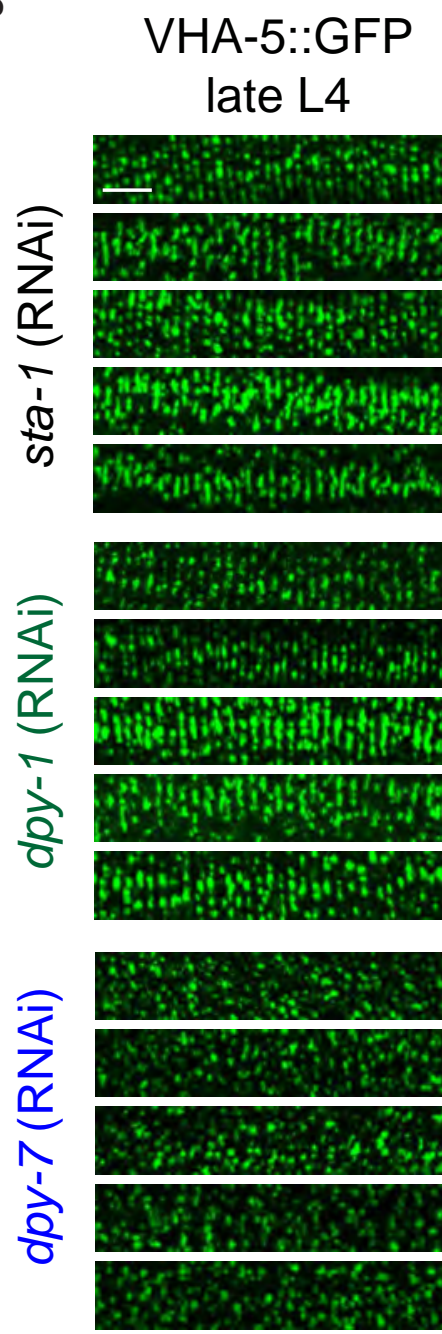

C C VHA-5::GFP

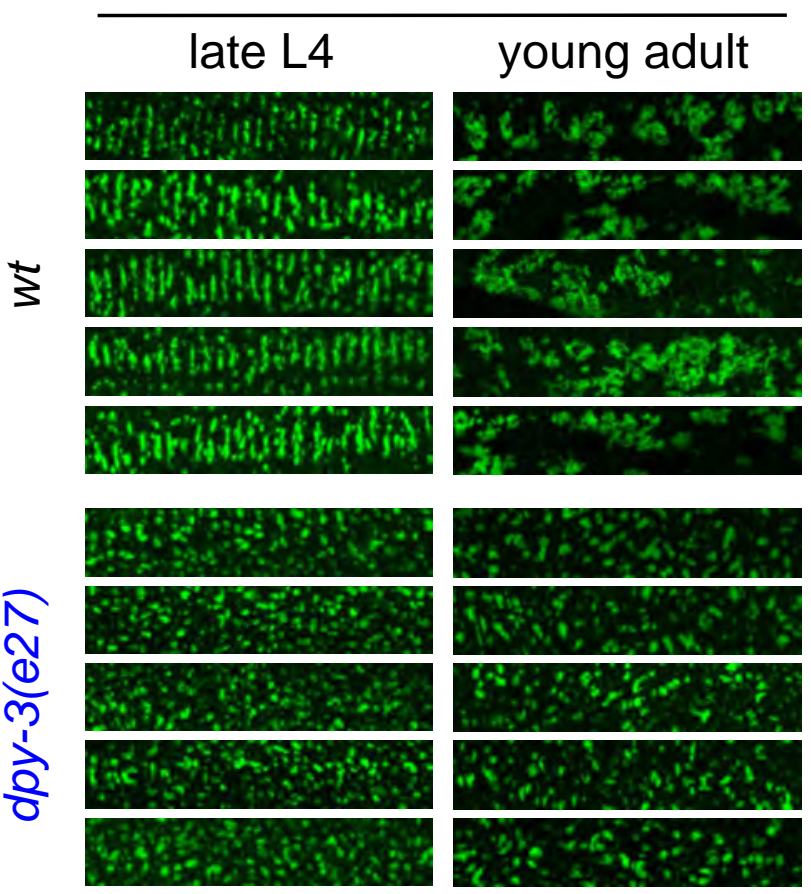

Figure 5-figure supplement 1: Furrow collagen inactivation provokes a loss of meisosomes alignment during the $\mathrm{L} 4$ stage.

(A) Confocal images of worms expressing VHA-5::GFP from early L4 to young adult (YA) stage. To define the precise L4 stage of all observed worms, the vulva was observed and worms classified according to (Cohen et al., 2020). (B) A selection of confocal images of selected regions on the lateral epidermis of late L4 wild-type worms expressing VHA-5::GFP and treated with the indicated RNAi clones. Control: sta-1; annuli Dpy: $d p y-1$ and furrow Dpy: $d p y-7, n>7$. (C) A selection of confocal images of late $L 4$ and young adult worms of wild-type and $d p y-3(e 27)$ mutant worms expressing VHA-5::GFP. Scale bar, $5 \mu \mathrm{m}$. 


\section{FIGURE 5-Supplement 2}

bioRxiv preprint doi: https://doi.org/10.1101/2021.11.26.470028; this version posted November 26, 2021. The copyright holder for this preprint (which was not certified by peer review) is the author/funderw who has granted bioRxiv a license to display the preprint in perpetuity. It is made available undeLAEBAIC-ND 4.0 International license.

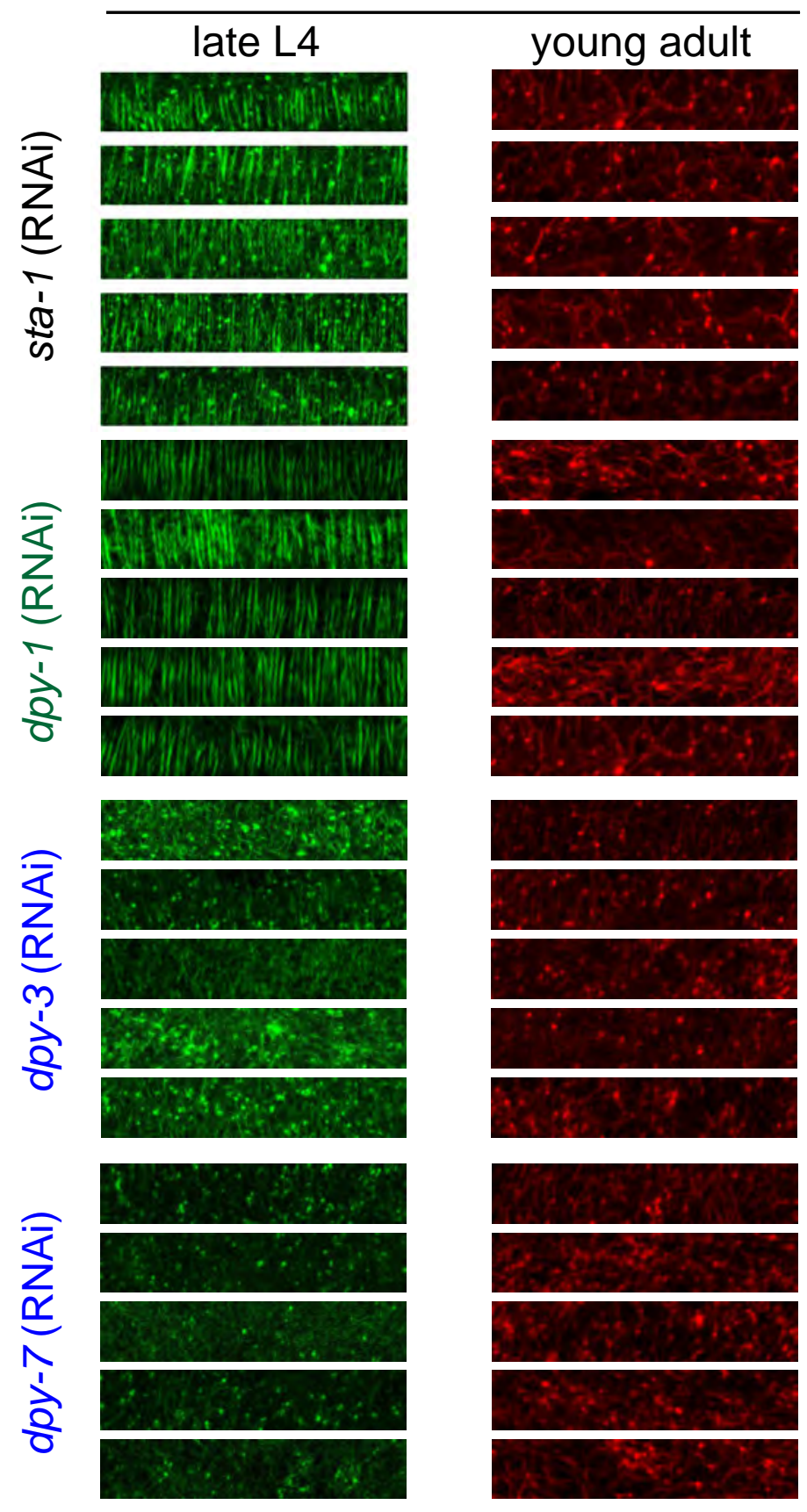

Figure 5-figure supplement 2: Furrow collagen inactivation provokes a loss of actin alignment during the L4 stage.

A selection of confocal images of selected regions on the lateral epidermis of wild-type worms expressing LIFEACT::GFP (for the late L4 stage) or LIFEACT::mKate (for the adult stages) and treated with the indicated RNAi clones. Control: sta-1, annuli Dpy: $d p y-1$, furrow Dpy: $d p y-3$ and dpy-7. Scale bar, $5 \mu \mathrm{m}$. 


\section{FIGURE 5-Supplement 3}

bioRxiv preprint doi: https://doi.org/10.1101/2021.11.26.470028; this version posted November 26, 2021. The copyright holder for this preprint (which was not certified by peer review) is the author/funder, who has granted bioRxiv a license to display the preprint in perpetuity. It is made available under aCC-BY-NC-ND 4.0 International license.

A
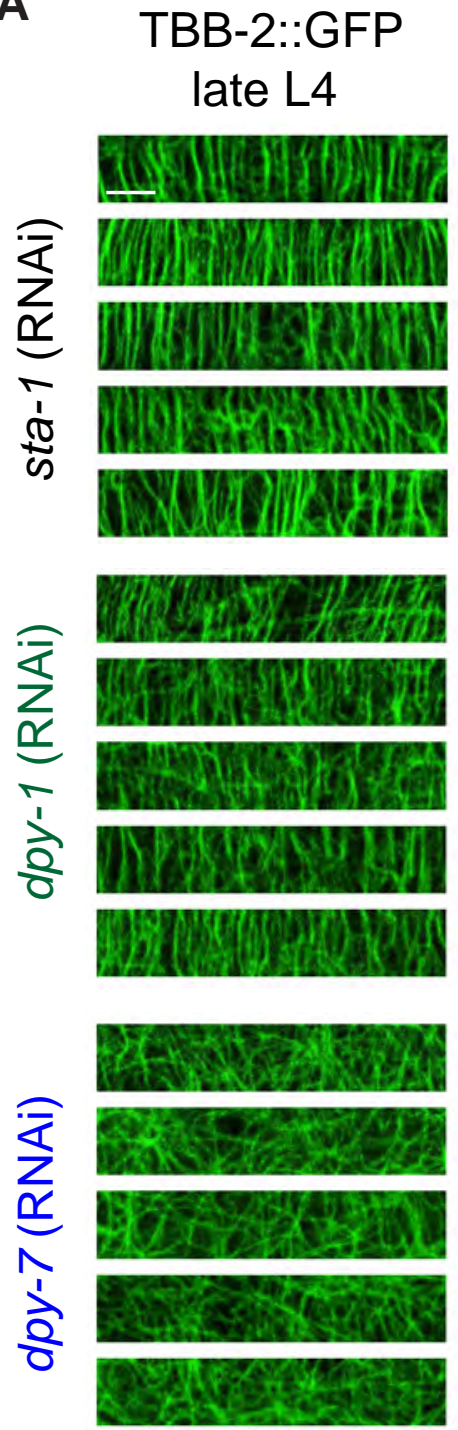

B
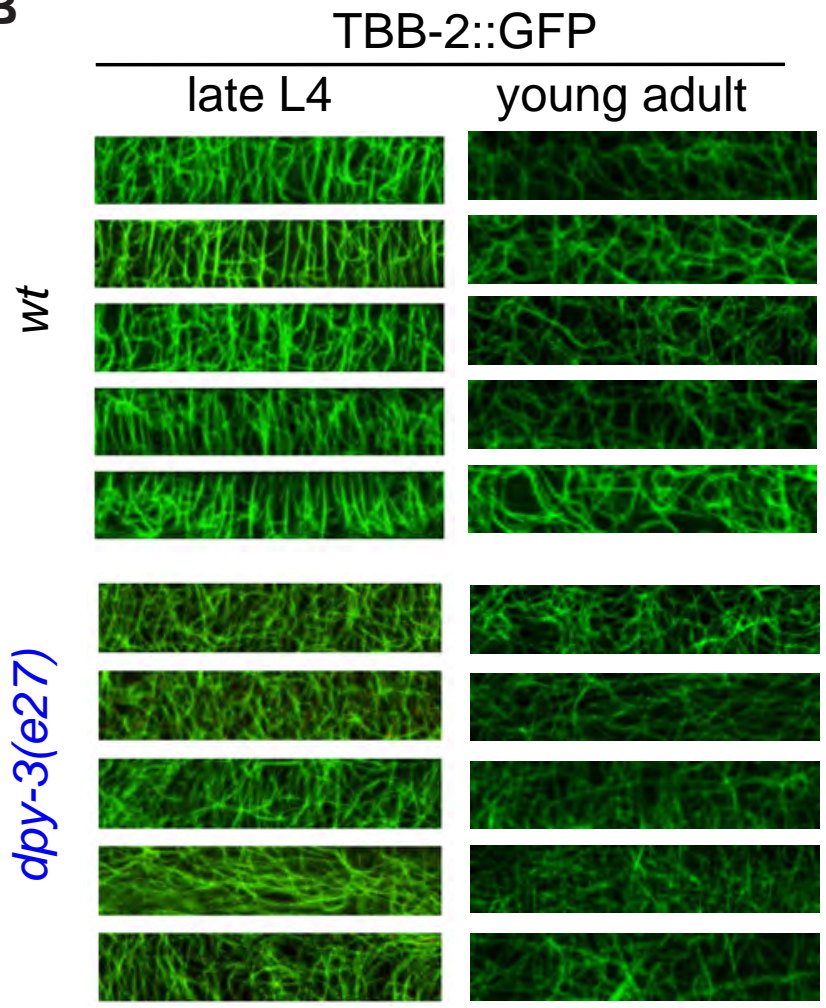

Figure 5-figure supplement 3: Furrow collagen inactivation provokes a loss of microtubule alignment during the $L 4$ stage.

(A) A selection of confocal images of selected regions on the lateral epidermis of late L4 wild-type worms expressing TBB-2::GFP and treated with the indicated RNAi clones. Scale bar, $5 \mu \mathrm{m}$. sta-1 (control) ( $\mathrm{n}=7), d p y-1(\mathrm{n}=6), d p y-7(\mathrm{n}=6)$. (B) A selection of confocal images of late $\mathrm{L} 4$ and young adult worms of wild-type and $d p y-3(e 27)$ mutant worms expressing TBB-2::GFP. $n>5$. Scale bar, 5 $\mu \mathrm{m}$. 


\section{FIGURE 6}

bioRxiv preprint doi: https://doi.org/10.1101/2021.11.26.470028; this version posted November 26, 2021. The copyright holder for this preprint (which was not certified by peer review) is the author/funder, who has granted bioRxiv a license to display the preprint in perpetuity. It is made available under aCC-BY-NC-ND 4.0 International license.
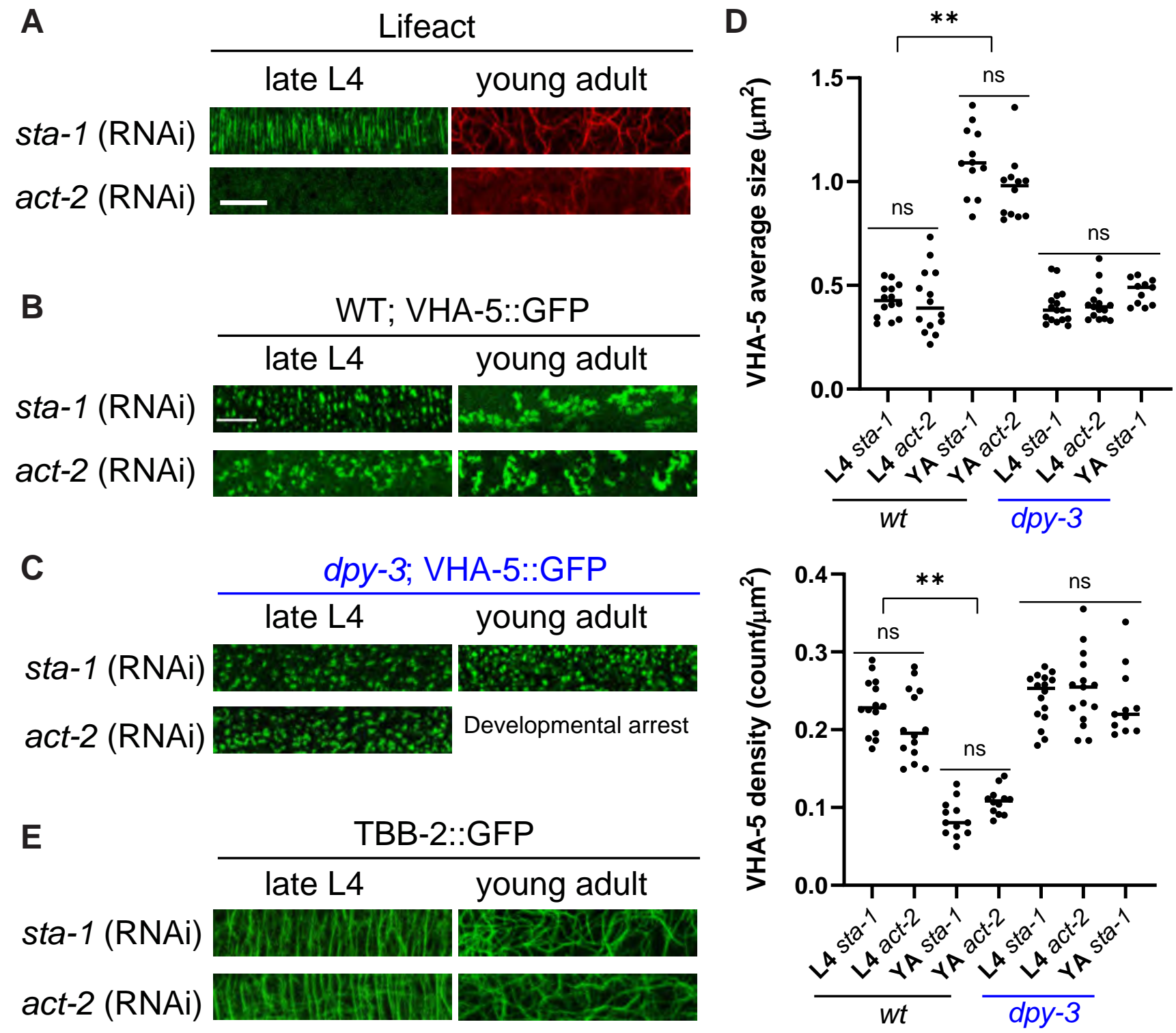

Figure 6: Actin is required for the alignment of meisosomes in L4 larvae but is dispensable for their maturation in the adult.

(A) Confocal images of selected regions on the lateral epidermis of wild-type L4 worms expressing LifeAct::GFP (left) or young adult worms expressing LifeAct::mkate (right) treated with the sta-1 (control) or act-2 RNAi clones. (B-C) Confocal images of selected regions on the lateral epidermis of wild-type (B) or dpy-3 (C) worms expressing VHA-5::GFP, either at the L4 (left) or young adult (right) stage treated with the sta-1 (control) or act-2 RNAi clones. Scale bar, $5 \mu \mathrm{m}$. (D) Quantification of VHA-5 average size and density. Statistics are described in Table S2, ${ }^{* *} p<0.005$.(E) Confocal images of selected regions on the lateral epidermis of wild-type L4 (left) or young adult (right) worms expressing TBB-2::GFP, treated with the sta-1 (control) or act-2 RNAi clones. Scale bar, $5 \mu \mathrm{m}$. 
FIGURE 6-Supplement 1

bioRxiv preprint doi: https://doi.org/10.1101/2021.11.26.470028; this version posted November 26, 2021. The copyright holder for this preprint (which was not certified by peer review) is the author/funder, who has granted bioRxiv a license to display the preprint in perpetuity. It is made

A

VHA-5::GFP

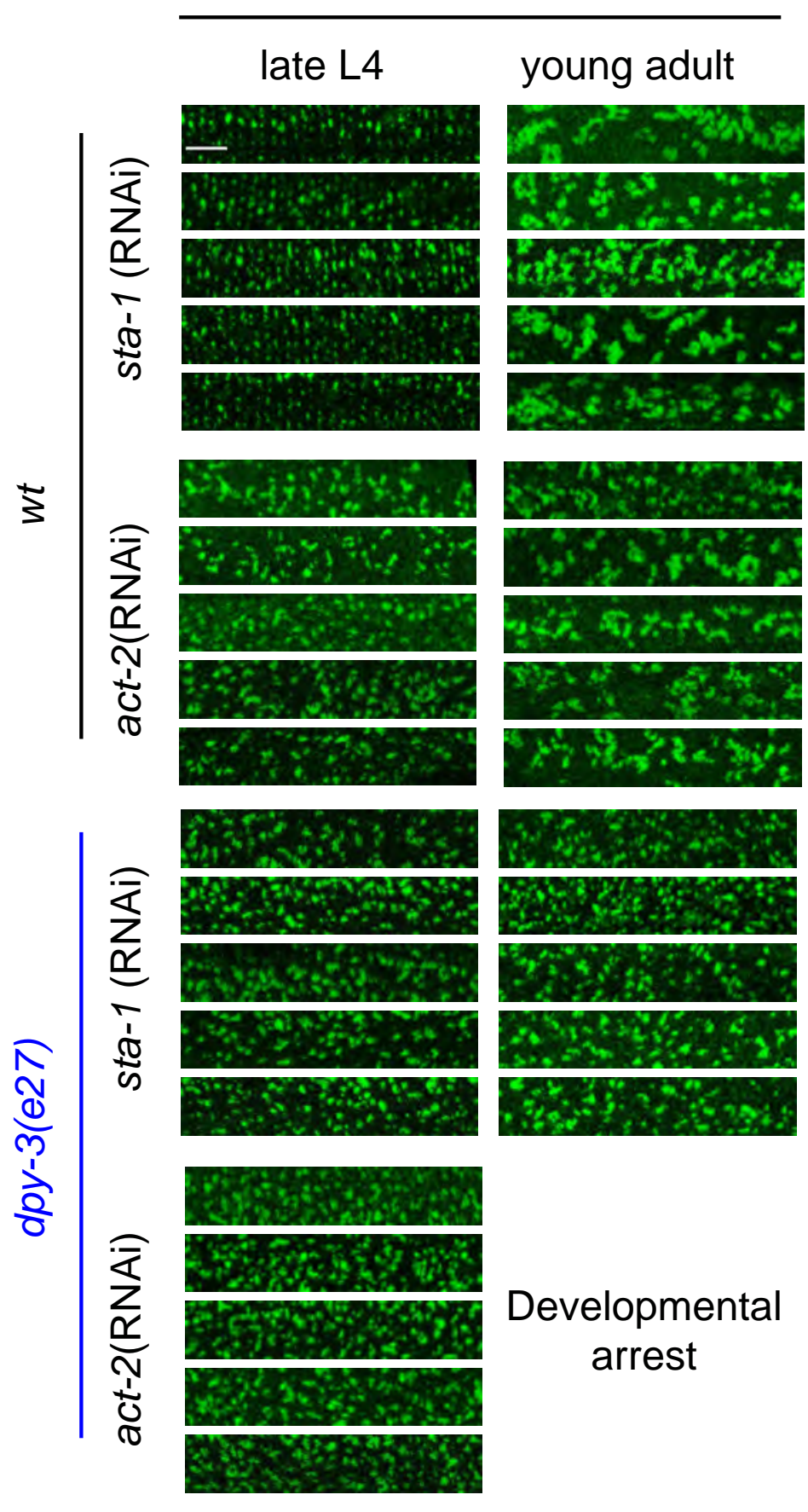

TBB-2::GFP

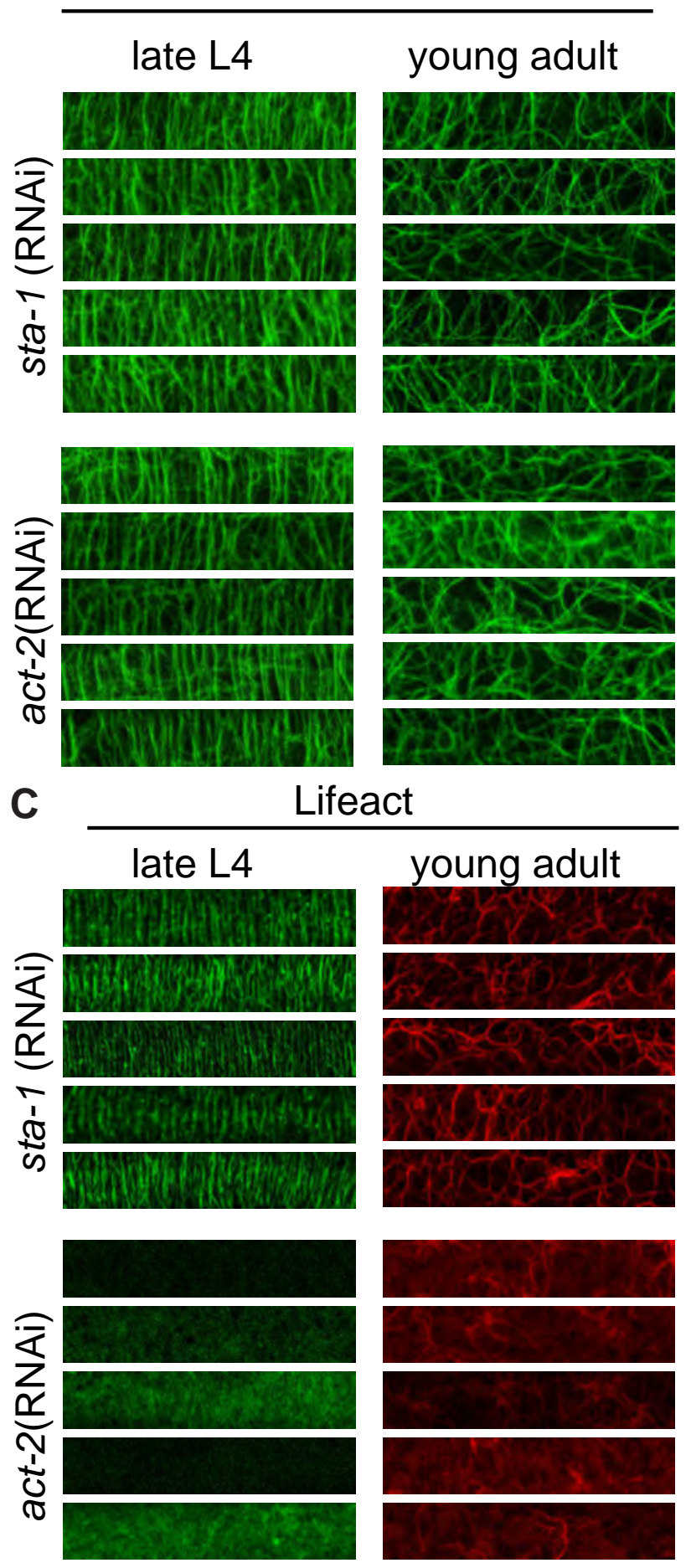

Figure 6-figure supplement 1: Actin is required for the alignment of meisosomes in the L4 but is dispensable for their maturation in the adult.

A selection of confocal images of selected regions on the lateral epidermis of wild-type or dpy- 3 worms expressing VHA-5::GFP (A), wild-type worms expressing TBB-2::GFP (B), LIFEACT::GFP (C, left) or LIFEACT::mKate (C, right), treated with the sta-1 (control) or act-2 RNAi clones. Scale bar, $5 \mu \mathrm{m}$. For each condition late L4 stage (left) and young adult (right) are presented, $\mathrm{n}>6$. Scale bar, $5 \mu \mathrm{m}$. 


\section{FIGURE 7}

bioRxiv preprint doi: https://doi.org/10.1101/2021.11.26.470028; this version posted November 26, 2021. The copyright holder for this preprint (which was not certified by peer review) is the author/funder, who has granted bioRxiv a license to display the preprint in perpetuity. It is made available under aCC-BY-NC-ND 4.0 International license.

\section{A DPY-7::GFP}
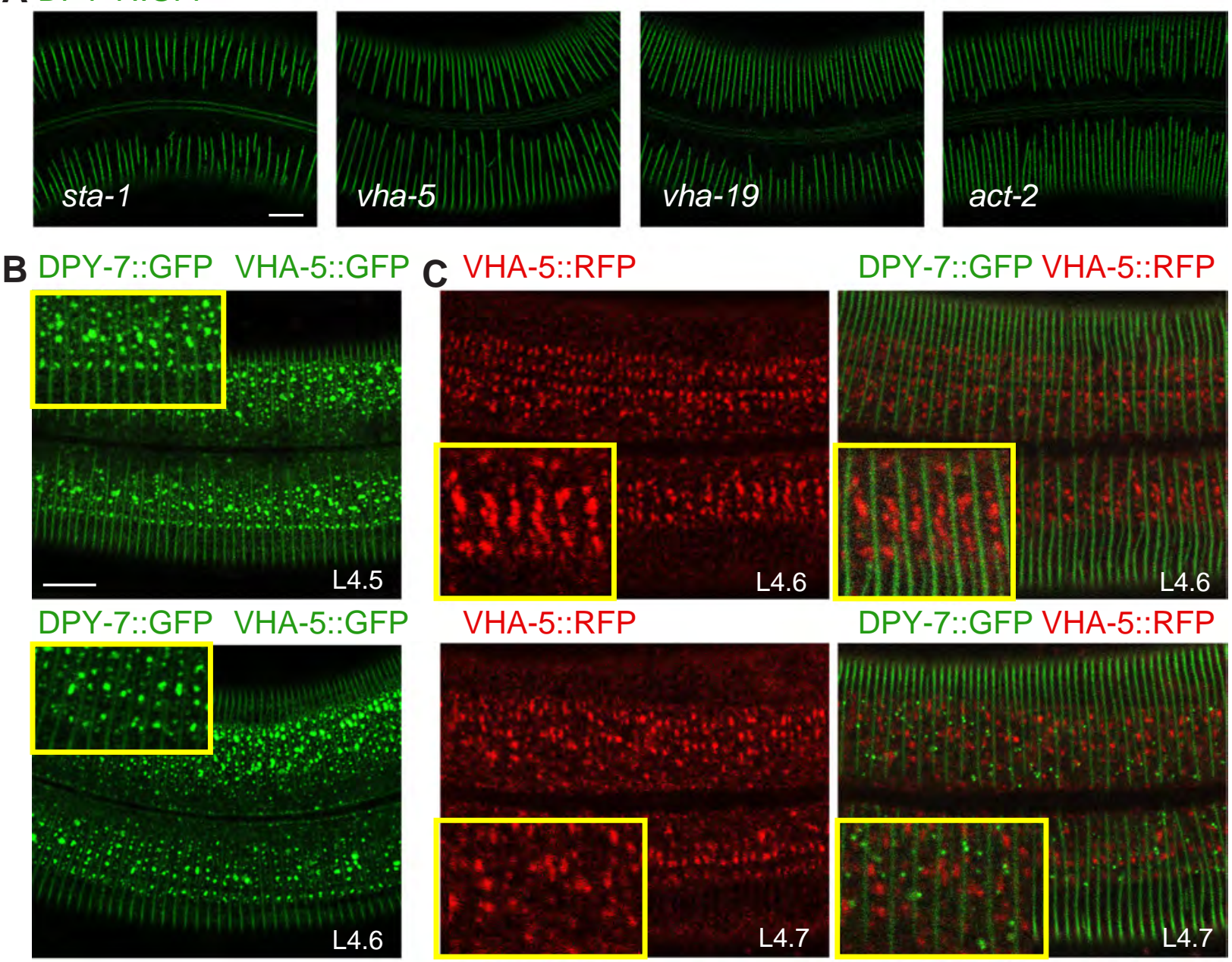

Figure 7: Furrow collagen inactivation leads to smaller and abnormal meisosomes and detachment of the cuticle.

(A) Confocal images of worms expressing DPY-7::GFP, treated with the sta-1 (control), vha-5, vha-19 or act-2 RNAi clones. (B) Confocal images of worms expressing both DPY-7::GFP and VHA-5::GFP. (C) Confocal images of worms expressing both DPY-7::GFP and VHA-5::RFP, red channel on the left, merge channel on the right. The inserts show selected regions at a 1,6 X higher magnification. Scale bar, $5 \mu \mathrm{m}$. 


\section{FIGURE 7-Supplement 1}

bioRxiv preprint doi: https://doi.org/10.1101/2021.11.26.470028; this version posted November 26, 2021. The copyright holder for this preprint (which was not certified by peer review) is the author/funder who has granted bioRxiv a license to display the preprint in perpetuity. It is made available uBdTaKE-B.Y. - 4.0 International license.

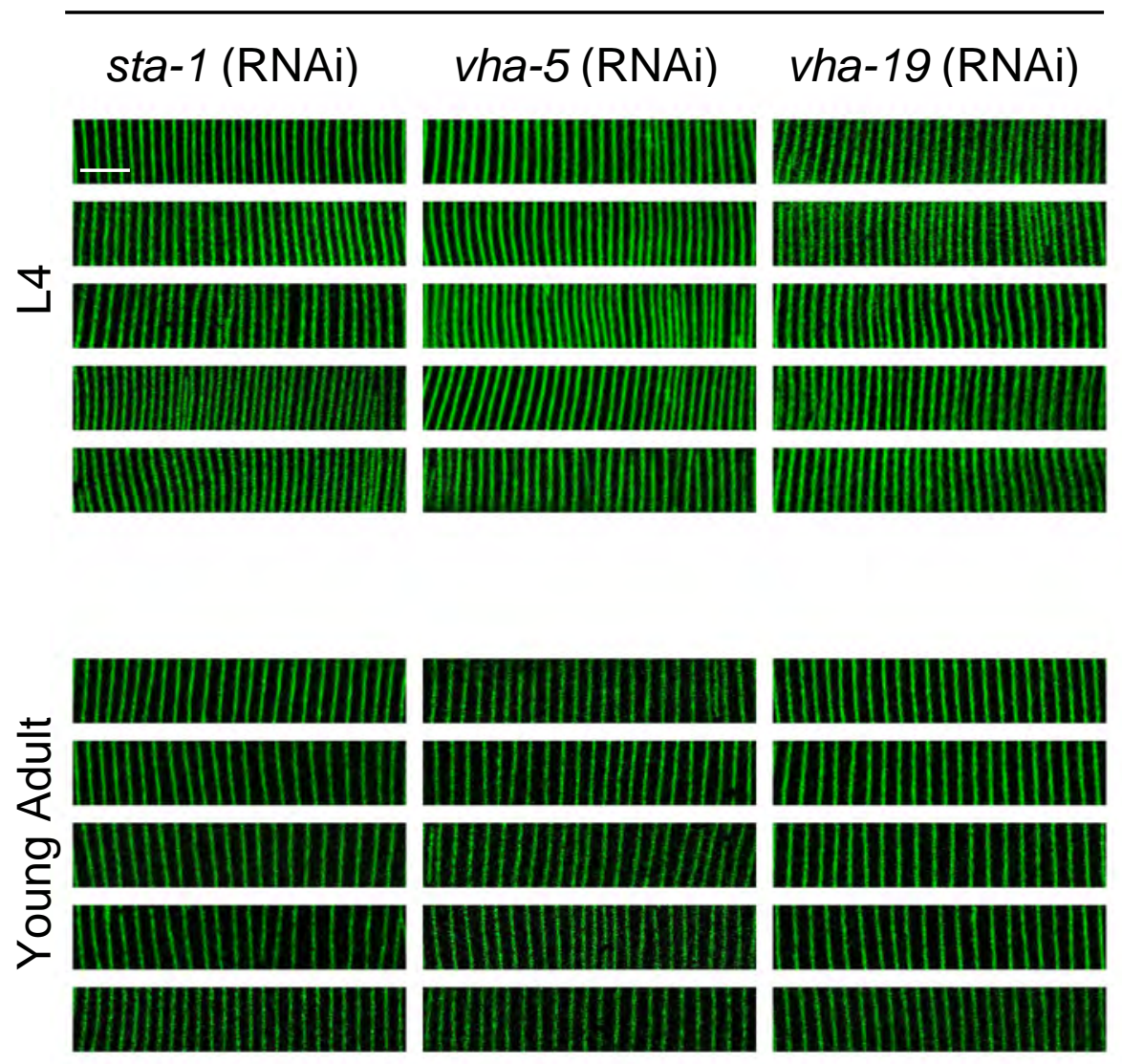

Figure 7-figure supplement 1: DPY-7 furrow collagen is present upon vha-5 or vha-19 inactivation.

A selection of confocal images of selected regions on the lateral epidermis of $L 4$ stage and young adult worms expressing DPY-7::GFP and treated with the indicated RNAi clones. Control: sta-1, vha-5 and vha-19. Scale bar, $5 \mu \mathrm{m}$. 


\section{FIGURE 8}

bioRxiv preprint doi: https://doi.org/10.1101/2021.11.26.470028; this version posted November 26, 2021. The copyright holder for this preprint (which was not certified by peer review) is the author/funder. who has granted bioRxiv a license to display the preprint in perpetuity. It is made
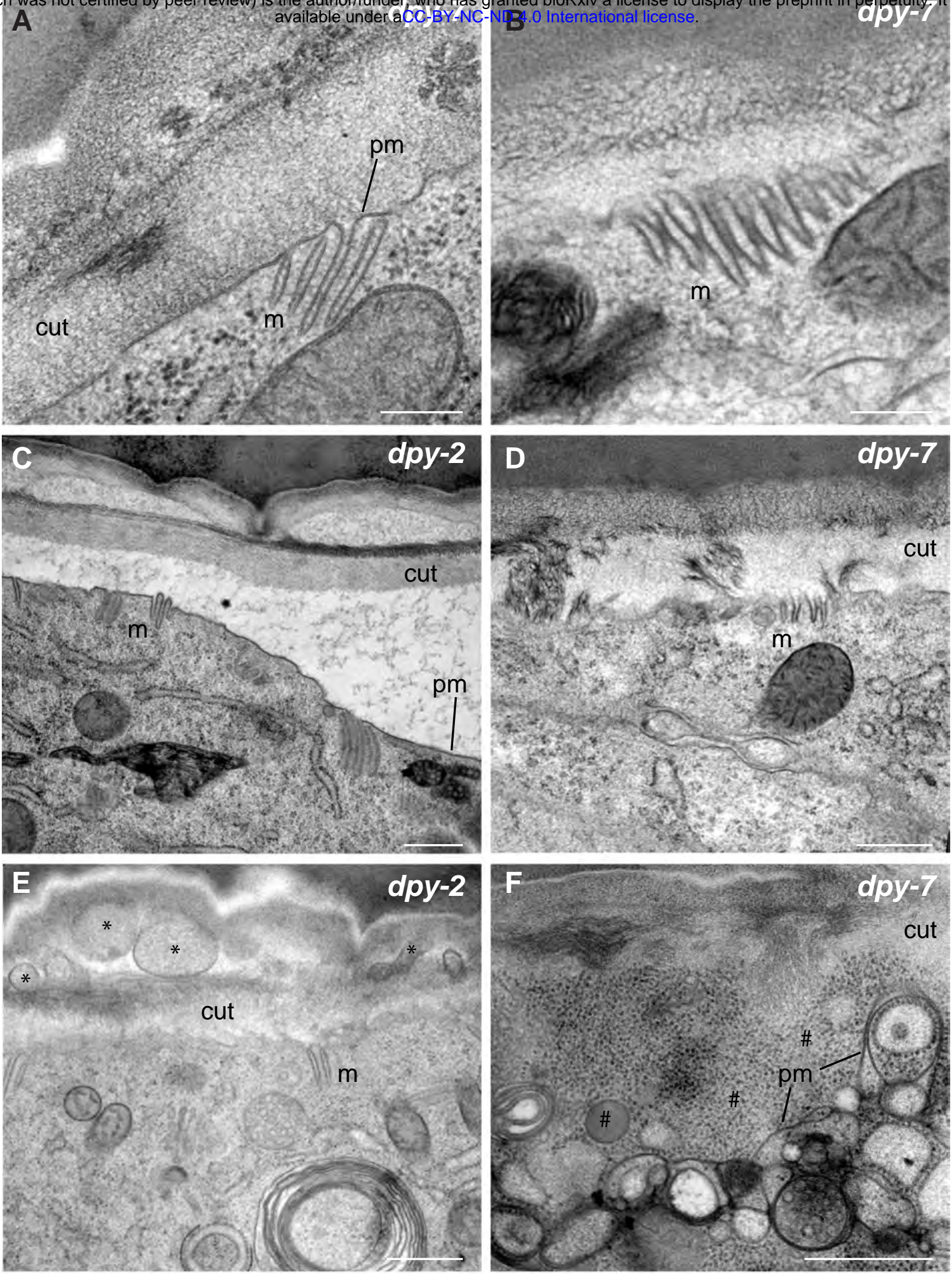

G

$w t$

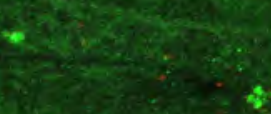

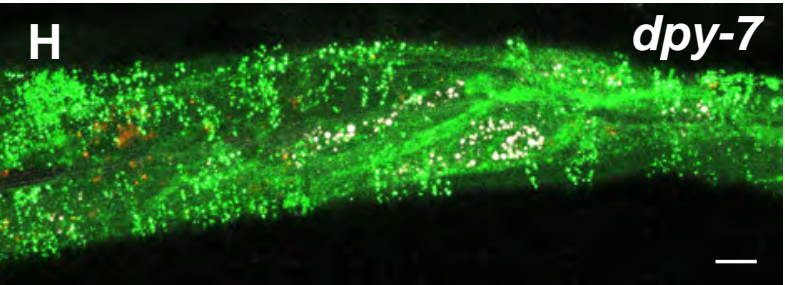

CAAX-1::GFP 
bioRxiv preprint doi: https://doi.org/10.1101/2021.11.26.470028; this version posted November 26, 2021. The copyright holder for this preprint (which was not certified by peer review) is the author/funder, who has granted bioRxiv a license to display the preprint in perpetuity. It is made available under aCC-BY-NC-ND 4.0 International license.

Figure 8: Furrow collagen inactivation leads to smaller and abnormal meisosomes and detachment of the cuticle.

TEM images of longitudinal sections of young adult mutant worms reveal abnormally small meisosomes $(m)(A-C)$, with irregular spacing (B), detachment of the cuticle (cut) from the plasma membrane (pm) (C-D), and the presence of organelles $\left(^{*}\right)$ and cytoplasmic content, including ribosome-like particles (\#), in between the cuticle and the plasma membrane (E-F). Scale bar, 200 $\mathrm{nm}$ in A\&B, and $500 \mathrm{~nm}$ in C-F. (G-H) Confocal images of wild-type (G) and dpy-2 (H) young adult worms expressing CAAX::GFP revealed accumulation of membrane material at the level of the cuticle. Scale bar, $5 \mu \mathrm{m}$. 
FIGURE 8-Supplement 1

bioRxiv preprint doi: https://doi.org/10.1101/2021.11.26.470028; this version posted November 26, 2021. The copyright holder for this preprint (which was not certified by peer review) is the author/funder, who has granted bioRxiv a license to display the preprint in perpetuity. It is made

A available under aCC-BY-NC-DAAIx eriatidurtipense.

sta-1 (RNAi)

cuticular

dpy-1 (RNAi)

dpy-4 (RNAi)

dpy-5 (RNAi)

dpy-13 (RNAi)

dpy-3 (RNAi)

dpy-7 (RNAi)

B

sta-1 (RNAi)

dpy-1 (RNAi)

dpy-4 (RNAi)

dpy-5 (RNAi)

dpy-13 (RNAi)

dpy-3 (RNAi)

dpy-7 (RNAi)
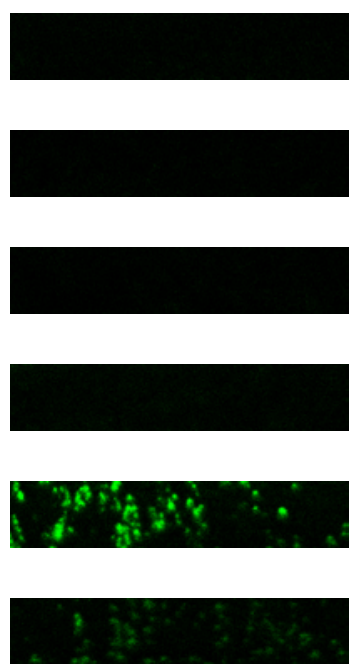

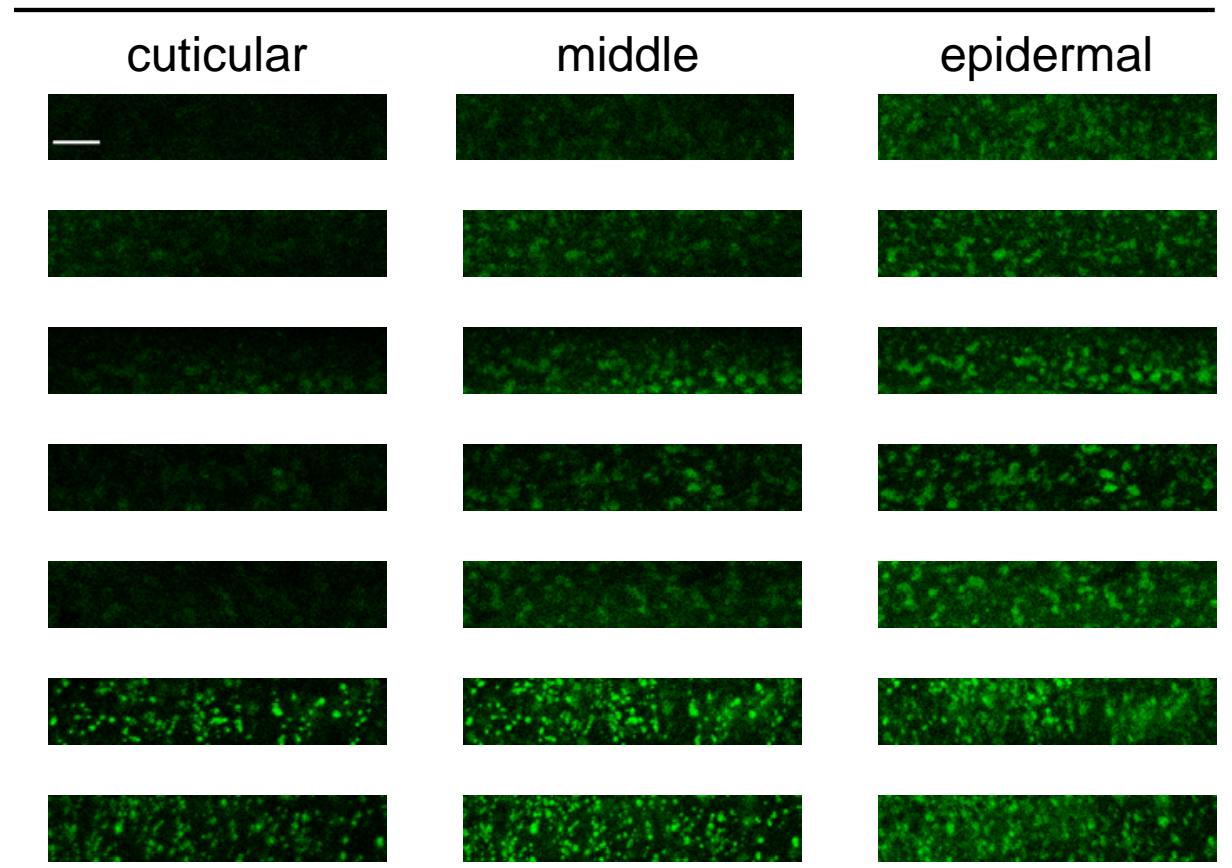

PH-PLC-1::GFP
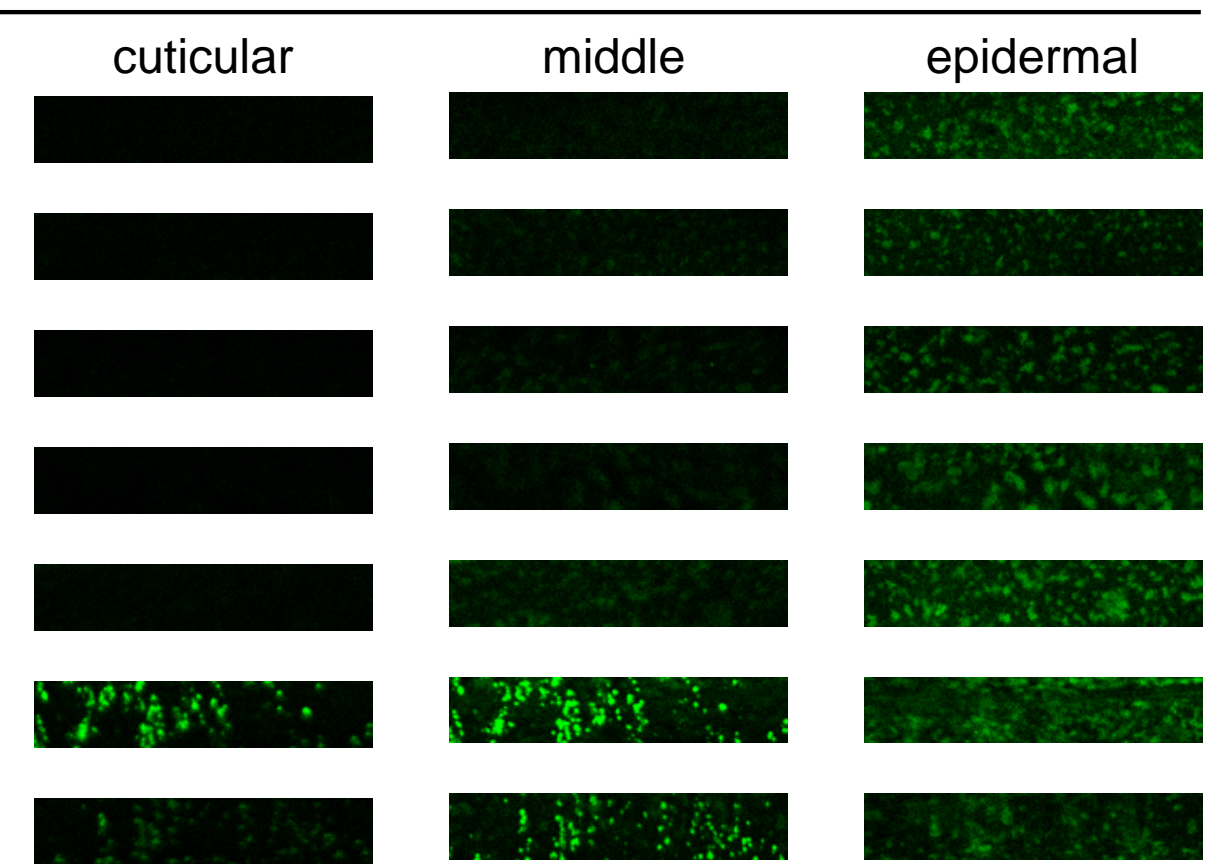

Figure 8-figure supplement 1: Accumulation of cytoplasmic content in the cuticle in Dpy furrow mutants.

A selection of confocal images of selected regions on the lateral epidermis of young wild-type worms expressing CAAX::GFP (A) or PH-PKC-1::GFP (B) and treated with the indicated RNAi clones. 3 different confocal planes at $0.5 \mu \mathrm{m}$ intervals from cuticle (left) to the epidermis (right). Control: sta-1; annuli Dpy: $d p y-1, d p y-4$, $d p y-5$ or $d p y-13$ and furrow Dpy: $d p y-3$ or $d p y-7$. Scale bar, $5 \mu \mathrm{m}, \mathrm{n}=5$. 


\section{FIGURE 9}

bioRxiv preprint doi: https://doi.org/10.1101/2021.11.26.470028; this version posted November 26, 2021. The copyright holder for this preprint (which was not certified by peer review) is the author/funder, who has granted bioRxiv a license to display the preprint in perpetuity. It is made

A available under aCC-BY-NC-ND 4.0 International license.

$w t$

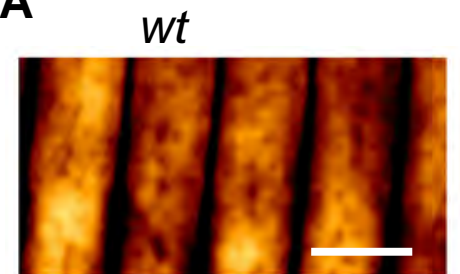

dpy-3

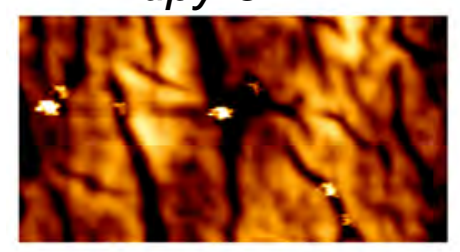

B

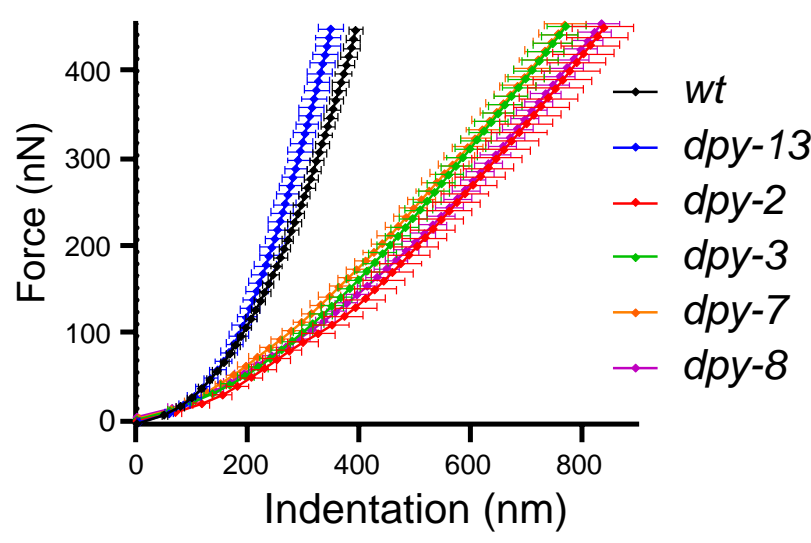

dpy-13

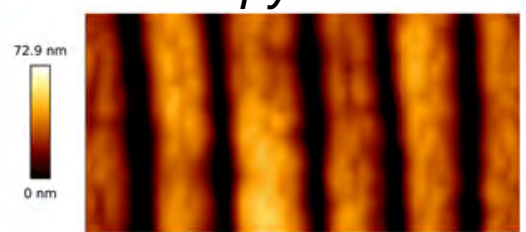

dpy-7

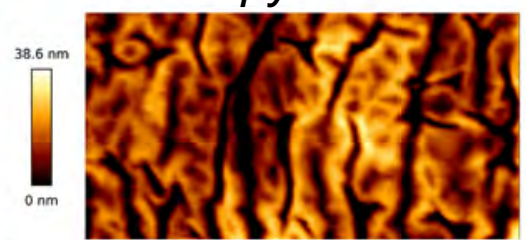

dpy-2

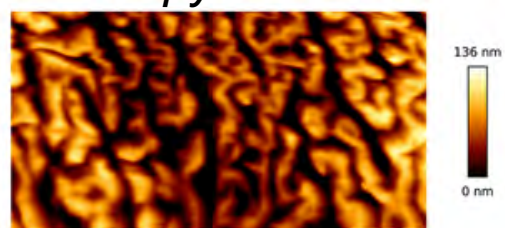

dpy-8

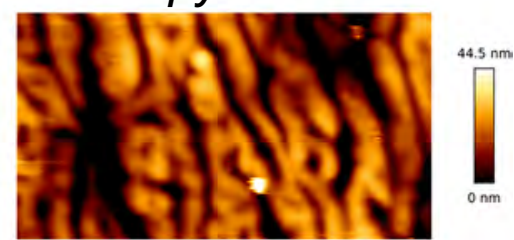

C

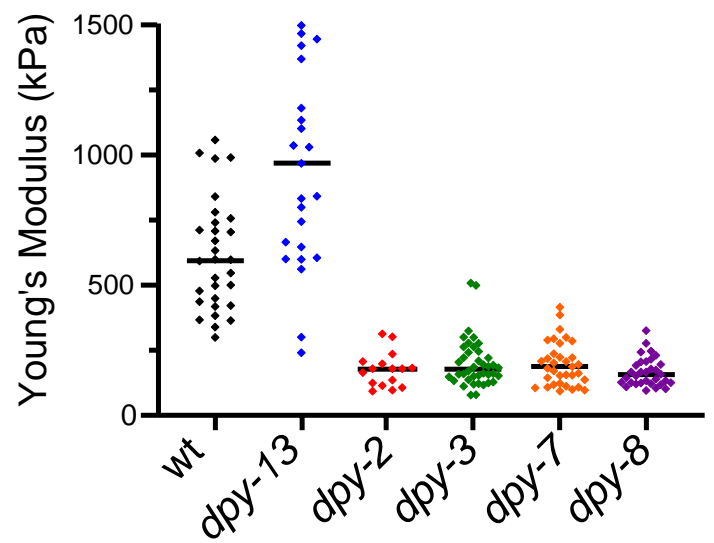

Figure 9: Furrow collagen inactivation provokes a reduction in stiffness of the cuticle.

(A) AFM topography of the cuticle in wild-type, $d p y-13, d p y-2, d p y-3, d p y-7, d p y-8$ mutant adult worms. Scale bar, $1 \mu \mathrm{m}$. (B) Mean force-indentation curves of wild-type and collagen mutants acquired by AFM. (C) Young's Modulus estimation from force curves by applying the Hertz model for contact mechanics. Data are from 3 independent experiments with a total of $n=30,25,32,34$, 41,16 for wild-type and $d p y-13, d p y-8, d p y-7, d p y-3, d p y-2$ mutant worms respectively. 
bioRxiv preprint doi: https://doi.org/10.1101/2021.11.26.470028; this version posted November 26, 2021. The copyright holder for this preprint (which was not certified by peer review) is the author/funder, who has granted bioRxiv a license to display the preprint in perpetuity. It is made

\begin{tabular}{|c|c|c|c|c|c|c|c|}
\hline genotype & cut & $\begin{array}{c}n^{\text {availa }} \\
\text { (worms) }\end{array}$ & $\begin{array}{l}\text { le under }{ }^{C C-B Y-N} \\
\text { (meisosome) }\end{array}$ & 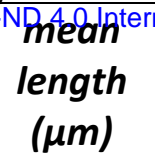 & $\begin{array}{l}\text { atjanthiarard } \\
\text { deviation }\end{array}$ & 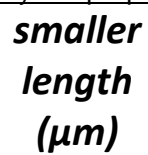 & $\begin{array}{c}\text { longer } \\
\text { length } \\
(\mu \mathrm{m})\end{array}$ \\
\hline$w t$ & Transv & 5 & 29 & 0.78 & 0.85 & 0.1 & 4 \\
\hline$w t$ & Longit & 4 & 25 & 0.49 & 0.29 & 0.2 & 1.2 \\
\hline$d p y-2$ & Transv & 1 & 6 & 0.28 & 0.20 & 0.1 & 0.6 \\
\hline$d p y-2$ & Longit & 4 & 45 & 0.39 & 0.25 & 0.05 & 1 \\
\hline$d p y-3$ & Longit & 1 & 6 & 0.36 & 0.24 & 0.15 & 0.8 \\
\hline$d p y-7$ & Transv & 2 & 24 & 0.28 & 0.19 & 0.05 & 0.7 \\
\hline$d p y-7$ & Longit & 4 & 37 & 0.37 & 0.25 & 0.1 & 1.5 \\
\hline
\end{tabular}

Table S1. Meisosomes length were measured in TEM images acquired in different young adult worms from different genotypes. 
bioRxiv preprint doi: https://doi.org/10.1101/2021.11.26.470028; this version posted November 26, 2021. The copyright holder for this preprint (which was not certified by peer review) is the author/funder who has granted bioBxiv a license to display the preprint in perpetuity It is made

\begin{tabular}{|c|c|c|c|c|c|c|c|c|c|c|c|c|}
\hline Figure & \multicolumn{3}{|c|}{ (which was not certified by peer review) is the } & \multicolumn{3}{|c|}{$\begin{array}{c}\text { he author/funder, who has granted } \\
\text { vailable under aCC-BY-NC-ND 4.d } \\
\text { Average size ( } \mu \mathrm{m} 2)\end{array}$} & \multicolumn{3}{|c|}{$\begin{array}{l}\text { International license. } \\
\text { Feret's diameter }(\mu \mathrm{m})\end{array}$} & \multicolumn{3}{|c|}{ Density (count/ $\mu \mathrm{m} 2)$} \\
\hline $4 S 2 B$ & $\begin{array}{l}\text { sta-1 dpy- } \\
13 d p y-3 \\
d p y-7\end{array}$ & $\begin{array}{l}18 \\
18 \\
18 \\
20\end{array}$ & $\begin{array}{l}28492 \\
22277 \\
21686 \\
30871\end{array}$ & $\begin{array}{l}1,40 \\
1,20 \\
0,70 \\
0,60\end{array}$ & $\begin{array}{l}0,510 \\
0,160 \\
0,150 \\
0,130\end{array}$ & $\begin{array}{c}0,7193 \\
<0,0001 \\
<0,0001\end{array}$ & $\begin{array}{l}1,8 \\
1,7 \\
1,2 \\
1,2\end{array}$ & $\begin{array}{c}0,28 \\
0,13 \\
0,13 \\
0,1\end{array}$ & $\begin{array}{c}0,7968 \\
<0,0001 \\
<0,0001\end{array}$ & $\begin{array}{l}0,11 \\
0,11 \\
0,22 \\
0,19\end{array}$ & $\begin{array}{l}0,020 \\
0,020 \\
0,040 \\
0,030\end{array}$ & $\begin{array}{c}0,3890 \\
<0,0001 \\
<0,0001\end{array}$ \\
\hline 4S2D & $\begin{array}{l}\text { wt dpy- } \\
3\end{array}$ & $\begin{array}{l}18 \\
20\end{array}$ & $\begin{array}{c}5739 \\
28154\end{array}$ & $\begin{array}{l}1,75 \\
0,59 \\
\end{array}$ & $\begin{array}{l}0,620 \\
0,080\end{array}$ & $<0,0001$ & $\begin{array}{c}2 \\
1,1\end{array}$ & $\begin{array}{c}0,4 \\
0,08\end{array}$ & $<0,0001$ & $\begin{array}{l}0,15 \\
0,24\end{array}$ & $\begin{array}{l}0,040 \\
0,030\end{array}$ & $<0,0001$ \\
\hline 6 & $\begin{array}{l}\text { L4 sta-1 } \\
\text { L4 act-2 } \\
\text { YA sta-1 } \\
\text { YA act-2 } \\
\text { L4 } d p y-3 \text { sta-1 } \\
\text { L4 } d p y-3 \text { act-2 } \\
\text { YA } d p y-3 \text { sta-1 }\end{array}$ & $\begin{array}{l}14 \\
14 \\
12 \\
12 \\
16 \\
15 \\
11\end{array}$ & $\begin{array}{c}10664 \\
9609 \\
12326 \\
13509 \\
7424 \\
5510 \\
4798\end{array}$ & $\begin{array}{l}0,43 \\
0,42 \\
1,10 \\
0,97 \\
0,40 \\
0,41 \\
0,47\end{array}$ & $\begin{array}{l}0,079 \\
0,156 \\
0,164 \\
0,154 \\
0,085 \\
0,084 \\
0,061\end{array}$ & $\begin{array}{c}>0,9999 \\
0,0001 \\
0,0019 \\
>0,9999 \\
>0,9999 \\
>0,9999\end{array}$ & & & & $\begin{array}{l}0,23 \\
0,21 \\
0,09 \\
0,11 \\
0,24 \\
0,25 \\
0,23\end{array}$ & $\begin{array}{l}0,035 \\
0,046 \\
0,024 \\
0,017 \\
0,032 \\
0,048 \\
0,045\end{array}$ & $\begin{array}{c}>0,9999 \\
<0,0001 \\
0,0014 \\
>0,9999 \\
>0,9999 \\
>0,9999\end{array}$ \\
\hline
\end{tabular}

Table S2. General statistics of the three quantified parameters (average size, Feret's diameter and density) of the VHA-5::GFP signal associated with Figures 4, 6 and 4S2. 
bioRxiv preprint doi: https://doi.org/10.1101/2021.11.26.470028; this version posted November 26, 2021. The copyright holder for this preprint (which was not certified by peer review) is the author/funder, who has granted bioRxiv a license to display the preprint in perpetuity. It is made

\begin{tabular}{|c|c|c|c|}
\hline Strain & VD 4.0 International & Figure & Source \\
\hline IG274 & frIs7[col-12p::DsRed, nlp-29p::GFP] IV & $4 \mathrm{~S} 1$ & (Pujol et al., 2008) \\
\hline IG1813 & $\begin{array}{l}\text { frSi9[pNP151(col-62p::Lifeact::mKate_3'c-nmy), unc- } \\
\text { 119(+) ttTi5605]/+ II; tbb-2(tj26[GFP::TBB-2]) III }\end{array}$ & $\begin{array}{l}5,6,5 \mathrm{~S} 3,6 \mathrm{~S} \\
1\end{array}$ & (Taffoni et al., 2020) \\
\hline IG1814 & $\begin{array}{l}\text { dpy-3(e27) X; frSi9[pNP151(col- } \\
\text { 62p::Lifeact::mKate_3'c-nmy), unc-119(+) ttTi5605] II; } \\
\text { tbb-2(tj26[GFP::TBB-2]) III }\end{array}$ & $6,6 \mathrm{~S} 1,5 \mathrm{~S} 3$ & (Taffoni et al., 2020) \\
\hline IG1930 & frEx624[pML670(VHA-5::GFP, unc-122p::GFP)] & $\begin{array}{l}3,4,6,4 \mathrm{~S} 3,5 \\
\mathrm{~S} 1,6 \mathrm{~S} 1\end{array}$ & This study \\
\hline IG1935 & $\begin{array}{l}\text { frSi9[pNP151(col-62p::Lifeact::mKate_3'c-nmy), unc- } \\
\text { 119(+) ttTi5605] II; Is[wrt-2p::GFP::PH-PLC1 } \delta \text {, wrt- } \\
\text { 2p::GFP::H2B, lin-48p::mCherry] }\end{array}$ & 7S1 & (Taffoni et al., 2020) \\
\hline IG1961 & $\begin{array}{l}\text { dpy-3(e27) X; frEx624[pML670(VHA-5::GFP, unc- } \\
122 p:: G F P)]\end{array}$ & $5 S 1,6,6 S 1$ & This study \\
\hline IG1990 & $\begin{array}{l}\text { pwSi46[hyp7p::mScarlet::HGRS-1,G418-R]; } \\
\text { frEx624[pML670(VHA-5::GFP, unc-122p::GFP)] }\end{array}$ & 3,3S1 & This study \\
\hline IG2011 & $\begin{array}{l}\text { pwSi62[hyp7p::mScarlet::LGG-1,G418-R]; } \\
\text { frEx624[pML670(VHA-5::GFP, unc-122p::GFP)] }\end{array}$ & $3 S 1$ & This study \\
\hline IG2012 & $\begin{array}{l}\text { pwSi65[hyp7p::mScarlet::SNX-1,G481-R]; } \\
\text { frEx624[pML670(VHA-5::GFP, unc-122p::GFP)] }\end{array}$ & 3S1 & This study \\
\hline IG2118 & frSi26[pNP165(dpy-7p::VHA-5::GFP) ttTi5605] II & 5 & This study \\
\hline IG1697 & dpy-2(e8) II; frIs7[nlp-29p::GFP, col-12p::DsRed] IV & 8,9 & This study \\
\hline IG1685 & dpy-3(e27) X; frIs7[nlp-29p::GFP, col-12p::DsRed] IV & 8,9 & (Dodd et al., 2018) \\
\hline IG1689 & dpy-7(e88) X; frIs7[nlp-29p::GFP, col-12p::DsRed] IV & 8,9 & (Dodd et al., 2018) \\
\hline IG1699 & dpy-8(e130) X; frIs7[nlp-29p::GFP, col-12p::DsRed] IV & 9 & This study \\
\hline IG344 & dpy-13(e184) frIs7[nlp-29p::GFP, col-12p::DsRed] IV & 9 & This study \\
\hline MBA365 & Ex[dpy-7p::GFP::CAAX, туо-2p::GFP] & $8,7 \mathrm{~S} 1$ & $\begin{array}{l}\text { Michalis Barkoulas, } \\
\text { UCL }\end{array}$ \\
\hline ML2113 & $\begin{array}{l}\text { mcls67[dpy-7p::LifeAct::GFP; unc-119(+)] V; } \\
\text { stls10088[hlh-1::his-24::mCherry, unc-119(+)] }\end{array}$ & $5 \mathrm{~S} 2$ & $\begin{array}{l}\text { (Lardennois et al., } \\
\text { 2019) }\end{array}$ \\
\hline RT424 & pwIs126[eea-1p::GFP::EEA-1] & $4 \mathrm{~S} 4$ & (Shi et al., 2009) \\
\hline RT3657 & pwSi46[hyp-7p::mScarlet::HGRS-1,G418-R] & cross & $\begin{array}{l}\text { (Serrano-Saiz et al., } \\
\text { 2020) }\end{array}$ \\
\hline RT3640 & pwSi65[hyp-7p::mScarlet::SNX-1,G481-R] & cross & $\begin{array}{l}\text { (Serrano-Saiz et al., } \\
\text { 2020) }\end{array}$ \\
\hline RT3635 & pwSi62[hyp-7p::mScarlet::LGG-1,G418-R] & cross & $\begin{array}{l}\text { (Serrano-Saiz et al., } \\
\text { 2020) }\end{array}$ \\
\hline XW18042 & qxSi722[dpy-7p::DPY-7::sfGFP; ttTi5605] II & $7,4 \mathrm{~S} 5$ & (Miao et al., 2020) \\
\hline
\end{tabular}

Table S3. Strain name \& genotype used in the mentioned figure with their associated references 